Emerson Carlos Colin

Engenheiro Industrial Mecânico pela Universidade Braz Cubas em 1995

Mestre em Engenharia de Produção pela Escola Politécnica da USP em 1997

\title{
Distribuição de carga e variação de capacidade na programação da produção: resultados na inserção de espera e na utilização de capacidade adicional
}

\author{
Tese apresentada à Escola Politécnica da \\ Universidade de São Paulo para obtenção \\ do título de Doutor em Engenharia \\ Área de concentração: \\ Engenharia de Produção \\ Orientador: Tamio Shimizu
}

São Paulo, fevereiro de 2000 


\section{O temor de Deus}

Os que temem o Senhor terão vida longa,

pois sua esperança repousa naquele que os pode salvar.

Quem teme o Senhor não tem nada a recear:

jamais se amedronta, pois Ele é a sua esperança.

Feliz a alma daquele que teme o Senhor!

Em quem se apóia? Quem é seu sustentáculo?

Os olhares do Senhor estão sobre aqueles que o amam:

escudo possante, sustentáculo vigoroso,

abrigo contra o vento escaldante, sombra contra os ardores do meio-dia, salvaguarda contra os obstáculos e proteção contra a queda.

Ele eleva a alma e faz brilhar o olhar,

trazendo cura, vida e benção.

Sirácida, versículos 14 a 20 do capitulo 34

(Tradução do grego conforme edição crítica de J. Ziegler (Göttingen, 1965). Nas edições anteriores o capitulo 


\section{AGRADECIMENTOS}

Mais uma vez agradeço ao prof. Tamio Shimizu pela orientação e pelas muitas conversas que tivemos no desenvolvimento desta tese. Sua boa vontade além da constante disponibilidade colaboraram muito para a realização deste trabalho.

Gostaria de agradecer a todas as pessoas que colaboraram para a melhoria de versões preliminares da tese, dentre eles os professores Carlos Eduardo Ferreira (DCC-IME-USP), Horácio Hideki Yanasse (LAC-INPE-MCT), Miguel Cezar Santoro e Pedro R. Bueno Neto. Ao professor Horácio vai um agradecimento especial pelo esforço suplementar e pela localização de erros que invalidariam grande parte de meu trabalho.

Os alunos do DEP, muitos deles mais professores do que alunos, seguramente deixarão saudades pelos 4 anos de convivio. Dentre eles gostaria de mencionar os mais próximos: Ana Valéria, Antônio Martos, Arthur Teixeira, Carlos Cruz, Davi Nakano, Fernando Laurindo, Helvécio Reis, Jorge Matsuoka, Marcelo Menezes, Marcelo Oishi, Marcelo Pedroso, Maria Elena, Ricardo Cruz, Ricardo Pacheco e Roberto Quinino. Antecipadamente já peço desculpas aos não-mencionados; a lista seguramente poderia se estender em muito.

$O$ tese teve apoio financeiro fornecido pela FAPESP - Fundação de Amparo à Pesquisa do Estado de São Paulo (processo FAPESP 97/11282-2 e auxílio reserva técnica bolsa proc. 97/13787-4) por intermédio de uma bolsa de doutoramento individual.

Um último agradecimento às pessoas mais próximas, meus pais e minha noiva, que talvez tenham sido os que mais me ajudaram. O bom convivio social e familiar, relevando grades não pintadas, passeios não realizados, etc., forneceu a tranqüilidade necessária para o desenvolvimento do trabalho. 


\section{ÍNDICE}

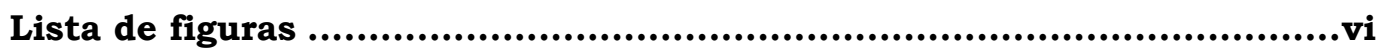

Lista de tabelas ..........................................................................vii

Lista de abreviaturas .............................................................. viii

Lista de simbolos .....................................................................ix

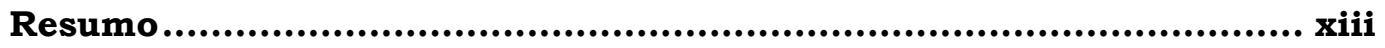

Abstract ...........................................................................

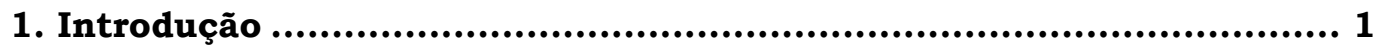

1.1. Critérios competitivos de tempo na administração de operações: definindo funções-objetivo .......................................................... 1

1.2. Relacionamento entre decisões de planejamento e de programação ... 5 1.2.1. Procedimentos clássicos de relacionamento entre decisões de curto e longo prazos no planejamento da produção........................ 6

1.2.2. Outras propostas para o relacionamento entre decisões de planejamento e programação............................................. 10

1.3. Trabalho elaborado, importância e principais justificativas para sua realização ................................................................. 13

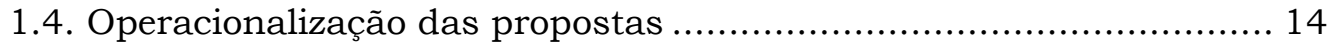

1.5. Organização da tese ...................................................... 16

2. Algoritmo de inserção de espera para o problema de uma máquina com função-objetivo representada pela soma de funções convexas do

horário de término independentes para cada ordem ..................... 17

2.1. Conceitos preliminares e definição do problema........................... 17

2.2. Exemplo introdutório ............................................................ 19

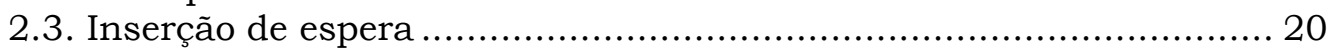

2.4. Algoritmo de Inserção de Espera (AIE) ......................................... 22

2.4.1. Visão geral do AIE.............................................................. 26

2.4.2. Detalhamento do AIE ......................................................... 28

2.4.3. Análise do AIE................................................................. 29

2.5. Implementação computacional do AIE utilizando estruturas de filas de

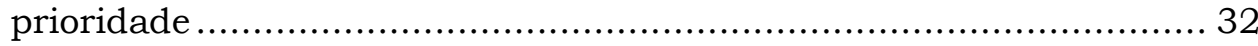

2.6. Exemplo da utilização do AIE ............................................. 36

2.7. Programação da produção do problema de uma máquina via programação linear ......................................................... 40

2.8. AIE para problemas com custos representados por funções convexas dos horários de término ................................................ 41

2.8.1. Preliminares ..................................................................... 41

2.8.2. Construção do AIE............................................................. 43

2.8.3. Implementação computacional e questões relacionadas............ 49

3. Variação de capacidade no problema de programação de uma

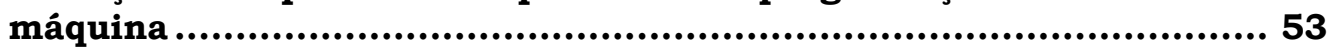

3.1. Conceitos preliminares e definição do problema.......................... 54

3.2. Primeiro exemplo: idéia geral da solução proposta ......................... 58

3.3. Outros estudos correlacionados realizados previamente ................ 59

3.4. Formulação do problema de programação da produção com capacidade variável via programação matemática ......................... 61 
3.5. Algoritmo de programação de uma máquina com possibilidade de inserção de capacidade no problema com função-objetivo do tipo $\sum_{j \in J}\left(h_{j} E_{j}+w_{j} T_{j}\right)+\sum_{t \in N} o_{t} O_{t}$ 64

3.6. Análise da otimalidade do Algoritmo de Inserção de Capacidade (AIC) 71

3.7. Implementação computacional do AIC ...................................... 77

3.8. Exemplos de funcionamento do AIC .................................... 80

3.8.1. Segundo exemplo: noção geral de funcionamento com

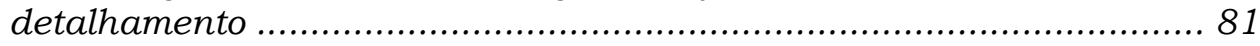

3.8.2. Terceiro exemplo: divisão de bloco ................................. 87

3.9. Generalizações e casos particulares do AIC ................................ 89

3.9.1. Casos particulares ............................................................ 90

3.9.2. Generalizações............................................................ 91

3.9.2.1. Diversos custos de capacidade adicional entre dois intervalos de capacidade normal .............................. 91

3.9.2.2. Utilização do AIC em múltiplas máquinas................ 93

3.10. Procedimentos de variação de capacidade utilizados para definição de horas-extras e turnos de trabalho....................................... 95

4. Discussão adicional e conclusões ......................................... 99

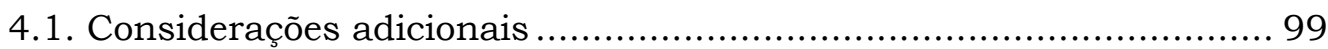

4.2. Contribuições contidas na tese ............................................. 100

4.3. Utilização na prática e impacto potencial na gestão de operações .. 101

4.4. Algumas sugestões de temas para pesquisa futura ..................... 103

Referências bibliográficas....................................................105 


\section{Lista de figuras}

Figura 1: Múltiplas dimensões do critério competitivo tempo …................. 3

Figura 2: Hierarquia de funções-objetivo (baseado em LAWLER et al. (1993)) 19

Figura 3: Prova gráfica da proposição ........................................... 24

Figura 4: Configuração de um bloco $b$ qualquer com relação aos tempos de processamento e índice das ordens pertencentes ao mesmo................. 25

Figura 5: Configuração genérica dos blocos de um programa parcial ou

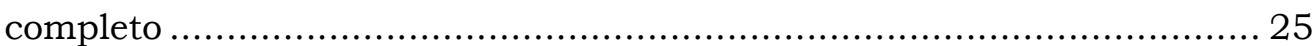

Figura 6: Pseudocódigo para construção de blocos ............................... 34

Figura 7: Pseudocódigo para antecipação de blocos ............................. 35

Figura 8: Passo 1 do exemplo da utilização do AIE ................................... 37

Figura 9: Passo 2 do exemplo da utilização do AIE ................................. 38

Figura 10: Passo 3 do exemplo da utilização do AIE ............................... 38

Figura 11: Passo 4 do exemplo da utilização do AIE ............................... 39

Figura 12: Regiões possiveis numa função convexa ............................ 44

Figura 13: Pseudocódigo para inserção de espera em seqüência predefinida; custos das ordens representados por funções convexas dos horários de

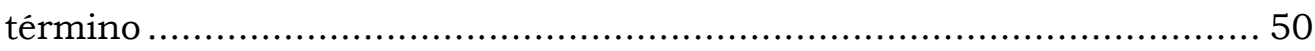

Figura 14: Pseudocódigo do procedimento Antecipa2 ............................. 50

Figura 15: Conjuntos e subconjuntos relacionados aos intervalos de tempo . 55

Figura 16: Gráfico de Gantt de uma instância mostrando os intervalos de tempo de capacidade normal..................................................... 55

Figura 17: Variáveis relacionadas aos intervalos de capacidade adicional .... 55

Figura 18: Relacionamentos possiveis entre intervalos de processamento de ordens e intervalos de tempo............................................... 57

Figura 19: Primeiro exemplo antes da inserção de capacidade .................... 58

Figura 20: Primeiro exemplo após a inserção de capacidade .................... 59

Figura 21: Pseudocódigo do AIC ............................................... 78 


\section{Lista de tabelas}

Tabela 1: Decisões relacionadas à capacidade do sistema produtivo de acordo com o tipo de recurso e de procedimento utilizado para a variação de capacidade......................................................................... 12

Tabela 2: Dados do exemplo para inserção de espera ................................ 37

Tabela 3: Cálculo do exemplo sem inserção de espera.............................. 37

Tabela 4: Cálculo do exemplo com inserção de espera............................... 39

Tabela 5: Relações possiveis entre os tipos de regiões de uma função convexa em duas iterações do algoritmo.................................................. 45

Tabela 6: Configurações possiveis para os blocos parciais pertencentes ao

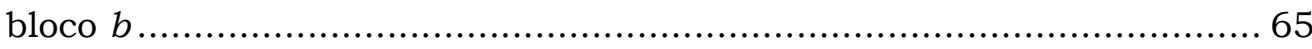

Tabela 7: Dados das ordens do segundo exemplo para inserção de capacidade 81

Tabela 8: Dados dos intervalos de tempo disponíveis do segundo exemplo para inserção de capacidade ........................................................ 81

Tabela 9: Cálculo do segundo exemplo sem possibilidade de inserção de espera

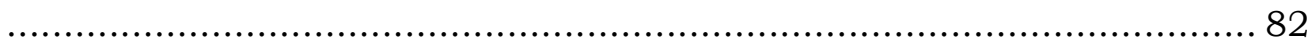

Tabela 10: Cálculo do segundo exemplo com possibilidade de inserção de

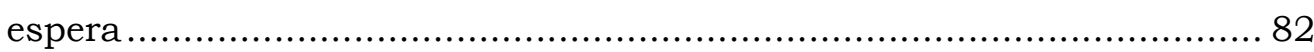

Tabela 11: Custos de adiantamento e atraso do segundo exemplo ............... 86

Tabela 12: Custos de utilização de capacidade adicional do segundo exemplo 86

Tabela 13: Dados das ordens do terceiro exemplo ............................... 87

Tabela 14: Dados do intervalo de tempo disponivel do terceiro exemplo ........ 87

Tabela 15: Cálculo do terceiro exemplo com possibilidade de inserção de

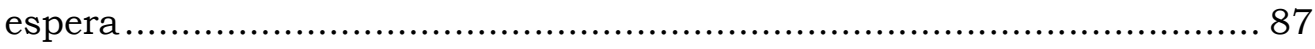

Tabela 16: Custos de adiantamento e atraso do terceiro exemplo................ 89

Tabela 17: Custo de utilização de capacidade adicional do terceiro exemplo . 89 


\section{Lista de abreviaturas}

$\begin{array}{ll}\text { AIC } & \text { Algoritmo de Inserção de Capacidade; } \\ \text { AIE } & \text { Algoritmo de Inserção de Espera; } \\ \text { FMS } & \text { Flexible Manufacturing System (sistema flexivel de manufatura); } \\ \text { JIT } & \text { Just-in-Time; } \\ \text { MRP } & \text { Materials Requirements Planning (planejamento de requisitos de } \\ & \text { materiais); } \\ \text { MRPII } & \text { Manufacturing Resources Planning (planejamento de recursos de } \\ & \text { manufatura); } \\ \text { NP } & \text { Classe dos problemas não-determinísticos polinomiais; } \\ \text { OPT } & \text { Optimized (algumas vezes Optimum) Production Technology; } \\ \text { PHP } & \text { Planejamento Hierárquico da Produção; } \\ \text { TOC } & \text { Theory of Constraints (teoria das restrições). }\end{array}$




\section{Lista de simbolos}

As notações mais específicas e utilizadas brevemente no decorrer da tese não são apresentadas aqui; apresenta-se apenas a notação mais utilizada. Quando um termo estiver aparecendo pela primeira vez no texto, ele será explicado no nivel de detalhe necessário.

$\forall \quad=$ qualquer que seja;

$(\cdot, \cdot) \quad$ =intervalo aberto;

$[\cdot, \cdot] \quad=$ intervalo fechado;

$[x] \quad=$ parte inteira do número $x$;

$\{X\} \quad=$ conjunto ordenado $X$;

$|X| \quad=$ cardinalidade do conjunto $X$, isto é, número de elementos de $X$;

$|x| \quad=$ módulo do número $x$;

$\backslash$ =símbolo de diferença entre conjuntos; operação inversa da união;

$\alpha \quad=$ número real;

$\Delta \quad=$ unidades de tempo de antecipação;

$\Delta\left(b_{[n]}, O_{t_{[n]}^{*}}\right)=$ diminuição da função-objetivo quando acontecer a inserção de $O_{t_{[n]}^{*}}$ unidades de capacidade adicional no bloco $b_{[n]}$;

$\theta, \bar{\theta}, \underline{\theta}=$ número, número máximo e número mínimo de turnos de trabalho;

$\lambda \quad=$ unidades de tempo de movimentação;

$\pi \quad=$ programa com todas as ordens de $J$;

$\Pi, \Pi_{j}=$ conjunto de todos os programas possiveis e conjunto de todos os programas possiveis para as $j$ primeiras ordens;

$\pi_{j}, \pi_{j}^{A I E}=$ programa parcial e programa parcial gerado pelo AIE, contendo as $j$ primeiras ordens de $J$;

$\tau \quad=$ instante qualquer;

$a_{j} \quad=$ horário de início desejado da ordem $j$;

$\operatorname{Aum}(b)=$ conjunto de ordens pertencentes ao bloco $b$ que possuem a propriedade de que se $b$ for antecipado, aumenta-se o adiantamento de $j$, e portanto, aumenta-se o valor da função-objetivo;

$\operatorname{AumDim}(b)=$ conjunto de ordens pertencentes a $b$ cujo horário de término efetivo seja igual ao horário de término desejado;

$\arg f(x)=x$, argumento de $f(x)$;

$b \quad=$ indice de um bloco qualquer; 
$B \quad=$ conjunto de índice dos blocos;

$b^{-}, b^{+}=$bloco $b$ postergado e adiantado em um pequeno valor;

$b_{[n]} \quad=$ estado do bloco $b$ após $n$ iterações;

$B_{i} \quad=$ bloco $i$ de um programa;

$b_{k} \quad=$ bloco parcial $k$ pertencente a $b$;

$C(\theta)$ =custo da utilização de $\theta$ turnos de capacidade normal;

$C_{j}, C_{j}^{*}=$ horário de término e horário de término ótimo da ordem $j$;

$C_{m j} \quad=$ horário de término da operação $m$ da ordem $j$;

$\operatorname{Dim}(b)=$ conjunto de ordens pertencentes ao bloco $b$ que possuem a propriedade de que se $b$ for antecipado, diminui-se o atraso de $j$, e portanto, diminui-se o valor da função-objetivo;

$d_{j}, d_{m j}=$ data de entrega da ordem $j$ e da operação $m$ da ordem $j$;

$E_{j}, E_{m j}=$ adiantamento da ordem $j$ e da operação $m$ da ordem $j$;

$e_{j}, e_{j}^{A I E}=$ horário efetivo de início da ordem $j$ e horário efetivo de início da ordem $j$ determinado pelo AIE;

$f_{\theta} \quad=$ instante de término do intervalo de tempo onde haverá $\theta$ turnos;

$f(j)=$ função de $j$;

$f_{t} \quad=$ instante de término do intervalo de tempo $t$;

$g(\pi) \quad=$ função de custo de $\pi$, onde $\pi=f(j \in J)$;

$G(b) \quad=$ valor da função-objetivo para o bloco $b$;

$g_{j}(x) \quad=$ função de custo de $x$, onde $x=f(j)$;

$H(a, b)=$ diminuição do adiantamento com o postergamento das ordens com horários de término pertencentes ao intervalo $[a, b)$;

$H(b)$ = potencial de aumento de custo com o adiantamento do bloco $b$;

$h_{j} \quad=$ custo de adiantamento da ordem $j$;

$i_{\theta} \quad=$ instante de início do intervalo de tempo onde haverá $\theta$ turnos;

$I_{i t}=$ número de unidades armazenadas do produto do tipo $i$ mantidas no estoque entre $t$ e $t+1$;

$i_{t} \quad=$ instante de início do intervalo de tempo $t$;

$J \quad=$ conjunto finito de índices das ordens;

$j \quad=$ =indice de uma ordem qualquer;

$J_{j} \quad=\operatorname{ordem} j(j=1,2, \ldots, n)$;

$K \quad=$ conjunto finito de índices dos blocos parciais;

$L$ =função Lagrangeana; 
$l \quad=$ número de blocos em um programa;

$L_{j} \quad=$ diferença da ordem $j$;

$\ln , \log =\log$ aritmo de base $e$ (ou neperiano) e de base 2;

$M \quad=$ conjunto finito de índices das máquinas;

$m \quad$ =indice de uma máquina qualquer;

$m$ =número inteiro estritamente positivo;

$n \quad=$ número inteiro estritamente positivo;

$N \quad=$ conjunto finito de índices dos intervalos de tempo pertencentes à capacidade adicional;

$N(\theta) \quad=$ conjunto finito de índices dos intervalos de tempo pertencentes à capacidade adicional caso haja $\theta$ turnos de trabalho;

$N_{b} \quad=$ conjunto de indices de intervalos de tempo de capacidade adicional que pertencem ao intervalo de processamento do bloco $b$;

$O=$ conjunto finito de índices dos intervalos de tempo pertencentes à capacidade adicional que foram efetivamente utilizados;

$O(x) \quad=$ ordem de $x$;

$O_{j t} \quad=$ quantidade de capacidade adicional do intervalo $t$ que foi utilizada no processamento de $j$;

$o_{m t} \quad=$ custo por unidade de tempo associado ao intervalo $t$ de $m$;

$O_{m t}=O_{t}$ da operação $m$;

$O_{t} \quad=$ capacidade adicional inserida no intervalo de tempo $t$

$O_{t} \quad=$ número de horas-extras de mão-de-obra utilizadas em $t$;

$o_{t} \quad=$ custo por unidade de tempo associado a $t$;

$P \quad=$ fila de prioridade;

$P(b) \quad=$ fila de prioridade $b$;

$p_{j} ; p_{m j}=$ tempo de processamento da ordem e da operação $m$ da ordem $j$;

$p_{j}^{S} \quad=$ tempo de processamento da ordem $j$ que aconteceu num intervalo de capacidade normal;

primeiro $(b)=$ indice da primeira ordem do bloco $b$;

$r \quad=$ indice de um bloco de intervalo de tempo de capacidade adicional;

$R \quad$ =conjunto de índices de blocos de intervalos de tempo de capacidade adicional;

$R ; R_{+}=$conjunto dos números reais e dos reais positivos;

$R_{t} \quad=$ número de horas-regulares de mão-de-obra utilizadas em $t$; 
$S \quad=$ conjunto finito de indices dos intervalos de tempo pertencentes à capacidade normal;

$T=$ conjunto finito de índices dos intervalos de tempo;

$t \quad=$ índice de um intervalo de tempo qualquer;

to =instante inicial;

$T_{j} ; T_{m j}=$ atraso da ordem $j$ e da operação $m$ da ordem $j$;

último $(b)=$ índice da última ordem do bloco $b$;

$v_{j} \quad=$ custo do horário de término da ordem $j$;

$W(a, b)=$ diminuição do atraso com a antecipação das ordens com términos pertencentes ao intervalo $(a, b]$;

$W(b) \quad$ potencial de diminuição de custo com o adiantamento do bloco $b$;

$w_{j} \quad=$ custo de atraso da ordem $j$;

$W_{j} ; W_{t}=$ período de espera precedendo o processamento de $j$; antecedendo $f_{t}$;

$x \quad=$ variável qualquer;

$X_{i t} \quad=$ número de unidades do produto do tipo $i$ a ser produzido em $t$;

$X_{j t} \quad=$ variável 0-1 que associa a ordem $j$ ao intervalo $t$;

$y \quad=$ variável qualquer;

$Y_{j t} \quad=$ número de unidades da família $j$ a ser produzida em $t$;

$Y_{j t} \quad=$ variável $0-1$ que associa a ordem $j$ a $t$;

$z ; z^{[n]}=$ intervalo de incerteza e intervalo de incerteza na $n$-ésima iteração;

$Z_{k t} \quad=$ número de unidades do item $k$ a serem produzidos em $t$. 


\section{Resumo}

Esta tese apresenta análises de dois problemas de máquina única relacionados à programação da produção com seqüência predefinida. Para ambos os problemas são sugeridas modelagens via programação matemática e algoritmos que encontram a solução ótima em tempo polinomial.

O primeiro problema é o de inserção de espera no problema com funçãoobjetivo que considera s soma de funções convexas do horário de término independentes para cada ordem.

O segundo considera custos distintos de adiantamento e atraso para cada ordem e custos de utilização de capacidade adicional ponderados distintamente para cada periodo de capacidade adicional que possa ser utilizado. Sugere-se adicionalmente um procedimento onde o mesmo avalia a melhor opção entre se utilizar tempo de espera, horas-extras e criar ou eliminar turnos de trabalho. São feitas análises e algumas generalizações como a utilização de diversos intervalos de tempo com diferentes custos concatenados e uma sugestão para a utilização dos procedimentos num ambiente de múltiplas máquinas. 


\begin{abstract}
This thesis analyses two cases of one-machine problem regarding to production scheduling with fixed sequence. In both problems, modeling with mathematical programming, and polynomial-time algorithms are suggested.

The first problem deals with idle time insertion in the problem where the objective function (represented by a sum of costs) considers that each job has costs described as any convex function of its completion time.

The second problem considers earliness and tardiness with distinct costs for each job considering the possible use of additional capacity. For the additional capacity we assume that there are distinct costs for each time period where jobs can be processed. A procedure dealing with options of either to alter the number of shifts or to utilize overtime considering total costs is suggested. Analysis and generalizations based on the utilization of several contiguous time periods with distinct costs and a heuristic extension for the multiple-machine case are also presented.
\end{abstract}




\section{Introdução}

Neste capítulo procura-se fazer a contextualização da tese, de modo que os capítulos posteriores estejam justificados, tanto do ponto de vista da aplicação, quanto do ponto de vista da inserção dos temas em um contexto mais geral e abrangente.

A primeira seção trata de estratégia de manufatura e se presta para a definição de funções-objetivo que serão utilizadas nos procedimentos de programação desenvolvidos ao longo da tese. Ela fornece uma visão geral dos critérios competitivos de tempo na administração de operações por acreditarmos que empresas competindo num ambiente desse tipo sejam as mais interessadas nos temas tratados aqui. Apesar disso, uma empresa não precisa estar competindo num ambiente caracterizado pelo tempo para se beneficiar dos procedimentos aqui propostos. Os beneficios podem acontecer em qualquer ambiente onde a pontualidade e a rapidez de entrega são importantes. Ademais, ambientes onde haja possibilidade de variação de capacidade na atividade de programação também se relacionam com os temas abordados na tese. A seção 1.2 analisa as decisões de planejamento de longo e curto prazos, mostrando a abordagem clássica e a abordagem assumida aqui. A seção 1.3 especifica o que foi feito mostrando suas justificativas. A seção 1.4 explicita como as propostas aqui contidas podem ser operacionalizadas no mundo real.

\subsection{Critérios competitivos de tempo na administração de operações: definindo funções-objetivo}

As definições de como uma empresa deve funcionar e quais são seus principais objetivos acontecem na elaboração de sua estratégia. Na definição da estratégia de uma unidade de negócios aparecem características geralmente denominadas critérios - fundamentais para fazer frente aos competidores e para ter sucesso no decorrer do tempo. Um ambiente competitivo pode ser caracterizado como aquele no qual haja pelo menos duas empresas que concorrem pelos mesmos clientes, oferecendo produtos que se 
prestam ao mesmo uso. O sucesso no longo prazo acontece pela boa administração dos critérios competitivos, fazendo com isso que a empresa tenha vantagem competitiva em relação aos concorrentes.

Embora não haja na bibliografia uma concordância exata acerca dos critérios competitivos, há um alinhamento em certa direção. Pode-se dizer que os principais critérios competitivos abordados na literatura são relacionados com o custo, a qualidade e o tempo. Aqui na tese, ambos, os critérios de custo e de tempo, serão tratados de forma conjunta pois existe um relacionamento forte entre custos e tempos. Em verdade, podemos assumir que as competências são cumulativas, ou seja, para se ter competência em qualidade, deve-se necessariamente ter competência em custo e para se ter competência em tempo, deve-se ter competência em custo e qualidade; não adiantaria muito entregar um produto pontualmente sem que sua qualidade fosse suficientemente boa.

$\mathrm{Na}$ administração de operações, os elementos relacionados ao tempo têm sido tratados há muito tempo na literatura. Já num dos trabalhos pioneiros da teoria da programação da produção, SMITH (1956) utilizou funções-objetivo relacionadas com o tempo que são importantes até hoje em dia, como a minimização do atraso máximo e do atraso total. Uma outra função-objetivo que consegue capturar as dimensões de tempo e de custo denominada atraso total ponderado também foi estudada.

Assim como outras diversas tendências administrativas e organizacionais, os principais conceitos relacionados com o tempo são oriundos de casos reais. Em outras palavras, a geração de conhecimento aconteceu inicialmente nas empresas, e só mais tarde começou haver um desenvolvimento teórico mais consistente. Alguns autores como STALK (1988) e BOWER; HOUT (1988) acreditam que os critérios de tempo são extensões/evoluções dos princípios do JIT (Just-in-Time), uma abordagem de origem reconhecidamente industrial.

Com uma visão mais otimista, STALK; HOUT (1990) acreditam que o tempo de resposta rápido é uma evolução do ponto de vista estratégico, isto é, é uma inovação estratégica. Outras inovações anteriores de mesma repercussão e importância, cada uma em seu tempo, foram: a curva de aprendizado, indicando que quanto maior a produção, menor o custo; a administração de portifólio, que vê empresas de um grupo como um portifólio 
de negócios e não como centros de lucro; o uso estratégico da dívida, utilizando empréstimos para alavancar o crescimento da empresa; a redistribuição dos custos, repassando custos indiretos maiores para produtos de pequena produção; e a variedade a baixo custo, facilitando a produção de itens com variedade sem um aumento significativo dos custos.

Dentro dos critérios de tempo, a idéia é geralmente fazer a compressão do tempo - ou de sua variância - decorrido para a elaboração de uma determinada atividade. As implicações estratégicas da compressão do tempo dentro de organizações podem ser listadas como segue (STALK, HOUT, p. 31): aumento de produtividade; preços podem ser aumentados; riscos são diminuídos devido à melhor previsão de demandas; e a participação no mercado é aumentada.

Considerando um ambiente amplo, o critério competitivo relacionado ao tempo pode ter diversas dimensões como pode ser observado na Figura 1.

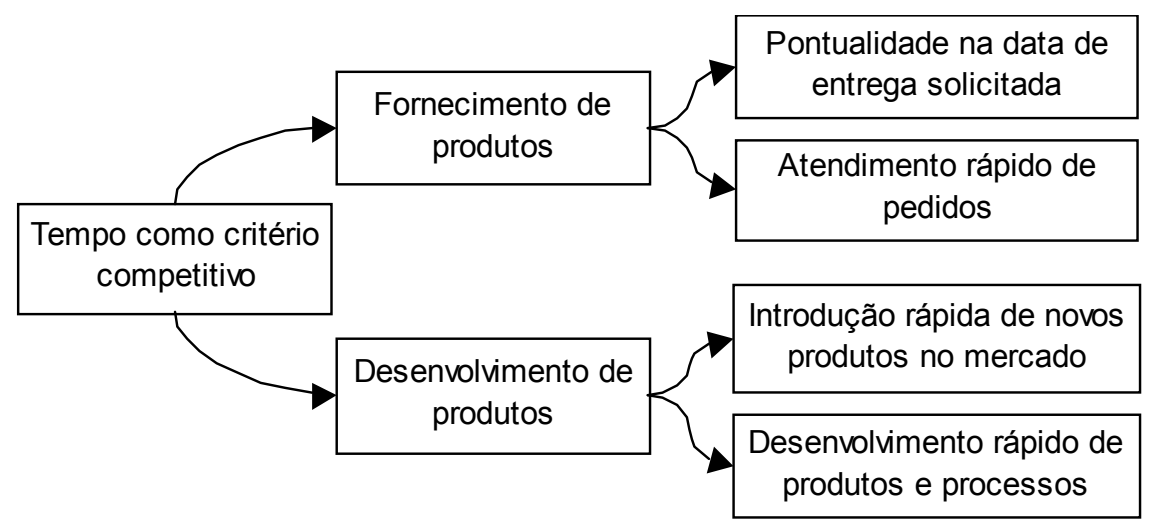

F giura 1:M úzịłas dimensões do crtérí compettivo tempo

Pela bibliografia básica pesquisada (STALK, BOWER; HOUT e STALK; HOUT), o tempo como critério competitivo pode ter dois enfoques: o primeiro se relaciona com o desenvolvimento de produtos, enquanto que o segundo se relaciona com o fornecimento de produtos. O desenvolvimento de produtos também pode ser encarado sob dois enfoques: o da introdução rápida de produtos no mercado e o do desenvolvimento rápido de produtos $\mathrm{e}$ processos. O fornecimento de produtos possui outras duas dimensões que são 
a pontualidade com relação à data de entrega definida no contrato de fornecimento de produtos e a rapidez com que os pedidos feitos pelos clientes podem ser atendidos.

Empresas não trabalham necessariamente em todas as dimensões apresentadas. Dependendo das características do mercado e da própria empresa, apenas uma das dimensões já é suficiente para caracterizar uma empresa cujo critério competitivo é o tempo, ou seja, um competidor baseado no tempo. Aqui na tese, o estudo é focado exclusivamente no fornecimento de produtos.

Enquanto o desenvolvimento rápido de produtos é importante para empresas líderes ou que querem chegar à liderança, o fornecimento rápido de produtos pode ser importante para qualquer empresa. Empresas que buscam uma maior eficiência em relação aos parâmetros de tempo no fornecimento de produtos terão um longo caminho pela frente. STALK; HOUT (p. 163) alegam que três anos é um tempo típico requerido para transformar a maioria das empresas, embora empresas extremamente complexas possam necessitar de muito mais tempo.

A capacidade de alteração do sistema de produção para atender demandas dos clientes no curto prazo, denominada muitas vezes na literatura como flexibilidade, também tem íntimo relacionamento com o tempo. As alterações no sistema de produção podem ser por exemplo na data de entrega, na quantidade vendida e no mix de produtos. Assim, uma empresa que possui uma alta capacidade de atendimento pedidos no curto prazo terá grande parte das características de uma empresa flexível. Sistemas produtivos com essas características associados a fortes doses tecnológicas são por vezes denominados FMS's (Flexible Manufacturing Systems).

A abordagem de fornecimento rápido de produtos também pode ser utilizada para ajudar a resolver um problema notório da administração de operações que é a previsão. Com o fornecimento rápido, as previsões podem ser feitas em horizontes de tempo menores e por conseqüência o planejamento também. SERSON (1993, p. 23) chega até a mencionar que a rapidez de entrega, é tanto mais importante para o cliente quanto maior a sua dificuldade de prever o futuro. Isso também se torna verdade para a própria empresa, isto é, o fornecimento rápido de produtos é tão mais importante quanto maior a dificuldade de se prever demandas futuras. 
Na programação da produção, a caracterização dos critérios de tempo pode ser feita por intermédio de funções-objetivo que representem os mesmos. O critério de pontualidade pode ser expresso matematicamente em uma função-objetivo como uma relação (ou função) da diferença entre as datas de entrega e os horários de término das ordens. A rapidez por sua vez pode ser caracterizada como uma função crescente do horário de término das ordens.

No capítulo 2 utilizamos uma função-objetivo que contempla a maximização conjunta da pontualidade e da rapidez de entrega, ambas consideradas como funções lineares do horário de término. Como será visto no capítulo 2, para o caso de funções lineares, a maximização conjunta da pontualidade e da rapidez de entrega pode ser reduzida (matematicamente por intermédio de uma transformação) à maximização da pontualidade apenas.

Para o caso de funções que não são lineares, os relacionamentos das variáveis já não são tão simples. Por essa razão, sugere-se um algoritmo bastante genérico, no sentido de que qualquer função que possa ser descrita como uma função convexa do horário de término pode ser contemplada. Dessa forma, cada ordem pode ter um custo associado ao seu horário de término; a restrição fica apenas por conta da convexidade dessa função de custo.

O capítulo 3 , além da maximização da pontualidade e minimização dos custos associados às ordens, trata de maneira conjunta a minimização dos custos de capacidade adicional utilizados. Obviamente que a capacidade adicional é utilizada caso ajude a diminuir os custos totais de programação, melhorando a pontualidade de atendimento das datas de entrega das ordens.

Todas as funções dos horários de término podem ser entendidas como penalizações e geralmente se relacionam aos custos associados ao horário de término ocorrido. Essas penalizações são elementos diferenciadores das importâncias das ordens, quer seja pelo seu custo intrínseco, importância do cliente ou outro fator relevante ao ambiente onde a empresa esteja inserida.

\subsection{Relacionamento entre decisões de planejamento e de programação}

Levando em conta os ambientes descritos na seção anterior, não é dificil perceber que a empresa como um todo deve ser adaptada para ter um bom 
desempenho nesse ambiente. As áreas responsáveis pelo planejamento não conseguem se esquivar disso também.

Para o atendimento rápido e pontual de pedidos, o planejamento tem que se modernizar, utilizando técnicas sofisticadas e que permitam, no mínimo, a tentativa de otimização dos custos.

Em linhas gerais, aqui na tese tratamos de duas dessas técnicas: uma que trata de inserir espera entre a realização de ordens de produção e outra que insere capacidade em algum intervalo de tempo do horizonte de planejamento. Ambos os casos ponderam os custos envolvidos, avaliando a viabilidade de se tomar as ações mencionadas. Existe um estreito relacionamento entre as duas ações pois ambas se influenciam mutuamente. As duas ações podem ser consideradas como procedimentos que distribuem a carga $^{1}$ na atividade de programação da produção.

Dependendo do contexto, algumas vezes os termos planejamento de curto prazo e programação da produção serão utilizados com o mesmo sentido. Consideramos que a atividade de planejamento engloba a atividade de programação e portanto o termo planejamento pode significar tanto planejamento de longo prazo como de curto prazo.

A seção 1.2.1 descreve em linhas gerais o tratamento clássico do planejamento (englobando a capacidade) que é normalmente aceito como o padrão. A seção 1.2.2 descreve um ponto de vista relativamente diferente para o tratamento do planejamento. Este último é o utilizado ao longo de toda tese remanescente.

\subsubsection{Procedimentos clássicos de relacionamento entre decisões de curto e longo prazos no planejamento da produção}

A classificação mais aceita para a separação entre decisões de planejamento (considerando planejamento num sentido amplo) pertence a ANTHONY (1965). Nessa classificação, ANTHONY separa as decisões a serem

\footnotetext{
${ }^{1}$ Aqui neste trabalho há uma diferença entre capacidade e carga de trabalho. Para um determinado recurso (como uma máquina por exemplo), considera-se capacidade como sua disponibilidade temporal total, enquanto que carga sua capacidade efetivamente utilizada. Algumas vezes a carga pode ser entendida como a capacidade necessária para o atendimento de todas as ordens em suas datas exatas, ou seja, a capacidade mínima para que a pontualidade máxima seja alcançada.
} 
tomadas em nivel estratégico, nivel tático e nivel operacional2. Essa separação é uma tentativa de simplificar os problemas de planejamento existentes, fazendo assim com que metodologias mais efetivas possam ser utilizadas em sua solução. O problema remanescente depois das soluções individualizadas ainda é o de reintegração das soluções dos subproblemas gerados pela abordagem.

HAX; CANDEA (1984, cap. 1) especificam de forma bem clara o que se considera como problemas em cada nível. Para os autores citados, as decisões de nivel estratégico se relacionam com decisões de longo prazo e grande importância para a empresa. No que tange à produção, decisões desse tipo se relacionam com o projeto de aquisição de instalações produtivas como por exemplo a localização de novas plantas. Por serem decisões tomadas no longo prazo, sua freqüência é baixa e por conseqüência não são incorporadas nos modelos tradicionais de planejamento. Quando decisões desse tipo devem ser tomadas, são elaborados estudos individuais e geralmente não há necessidade de integração com os níveis tático e operacional.

As decisões de planejamento no nivel tático se relacionam com o planejamento agregado da capacidade; poderíamos dizer que a preocupação está na utilização dos recursos disponíveis. Dentre esses recursos pode-se citar a determinação dos niveis de produção, de estoque e de força de trabalho, de modo a atender flutuações de demanda utilizando bem os recursos disponíveis. Observe que o planejamento estratégico define o limite da capacidade quando essa capacidade é pouco flexível (como equipamentos de alto valor por exemplo), enquanto que aqui, define-se o uso dessa capacidade pouco flexivel e o limite da capacidade flexível (como força de trabalho por exemplo). Obviamente que a capacidade menos flexivel em algum ponto restringe a capacidade mais flexivel.

No nivel de decisões operacional estão incluídas as decisões de programação da produção e dos recursos, bem como seu controle ${ }^{3}$. As atividades de controle são importantes para a definição do estado do sistema produtivo assim como para a tomada de ações corretivas quando a execução

\footnotetext{
${ }^{2}$ Os termos utilizados originalmente por ANTHONY foram planejamento estratégico, controle administrativo e controle operacional para os três níveis respectivamente.

${ }^{3}$ Considera-se aqui que o controle é a verificação e a tomada de ações para que a execução real siga o que fora planejado.
} 
real não está de acordo com o planejamento. Nesse nível as decisões se relacionam com atividades unitárias e estão em seu ponto de maior detalhamento e precisão.

Diversas outras classificações podem ser sugeridas, como pode ser observado no próprio livro de ANTHONY, entretanto, de uma forma geral, a divisão em três níveis é bem aceita.

No caso real, a efetivação das idéias mencionadas acima pode acontecer de diversas formas. Deve-se levar em consideração um grande número de fatores tais como o tipo de empresa, o tipo de mercado, o porte do problema de planejamento, a rapidez com que as decisões devem ser tomadas, o nível de agressividade e competência dos competidores, etc.

Como existem diversas formas de se implementar a abordagem de ANTHONY4, optou-se aqui em fazer uma descrição sucinta do modelo de Planejamento Hierárquico da Produção (doravante denominado PHP) (BITRAN; TIRUPATI, 1993, HAX; CANDEA). Apesar de não ser muito difundido nos meios industriais, é um procedimento conceitualmente correto para se implementar efetivamente a proposta de ANTHONY. Além disso, de uma maneira geral, o PHP trata o problema da mesma forma que nos casos mais práticos. Por esta razão, o mesmo será utilizado como padrão, de modo que os beneficios das propostas contidas na tese possam ser avaliados.

O PHP pode ser entendido como uma metodologia que tenta fazer integrações entre os diversos niveis de planejamento - três níveis mais especificamente - possuídos pelas empresas. De acordo com BITRAN; TIRUPATI (p. 526), os procedimentos propostos no PHP são baseados primordialmente em: (i) procedimentos de agregação/desagregação de informações acerca de componentes e produtos fabricados e (ii) integração entre modelos matemáticos dos níveis de decisão. A grosso modo, as decisões de nível estratégico são encaradas como restrições das decisões de nível tático, enquanto que as decisões de nível tático são encaradas como restrições das decisões de nivel operacional.

No decorrer da utilização do PHP, faz-se necessário a agregação e

\footnotetext{
${ }^{4}$ Nos ambientes reais, a lógica que utiliza o MRP/MRPII (Materials Requirement Planning/Manufacturing Resource Planning) (VOLLMANN et al., 1997) como base é de longe a mais aceita. Mesmo nesse caso, para a boa utilização do MRP, a abordagem de ANTHONY é a que deveria ser utilizada como pano de fundo. Essa força, muito provavelmente é oriunda da competência do MRP no tratamento de produtos com estruturas.
} 
desagregação produtos e componentes do sistema produtivo. BITRAN; TIRUPATI definem itens como produtos finais entregues aos clientes, produtos como grupos de itens que possuem custos, processos e sazonalidades semelhantes, enquanto familias como grupos de itens que pertencem ao mesmo produto e que possuem tempos de preparação similares.

Resumidamente, os procedimentos podem ser separados em 3 fases. Na fase 1 (planejamento agregado) elabora-se o planejamento agregado para os tipos de produtos. O modelo não é exato para vários recursos dentro de uma empresa, como por exemplo se houvessem custos diferentes para cada máquina e para cada tipo de mão-de-obra. Isso na realidade está de acordo com os objetivos do planejamento agregado. As variáveis de decisão dos modelos são $X_{i t}$ (número de unidades do produto do tipo $i$ a ser produzido no intervalo t), $I_{i t}$ (número de unidades armazenadas do produto do tipo $i$ mantidas no estoque entre $t$ e $t+1$ ), $R_{t}$ (número de horas-regulares de mão-deobra utilizadas no intervalo $t$ ) e $O_{t}$ (número de horas-extras de mão-de-obra utilizadas no intervalo t). O modelo admite muitas variações para outros casos relacionados, mas de uma forma geral todas essas variações seguem esse mesmo padrão.

Na fase 2 (desagregação de familias) determina-se a quantidade de cada família de modo a minimizar o custo total de preparação. A variável de decisão é o $Y_{j 1}$ (número de unidades da família $j$ a ser produzida no intervalo $1)$.

$\mathrm{Na}$ fase 3 (desagregação de itens), após $Y_{j 1}$ ser determinado, há a necessidade de se distribuir essas unidades entre os itens pertencentes a cada família $j$. As decisões tomadas nas fases 1 e 2 são para o intervalo subseqüente - intervalo 1 -, mas afetam decisões no futuro; a fase 3 é utilizada para corrigir esse ponto. Para economizar custos futuros de preparação, distribui-se a quantidade da familia entre os itens de modo que o término de todos os itens coincida com o término da família a que eles pertencem. A variável de decisão é o $Z_{k 1}$ (número de unidades do item $k$ a serem produzidos no intervalo 1 ).

Os modelos podem resultar em saídas inviáveis e nesse caso, BITRAN; TIRUPATI e HAX; CANDEA fornecem uma série de soluções para casos onde isso possa ocorrer. Segundo os autores, essas possiveis inviabilidades não 
podem ser eliminadas por completo e, se o forem, os problemas terão seu tempo computacional piorado, além de necessitar de um nível maior de detalhamento em cada fase.

BITRAN; TIRUPATI (p. 531) alegam que os beneficios do planejamento agregado são: (i) economia nos custos de necessidades computacionais e de levantamento de dados para a elaboração do modelo de planejamento; (ii) a previsão agregada da demanda terá uma pequena variância e (iii) a diminuição do número de itens facilita a tomada de decisão pois o administrador não se perde nos detalhes que um grande número de itens poderia trazer.

Após ter utilizado o planejamento conforme descrito anteriormente, o problema remanescente ainda é o de programação da produção. O PHP não garante que haja pelo menos um programa viável quando se cumpre suas saídas. Tentando preencher essa lacuna, LASSERRE (1992) desenvolveu uma abordagem baseada em procedimentos de decomposição com múltiplos passos, de maneira que a solução do PHP é um plano de produção baseado em uma seqüência predefinida.

Os modelos de PHP minimizam os custos de estoque e de preparação, mas não incorporam variáveis como os custos de estoque em processo, nem custos de atraso caso a entrega de ordens seja fora da data solicitada pelo cliente. Dessa forma, podemos dizer que para casos onde não haja altos custos de estocagem e preparação, ou onde os custos de adiantamento e atraso sejam grandes, o PHP tem sua importância diminuída.

\subsubsection{Outras propostas para o relacionamento entre decisões de planejamento e programação}

Como comentado anteriormente, os procedimentos de planejamento descritos na seção anterior podem ser alterados de diversas formas. Uma delas, é a que descreveremos nesta seção e que utilizaremos ao longo de toda tese. Basicamente, a idéia é tomar algumas decisões de planejamento agregado (nível tático) na programação (nível operacional).

O planejamento do nível tático não se preocupa muito com a viabilidade de implementação do plano gerado a nível operacional. Na realidade, o plano é utilizado mais como uma diretriz do que como um plano rígido. No sentido 
inverso, livros e artigos clássicos da teoria da programação e seqüenciamento como BAKER (1974), FRENCH (1982), LAWLER et al. (1993) e PINEDO (1995) foram avaliados e nenhuma referência acerca do assunto aqui tratado foi encontrada. O que normalmente acontece é que os estudos de programação assumem que haja uma capacidade fixa sem considerar a hipótese de alterála.

Em um trabalho relativamente antigo, HOLLOWAY; NELSON (1973) já citavam que a minimização do requisito de capacidade com a restrição do atendimento de datas é um problema muito mais comum na prática do que os normalmente estudados na literatura. Grande parte dos estudos publicados consideram a minimização de alguma medida do atraso supondo como restrição uma capacidade constante.

Outros poucos autores tecem comentários sobre o assunto. Por exemplo, GRAVES (1981) sugere a interação do programa de produção como uma área de pesquisa futura, visando com isso diminuir as discrepâncias entre os casos reais e os modelos teóricos. O autor afirma (p. 665) que "... decisões de programação afetam e são afetadas por decisões de planejamento da capacidade ... Essa interação não é refletida na maioria dos modelos de programação."

MORTON; PENTICO (1993, p. 8) apontam para um "problema de programação estendido", onde há, na prática, um certo número de outras decisões que interfaceiam com o problema de programação clássico. Para esse problema estendido, os autores mostram uma série de reconfigurações possiveis como a adição de pessoal ou o aumento da rapidez de fabricação de uma determinada máquina.

No mesmo trabalho, MORTON; PENTICO (p. 578) descrevendo o sistema "Dinâmica do Gargalo" mostra que sob certas condições de custos, seu sistema considera a capacidade adicional como se houvesse um recurso adicional, que obviamente nem sempre é o caso. Dessa forma, turnos adicionais ou horas-extras são tratados sem que haja um grande aumento de complexidade na atividade de programação. Os autores não especificam muitos detalhes da heurística citada, mencionando que heuristicas mais elaboradas podem ser envisionadas facilmente.

O trabalho realizado aqui irá considerar a possibilidade de distribuição de carga, e para isso, consideram-se dois artificios: 
- Inserção de espera;

- Inserção de capacidade.

Como iremos trabalhar com custos de adiantamento, o leitor pode verificar que a inserção de espera se relaciona com a variação de capacidade pois permite que quando um turno adicional for criado, não haja grandes aumentos dos custos.

A abordagem utilizada aqui para variação de capacidade é um pouco conflitante com o planejamento agregado. Idealmente, pelo planejamento agregado, a quantidade de horas-extras definidas nos modelos deveriam ser alocadas ao longo do horizonte de planejamento. Aqui, a cada programação de ordens que é feita, pondera-se entre os custos associados ao término das ordens - de atraso e de adiantamento - e os custos de se utilizar capacidade adicional. Se o custo de capacidade adicional for muito baixo comparado com os custos de adiantamento e atraso, haverá uma superutilização, ao passo que se for muito alto, não haverá utilização, independente da quantidade de capacidade especificada no planejamento agregado.

\begin{tabular}{|c|c|c|c|c|}
\hline \multirow{2}{*}{$\begin{array}{l}\text { Flexibilidade da } \\
\text { capacidade de } \\
\text { recursos }\end{array}$} & \multirow{2}{*}{$\begin{array}{l}\text { Procedimento } \\
\text { de variação } \\
\text { de capacidade }\end{array}$} & \multicolumn{3}{|c|}{ Decisões relacionadas à capacidade do sistema produtivo } \\
\hline & & $\begin{array}{c}\text { Nível } \\
\text { estratégico }\end{array}$ & $\begin{array}{l}\text { Nível } \\
\text { tático }\end{array}$ & $\begin{array}{c}\text { Nível } \\
\text { operacional }\end{array}$ \\
\hline \multirow{2}{*}{$\begin{array}{l}\text { baixa } \\
\text { (alto valor de } \\
\text { aquisição de } \\
\text { capacidade) }\end{array}$} & Clássico & $\begin{array}{l}\text {-Define limite } \\
\text { (adquire } \\
\text { capacidade) }\end{array}$ & $\begin{array}{l}\text {-Define nível de utilização; } \\
\text {-Define número de turnos e } \\
\text { número agregado de } \\
\text { horas-extras }\end{array}$ & $\begin{array}{l}\text {-Varia capacidade sem metodologia, } \\
\text { tentando respeitar o nível de utilização }\end{array}$ \\
\hline & Alternativo & $\begin{array}{l}\text {-Define limite } \\
\text { (adquire } \\
\text { capacidade) }\end{array}$ & & $\begin{array}{l}\text {-Varia capacidade respeitando o limite } \\
\text { de utilização de acordo com os custos } \\
\text { de capacidade, de atraso e de } \\
\text { adiantamento }\end{array}$ \\
\hline \multirow{2}{*}{$\begin{array}{l}\text { alta } \\
\text { (baixo valor de } \\
\text { aquisição de } \\
\text { capacidade) }\end{array}$} & Clássico & & $\begin{array}{l}\text {-Define limite (adquire } \\
\text { capacidade) }\end{array}$ & $\begin{array}{l}\text {-Define nível de utilização; } \\
\text {-Varia capacidade sem metodologia, } \\
\text { tentando respeitar o nível de utilização }\end{array}$ \\
\hline & Alternativo & & & $\begin{array}{l}\text {-Varia capacidade respeitando o limite } \\
\text { de utilização de acordo com os custos } \\
\text { de capacidade, de atraso e de } \\
\text { adiantamento }\end{array}$ \\
\hline
\end{tabular}

Tabeł 1:D ecisões rełcínadas à capacilade do sistem a produtijo de acordo com o tp̣o de recurso e de procedin ento utilizado para a varíção de capacílade 
Nos dois casos, é muito comum que se tome essas decisões em outros níveis do planejamento. Por exemplo, poderiamos pensar que a inserção de espera não deveria acontecer caso nossa empresa estivesse bem balanceada e planejada no nivel agregado. A espera em si tem um custo associado (embora não seja essa a modelagem utilizada aqui) e o ideal seria não haver espera. Entretanto, a ferramenta desenvolvida nesta tese é de programação; avalia-se o estado da empresa no instante da programação para então inserir-se ou não espera. No caso ideal, onde haveriam previsões perfeitas, a espera não precisaria acontecer. A programação de férias e de alocação de pessoal por exemplo, poderiam fazer com que a inserção de espera fosse eliminada por completo.

Já no caso da inserção de capacidade, o problema é um pouco diferente. Os modelos de planejamento agregado avaliam basicamente a capacidade disponivel e a capacidade necessária para se atender uma demanda prevista. Com isso, tentam otimizar os custos envolvidos nas atividades que se referem às atividades produtivas - como turnos de trabalho -, e de atendimento de demanda - como estoque. Tudo isso é feito de uma forma agregada, sem haver uma definição de como alocar as horas-extras por exemplo. A proposta apresentada aqui avalia, ordem a ordem, custo a custo, a viabilidade de se inserir capacidade adicional, assumindo que essa adição é limitada. Uma extensão dessa proposta avalia a possibilidade de se retirar capacidade até um limite pré-especificado também. A Tabela 1 fornece uma visão geral comparativa das duas abordagens entre valor de recurso, tipo de procedimento para variação de capacidade e nível em que a decisão está sendo tomada.

\subsection{Trabalho elaborado, importância e principais justificativas para sua realização}

O trabalho realizado aqui se resume basicamente em duas partes: uma de generalização do algoritmo de inserção de espera de GAREY et al. (1988) e outra de elaboração de um algoritmo para inserção de capacidade, que utiliza o algoritmo de GAREY et al. para programação das ordens de entrada. 
GAREY et al. elaboraram seu algoritmo considerando como funçãoobjetivo a minimização da soma das diferenças - adiantamentos ou atrasos dos términos das ordens. Outros autores, como pode ser visto no capítulo 2 desta tese, desenvolveram algoritmos para funções-objetivo que consideram a ponderação das diferenças. Aqui, altera-se o algoritmo para um caso bastante genérico, de modo que o mesmo possa ser utilizado em funções-objetivo que sejam representadas pela soma de quaisquer funções convexas dos horários de término. Dessa forma, o algoritmo proposto contempla todos os casos apresentados previamente na literatura (comentados no capitulo 2).

A segunda parte, do algoritmo de inserção de capacidade, é uma proposta nova, baseada em experiências práticas. É muito comum nas empresas a tomada de decisão desse tipo sem haver um procedimento específico para tal. Como a bibliografia acerca desse tema é bastante restrita especialmente se comparada aos estudos que consideram capacidade fixa -, o trabalho realizado se justifica tanto do ponto de vista de aplicação quanto do ponto de vista teórico.

Se levarmos em consideração que dois dos três principais problemas da administração de operações ${ }^{5}$ estão sendo tratados conjuntamente, podemos perceber a importância do problema abordado.

É interessante lembrar que o problema de capacidade não se reduz apenas à definição do nível de capacidade a ser utilizada, mas também de definição da capacidade máxima. A definição de capacidade máxima geralmente se relaciona aos estudos de planejamento estratégico e engenharia econômica que avaliam a viabilidade da aquisição de recursos como equipamentos e instalações.

\subsection{Operacionalização das propostas}

As abordagens aqui sugeridas podem ser implementadas de diversas formas, mas provavelmente a implementação ideal é a que as utiliza como

\footnotetext{
${ }^{5}$ WILD (1977) mostra claramente que os principais problemas da administração de operações são a administração da capacidade e dos estoques e a atividade de programação. Na atividade de programação, WILD incorpora o planejamento no sentido do termo que estamos utilizando aqui. O autor também mostra que a administração de estoques é uma atividade de programação pois pode ser entendida como um problema de gestão de horários.
} 
procedimentos de softwares de programação da produção. Como as abordagens foram desenvolvidas para máquina única, elas são diretamente aplicáveis em softwares que utilizam procedimentos de gargalo.

Podemos definir gargalo como qualquer recurso (localizado em compras, produção, distribuição, vendas, etc.) que esteja restringindo o fluxo produtivo ou capacidade produtiva da empresa; é o recurso que determina a produção máxima da empresa. Desde sua maior disseminação, começada especialmente em 1984 com o livro de GOLDRATT; COX (1992), "A meta”, propostas de modelos que de alguma forma estão embasadas em modelos de gargalo têm aparecido. Uma implementação bem sucedida das idéias de GOLDRATT está no software OPT (Optimized Production Technology) ainda disponivel comercialmente. SPENCER; COX (1995) fazem uma análise tanto do OPT quanto da filosofia, denominada TOC (Theory of Constraints), sob a qual o mesmo é embasado.

Não há necessidade de haver apenas um gargalo no sistema produtivo. Normalmente a restrição é que deve haver apenas um gargalo para cada fluxo de produto. Isso não impede que certas modelagens assumam mais de um gargalo em cada fluxo, entretanto sem garantir a viabilidade do programa gerado nos gargalos secundários.

Um software de programação da produção é composto por diversos procedimentos que trabalham de forma associada. A parte que faz a programação especificamente se utiliza de um procedimento de seqüenciamento e de outros procedimentos que fazem uma análise mais refinada e realística do problema. Do ponto de vista computacional a dificuldade principal acontece no procedimento de seqüenciamento. Os outros procedimentos que melhoram o seqüenciamento são bastantes dependentes do tipo de aplicação e das particularidades de cada empresa.

A forma de fazer a programação também é dependente da abordagem utilizada pelo software. Apesar de diversas aplicações comerciais não se utilizarem de funções-objetivo explícitas para guiar a busca da seqüência, acreditamos que essa seja a melhor abordagem.

Com uma função-objetivo para guiar a busca de uma seqüência, os procedimentos de programação podem ser utilizados: A) após uma seqüência final ser obtida, onde a seqüência é definida de forma desassociada dos procedimentos de programação e B) onde seqüências são geradas (tanto 
parciais quanto completas) e procedimentos de programação são utilizados ao mesmo tempo. No caso A, a função-objetivo é calculada sem haver a utilização dos procedimentos de programação enquanto que no caso $B$, os procedimentos de programação são utilizados juntamente com o seqüenciamento para a definição do direcionamento da busca. Observe que o caso A não exclui a possibilidade da seqüência ser definida por uma regra de despacho por exemplo.

As propostas apresentadas aqui nesta tese se aplicam tanto no caso A quanto no caso B, desde que as devidas adaptações sejam feitas.

\subsection{Organização da tese}

Depois desta introdução, a tese está dividida em outros 3 capítulos. O capítulo 2 trata da generalização do algoritmo de inserção de espera de GAREY et al. (1988). De forma diferente do trabalho de GAREY et al., considera-se que a função-objetivo seja uma função convexa dos horários de término.

O capítulo 3 trata do estudo da variação da capacidade. O problema é definido como o de inserção de capacidade, e um algoritmo é elaborado para sua solução. O capítulo se desenvolve fornecendo alguns resultados com relação à implementação computacional e provando a otimalidade do algoritmo. São apresentados alguns casos particulares bem como algumas generalizações. O capitulo é finalizado com uma apresentação de como os procedimentos poderiam ser utilizados para definição de horas-extras e número de turnos.

Finalmente, o capítulo 4 apresenta algumas outras discussões interessantes, juntamente com as conclusões deste trabalho. Avalia-se o possivel impacto dos procedimentos propostos no mundo real. No mesmo capítulo, apresenta-se algumas sugestões para pesquisas futuras relacionadas aos temas tratados aqui. 


\section{Algoritmo de inserção de espera para o problema de uma máquina com função-objetivo representada pela soma de funções convexas do horário de término independentes para cada ordem}

A consideração dos custos de adiantamento e atraso tem se tornado constante na realização da programação da produção. BAKER; SCUDDER (1990) fazem uma revisão bibliográfica acerca dos estudos que trataram desse tipo de problema. Posteriormente diversos outros trabalhos continuaram tratando de temas relacionados, como por exemplo BALAKRISHNAN et al. (1999) e FEDERGRUEN; MOSHEIOV (1997) dentre outros.

A maior contribuição deste capítulo é apresentada na seção 2.8. As seções anteriores são utilizadas para introduzir gradativamente o tema, de modo que a seção 2.8 seja mais inteligivel. O problema considerado nas seções 2.4 a 2.7 ainda não foi tratado diretamente na literatura; apenas casos particulares o foram. Entretanto, como veremos mais adiante, uma transformação de coeficientes e variáveis pode fazer com que o problema tratado aqui possa ser resolvido por abordagens utilizadas nos casos mais particulares e já disponiveis na literatura.

\subsection{Conceitos preliminares e definição do problema}

Seja $J=\{1,2, \ldots\}$ um conjunto ordenado finito de índices que representam as ordens. Cada ordem $j(j \in J)$ é caracterizada pela quíntupla $\left(h_{j}, w_{j}, v_{j}, p_{j}, d_{j}\right)$ representando respectivamente: custo de adiantamento, custo de atraso, custo do horário de término, tempo de processamento e data de entrega. Supondo que $C_{j}$ represente o horário de término da ordem $j$, podemos dizer que o custo total do horário de término da ordem $j$ é definido como $v_{j} C_{j}$, o custo total de adiantamento como $h_{j} E_{j}=h_{j} \max \left(0, d_{j}-C_{j}\right)$, ao passo que o custo total de atraso como $w_{j} T_{j}=w_{j} \max \left(0, C_{j}-d_{j}\right)$.

Todo o trabalho realizado nesta tese vai considerar que uma seqüência tenha sido definida previamente por algum outro procedimento adequado a 
esse fim. A programação aqui é definida como a determinação dos horários de início e de término das ordens de uma dada seqüência. Para uma dada ordem $j$, existe um intervalo de processamento $\left[e_{j}, e_{j}+p_{j}\right]$ onde $e_{j}$ significa o horário efetivo de início do processamento da ordem $j$, e $[\cdots]$ representa um intervalo fechado. Observe que para duas ordens consecutivas $j$ e $j+1$, trabalhando em uma única máquina, com intervalos de processamento definidos por $\left[e_{j}, e_{j}+p_{j}\right] \mathrm{e}$ $\left[e_{j+1}, e_{j+1}+p_{j+1}\right]$, pode haver intersecção dos intervalos apenas nos pontos extremos dos mesmos. Essa consideração será utilizada para facilitar o desenvolvimento posterior. Seja $W_{j}$ o período de espera antes da realização da ordem $j$. O programa $\pi$ de um conjunto de ordens $J$, é a determinação do horário de início de cada ordem, ou seja, $\pi=\left\{e_{1}, e_{2}, \ldots, e_{|J|}\right\}$, onde $e_{j}=C_{j-1}+W_{j}$. Um programa parcial, $\pi_{j}$, é um programa que contém as $j$ primeiras ordens de $J$.

Estamos considerando o caso de uma única máquina, que deve processar a seqüência de ordens definida por $J$. O programa é realizado de maneira a tentar cumprir as datas de entrega $d_{j}$, sabendo-se que cada ordem demanda um determinado tempo $p_{j}$ para o seu processamento. Há possibilidade de inserção de tempo de espera $W_{j}$ antes da elaboração de uma determinada ordem $j$. Considerando que $h_{j} \geq 0, w_{j} \geq 0$ e $v_{j} \geq 0$, as funções-objetivo estudadas aqui podem ser definidas como $\min g(\pi)=\sum_{j \in J}\left(h_{j} E_{j}+w_{j} T_{j}+v_{j} C_{j}\right)$, e $\min g(\pi)=\sum_{j \in J} g_{j}\left(C_{j}\right)$, onde $g_{j}(\cdot)$ é uma função convexa.

As funções-objetivo consideradas nos diversos estudos têm uma grande variedade, mostrando assim que muitas modelagens podem ser assumidas na resolução de problemas desse tipo. De qualquer forma, existe uma certa hierarquia na utilização de funções-objetivo pois algumas, por suas características, são generalizações de outras. LAWLER et al. (1993) fazem uma explanação acerca desse tema - especialmente relacionada ao aspecto computacional dos problemas -, mostrando algumas hierarquias com relação à funções-objetivo clássicas da teoria da programação e seqüenciamento.

A Figura 2 apresenta uma visão geral de um grupo de funções-objetivo que se relaciona com as funções estudadas neste trabalho. As funções que estão na ponta das setas são mais genéricas; se um procedimento resolve a função-objetivo da ponta da seta, ele também resolve as funções-objetivo que estão na cauda das setas, assim como das setas precedentes. Com abordagem 
semelhante a deles, podemos perceber facilmente como as funções-objetivo consideradas aqui são generalizações de diversas outras normalmente mais estudadas.

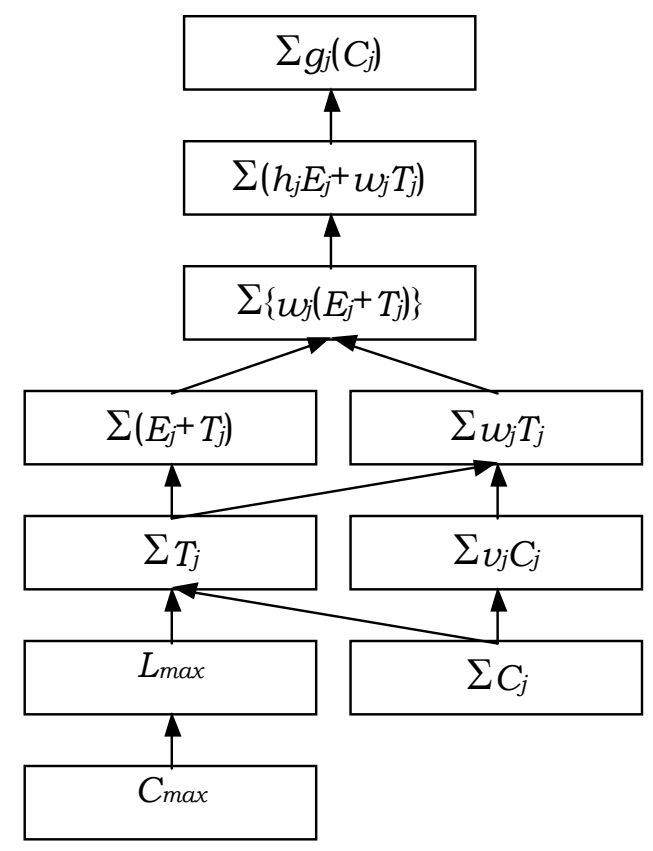

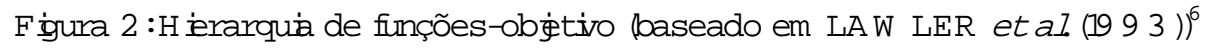

Veremos mais adiante que $\sum_{j \in J}\left(h_{j} E_{j}+w_{j} T_{j}+v_{j} C_{j}\right)$ é equivalente a $\sum_{j \in J}\left(h_{j} E_{j}+w_{j} T_{j}\right)$ do ponto de vista da solução do problema, e por essa razão, apenas o caso mais simples está contemplado na figura.

\subsection{Exemplo introdutório}

Considere duas ordens para serem programadas com as seguintes características: $\left(p_{1}, d_{1}, w_{1}, h_{1}\right)=(3,4,6,8),\left(p_{2}, d_{2}, w_{2}, h_{2}\right)=(4,10,6,8)$, onde $J_{1}$ deve ser

${ }^{6} L_{j}=C_{\mathcal{J}}-d_{j}$ e $L_{\max }=\max _{j \in \mathcal{J}}\left(C_{\mathcal{J}}-d_{j}\right)$. 
realizada antes de $J_{2}$. O instante de início da programação (momento em que a produção das ordens pode ser iniciada) é $t_{0}=0$.

Considerando a função-objetivo, o que desejamos é a minimização das diferenças entre os términos das ordens e suas datas de entrega. Então, idealmente, deveríamos terminar $J_{1}$ em $d_{1}=4$ e $J_{2}$ em $d_{2}=10$. Nesse caso a função-objetivo teria o mínimo valor que é equivalente a 0 .

Avaliando nossa instância podemos perceber que se houver uma unidade de espera, $W_{1}=1$, antes da realização da ordem $J_{1}$, mais o processamento da ordem, $p_{1}$, o horário de término é equivalente a $C_{1}=t_{0}+W_{1}+p_{1}=1+3=4=d_{1}$, como desejávamos. O mesmo raciocínio é válido para J2, de modo que $C_{2}=C_{1}+W_{2}+p_{2}=4+2+4=10=d_{2}$. Nesse caso, o valor da função-objetivo é mínimo pois ambas as ordens tiveram seus términos em suas datas de entrega.

Vamos imaginar agora que $d_{2}=7$. Aqui, não há possibilidade de ambas as ordens serem finalizadas em suas datas de entrega pois há concorrência pela utilização da máquina; ambas as ordens deveriam ser processadas ao mesmo tempo para que a função-objetivo seja mínima. Como isso não é possível, devemos ou adiantar o término da primeira ordem, atrasar o término da segunda, ou ambos.

Vamos considerar o caso de atrasar a segunda ordem. Assim, $C_{2}=C_{1}+W_{2}+p_{2}=4+0+4=8$. Observe que houve um atraso $T_{2}=C_{2}-d_{2}=8-7=1$ e portanto a função-objetivo é equivalente a $g(\pi)=w_{2} T_{2}=6.1=6$.

O algoritmo proposto mais adiante define quais ordens devem ser atrasadas e quais devem ser adiantadas, respeitando todas as restrições do problema, de modo que o valor da função-objetivo seja mínimo.

\subsection{Inserção de espera}

Provavelmente o primeiro trabalho publicado de forma ampla que apresentou um Algoritmo7 de Inserção de Espera (AIE) pertence a FRY et al. $(1987)^{8}$. De uma maneira bastante clara, os autores formularam o problema de

\footnotetext{
${ }^{7}$ Aqui na tese o termo algoritmo está associado à otimização. Quando não houver otimização, o procedimento será chamado de heurística ou mesmo de procedimento.

${ }^{8}$ Antes do trabalho de FRY et al., alguns outros trabalhos já haviam sido publicados, ou como teses, ou como relatórios internos.
} 
inserção de espera no problema de atraso e adiantamento com custos individuais, $\sum_{j \in J}\left(h_{j} E_{j}+w_{j} T_{j}\right)$, como um problema de programação linear. Pela característica do tipo de problema, o pior caso do mesmo é resolvido em tempo $O\left(|J|^{2}\right)$. Algum tempo depois, DAVIS; KANET (1993) propuseram um outro algoritmo para o mesmo problema com o mesmo tempo no pior caso.

De uma maneira provavelmente independente, GAREY et al. (1988) também propuseram um AIE para o problema de atraso e adiantamento sem custos, $\sum_{j \in J}\left(E_{j}+T_{j}\right)$, com tempo $O(|J| \log |J|)^{9}$. Para o caso da consideração de um custo único para adiantamento e atraso, $\sum_{j \in J}\left\{w_{j}\left(E_{j}+T_{j}\right)\right\}$, os autores indicam como o algoritmo deve ser reformulado de modo que a tempo computacional seja mantido. YANO; KIM (1991) elaboraram um AIE baseado na programação dinâmica. A inserção de espera é feita no problema com função-objetivo $\sum_{j \in J}\left(h_{j} E_{j}+w_{j} T_{j}\right)$, onde é suposto que $w_{j} \geq h_{j} \geq 0$. O tempo de solução no pior caso é $O\left(|J|^{2} \log |J|\right)$.

COLIN; SHIMIZU (2000) fazem uma adaptação do AIE de GAREY et al. possibilitando que o mesmo seja utilizado no problema do tipo $\sum_{j \in J}\left(h_{j} E_{j}+w_{j} T_{j}\right)$, mantendo o tempo de solução em $O(|J| \log |J|)$.

No item 2.7 desta tese é feita uma proposta de um AIE que pode ser utilizado em funções-objetivo convexas do horário de término do tipo $g(\pi)=\sum_{j \in J} g_{j}\left(C_{j}\right)$. Esse tipo de função engloba todos os outros trabalhos publicados previamente.

Todos os trabalhos mencionados supõem que os algoritmos sejam utilizados a partir de uma seqüência inicial definida preliminarmente. Como o problema de obtenção das seqüências é fortemente NP-difícil10,11, existem diversos métodos heurísticos para sua solução. Dentre esses métodos, podemos destacar as regras de despacho e outros procedimentos mais poderosos e intensivos computacionalmente como por exemplo a busca-tabu

\footnotetext{
${ }^{9}$ Nesta tese, a menos que especificado de forma contrária, $\log n=\log _{2} n$.

${ }^{10}$ LAWLER (1977) provou que o problema de otimização $\sum w_{j} T_{j}$ é fortemente NP-difícil. Como nossos problemas são casos mais genéricos do que o de LAWLER, também podemos dizer que os mesmos são fortemente NP-difíceis. O caso $\sum\left(E_{j}+T_{j}\right)$ também foi provado ser NP-difícil por GAREY et al. (1988).
} 
(MORTON; PENTICO, 1993).

Todos os AIE devem ser utilizados associados a procedimentos de seqüenciamento como pode ser observado por exemplo em COLIN (1998), que utilizou o beam search como um gerador de seqüências e um AIE para definir os programas.

\subsection{Algoritmo de Inserção de Espera (AIE)}

Nesta seção fazemos uma adaptação no AIE de GAREY et al. (1988) para a função-objetivo do tipo $\sum_{j \in J}\left(h_{j} E_{j}+w_{j} T_{j}+v_{j} C_{j}\right)$. Esta seção e a próxima seguem de forma bastante semelhante o desenvolvimento e a notação utilizados por GAREY et al.

Embora a espera seja destacada no próprio nome do algoritmo, sua utilização não a define diretamente. O algoritmo vai definir os horários de início das ordens, $e_{j}$; as esperas $W_{j}$, como já mostrado anteriormente, podem ser obtidas pela seguinte equação: $W_{j}=e_{j}-\left(e_{j-1}+p_{j-1}\right)$.

Para uma ordem $j$, a função-objetivo pode ser definida como $g_{j}\left(C_{j}\right)=h_{j} \max \left(0, d_{j}-C_{j}\right)+w_{j} \max \left(0, C_{j}-d_{j}\right)+v_{j} C_{j}$ e portanto

$$
g_{j}\left(C_{j}\right)=\left\{\begin{array}{l}
\left(v_{j}-h_{j}\right) C_{j}+h_{j} d_{j} \text { se } d_{j} \geq C_{j} \\
\left(v_{j}+w_{j}\right) C_{j}-w_{j} d_{j} \text { se } d_{j}<C_{j}
\end{array}\right.
$$

A proposição abaixo mostra como a função-objetivo tratada aqui pode ser reduzida à função de atraso e adiantamento ponderados independentemente. Podemos dizer que os problemas são equivalentes do ponto de vista matemático e de sua dificuldade de solução.

$$
\begin{array}{llllll}
\text { Proposição } & \text { 2.1. } & \text { Se } & h_{j}^{t}=h_{j}-v_{j} & \text { e } & w_{j}^{t}=w_{j}+v_{j}, \\
\sum_{j \in J}\left(h_{j} E_{j}+w_{j} T_{j}+v_{j} C_{j}\right)=\sum_{j \in J}\left(h_{j}^{t} E_{j}+w_{j}^{t} T_{j}+v_{j} d_{j}\right) . & &
\end{array}
$$

11 Definições bastantes formais acerca da NP-dificuldade podem ser encontrados em GAREY; JOHNSON (1979) e LAWLER et al. (1993). Para o caso da programação da produção, FRENCH (1982) expõe o tema de maneira mais didática e menos rigorosa. 
Demonstração: Seja $x^{+}=\max \{0, x\}$. Se $C_{j} \geq d_{j}$,

$$
h_{j}\left(d_{j}-C_{j}\right)^{+}+w_{j}\left(C_{j}-d_{j}\right)^{+}+v_{j} C_{j}=\left(w_{j}+v_{j}\right)\left(C_{j}-d_{j}\right)+v_{j} d_{j}
$$

por outro lado, se $C_{j}<d_{j}$,

$$
h_{j}\left(d_{j}-C_{j}\right)^{+}+w_{j}\left(C_{j}-d_{j}\right)^{+}+v_{j} C_{j}=-h_{j}\left(C_{j}-d_{j}\right)+v_{j} C_{j}=\left(v_{j}-h_{j}\right)\left(C_{j}-d_{j}\right)+v_{j} d_{j}
$$

portanto

$$
h_{j}\left(d_{j}-C_{j}\right)^{+}+w_{j}\left(C_{j}-d_{j}\right)^{+}+v_{j} C_{j}=\left(h_{j}-v_{j}\right)\left(d_{j}-C_{j}\right)^{+}+\left(w_{j}+v_{j}\right)\left(C_{j}-d_{j}\right)^{+}+v_{j} d_{j}
$$

conforme queriamos demonstrar.

A proposição de certa forma mostra alguma incoerência na utilização da função-objetivo como está proposta aqui. Entretanto, podemos citar duas razões que corroboram na utilização da forma apresentada: 1) Ela é um passo a mais na direção da generalização acontecida no item 2.7 ; 2) Para um caso real, é mais interessante deixar os custos utilizados na função-objetivo de forma explícita; dentro da empresa, a transformação dos custos pode de alguma forma dificultar o processo de gerenciamento e tomada de decisão.

Seja $C_{j}^{*}=\arg \min g_{j}\left(C_{j}\right)$ o horário de término que minimiza o custo relacionado à ordem $j$. Chamaremos de horário de início desejado, $a_{j}=C_{j}^{*}-p_{j}$, o horário em que a ordem deveria começar seu processamento para que sua contribuição ao valor da função-objetivo seja mínima. Isso supõe que não haja conflito pela utilização da máquina. O valor de $C_{j}^{*}$ vai ser alterado dependendo do relacionamento dos valores dos custos. A proposição 2.2 fornece os valores de $C_{j}^{*}$ para qualquer relação entre os valores dos custos.

O valor to na tabela indica que a ordem deveria estar sendo terminada no instante inicial - ou seja antes do início da primeira ordem do programa -, mas como isso não é possivel, ela deve ser realizada o quanto antes. Observe que para os casos onde $h_{j}=v_{j}$ existem dois pontos ótimos. Como num caso real é mais provável que $d_{j}$ esteja mais perto de $C_{j}^{*}$ do que de $t_{0}$, nesses casos 
2. Algoritmo de inserção de espera para o problema de uma máquina com função-objetivo representada 24 pela soma de funções convexas do horário de término independentes para cada ordem

definiremos arbitrariamente $C_{j}^{*}=d_{j}$.

Proposição 2.2. A tabela abaixo fornece os valores ótimos de $C_{j}$ para qualquer relacionamento entre os custos.

\begin{tabular}{|c|c|c|c|c|c|}
\hline $\begin{array}{c}\text { caso } \\
\text { número }\end{array}$ & $\begin{array}{c}\text { relações entre } \\
\text { os custos }\end{array}$ & $C_{j}^{*}$ & $\begin{array}{c}\text { caso } \\
\text { número }\end{array}$ & $\begin{array}{c}\text { relações entre } \\
\text { os custos }\end{array}$ & $C_{j}^{*}$ \\
\hline 1 & $h_{j}>w_{j}>v_{j}$ & $d_{j}$ & 7 & $h_{j}=w_{j}>v_{j}$ & $d_{j}$ \\
2 & $h_{j}>v_{j}>w_{j}$ & $d_{j}$ & 8 & $h_{j}=v_{j}>w_{j}$ & $t_{0}, d_{j}$ \\
3 & $v_{j}>h_{j}>w_{j}$ & $t_{0}$ & 9 & $v_{j}=w_{j}>h_{j}$ & $t_{0}$ \\
4 & $v_{j}>w_{j}>h_{j}$ & $t_{0}$ & 10 & $h_{j}>w_{j}=v_{j}$ & $d_{j}$ \\
5 & $w_{j}>h_{j}>v_{j}$ & $d_{j}$ & 11 & $v_{j}>h_{j}=w_{j}$ & $t_{0}$ \\
6 & $w_{j}>v_{j}>h_{j}$ & $t_{0}$ & 12 & $w_{j}>h_{j}=v_{j}$ & $t_{0}, d_{j}$ \\
& & & 13 & $w_{j}=v_{j}=h_{j}$ & $t_{0}, d_{j}$ \\
\hline
\end{tabular}

Demonstração12: A demonstração da proposição pode ser gráfica conforme pode ser visto na Figura 3. Para a construção da figura utilizou-se a equação (2.1) que define regiões constantes, crescentes e decrescentes para $g_{j}\left(C_{j}\right)$.

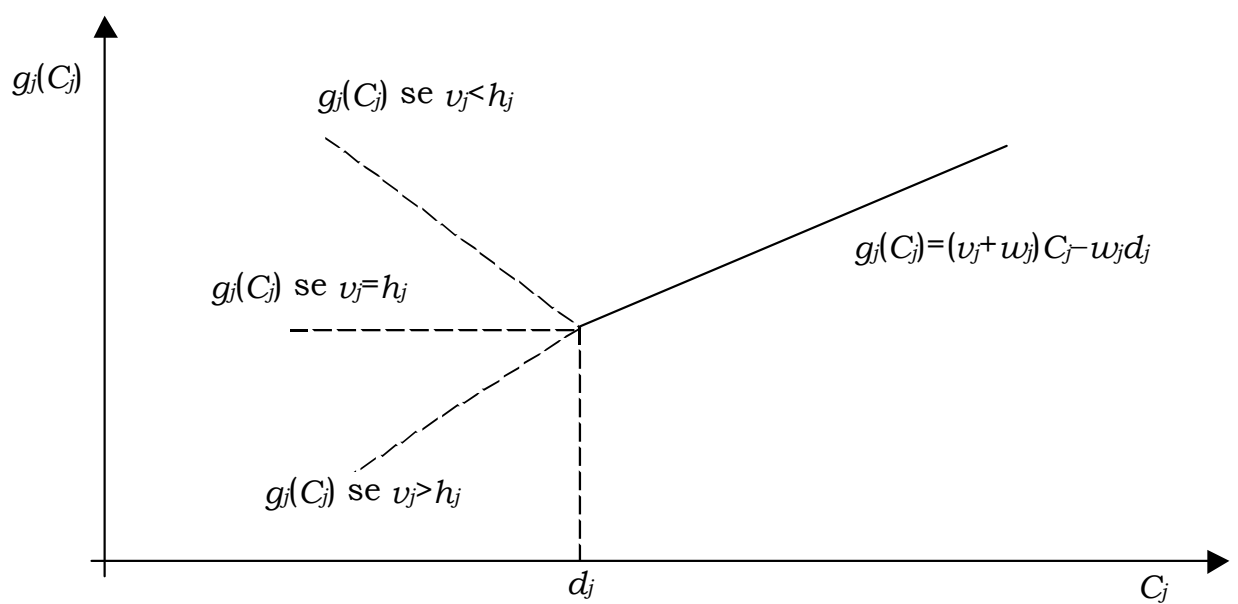

F ġura 3 :P rova gráfica da proposição

\footnotetext{
${ }^{12}$ Gostaria de agradecer ao prof. Carlos Eduardo Ferreira (IME-USP) pela sugestão desta prova. A prova antiga estava muito menos clara.
} 
Considerando a figura podemos dizer que se $v_{j}<h_{j}, C_{j}^{*}=d_{j}$; se $v_{j}>h_{j}$, $C_{j}^{*}=t_{0}$ e se $v_{j}=h_{j}, C_{j}^{*} \in\left[t_{0}, d_{j}\right]$.

Seja $B=\{1,2, \ldots, l\}$ um conjunto de índices dos blocos de ordens. Um bloco de ordens $b \subseteq B$ é definido como uma seqüência parcial que é programada contiguamente, ou seja, sem inserção de espera entre as ordens da mesma. A Figura 4 mostra esquematicamente a configuração genérica de um bloco. Matematicamente pode-se dizer que uma dada seqüência de ordens $M=\left\{J_{m_{1}}, J_{m_{2}}, \ldots, J_{m_{j}}\right\}$ é um bloco de ordens se $e_{k}+p_{k}=e_{k+1}$ (sendo $m_{1} \leq k<m_{j}$ ), $e_{m_{1}-1}+p_{m_{1}-1}<e_{m_{1}}\left(m_{1}>1\right)$ e $e_{m_{j}}+p_{m_{j}}<e_{m_{j+1}}\left(m_{j}<|J|\right)$. Ao longo do trabalho, além de uma seqüência parcial de ordens, um bloco será por vezes considerado como um intervalo de tempo ou como um conjunto ordenado de ordens.

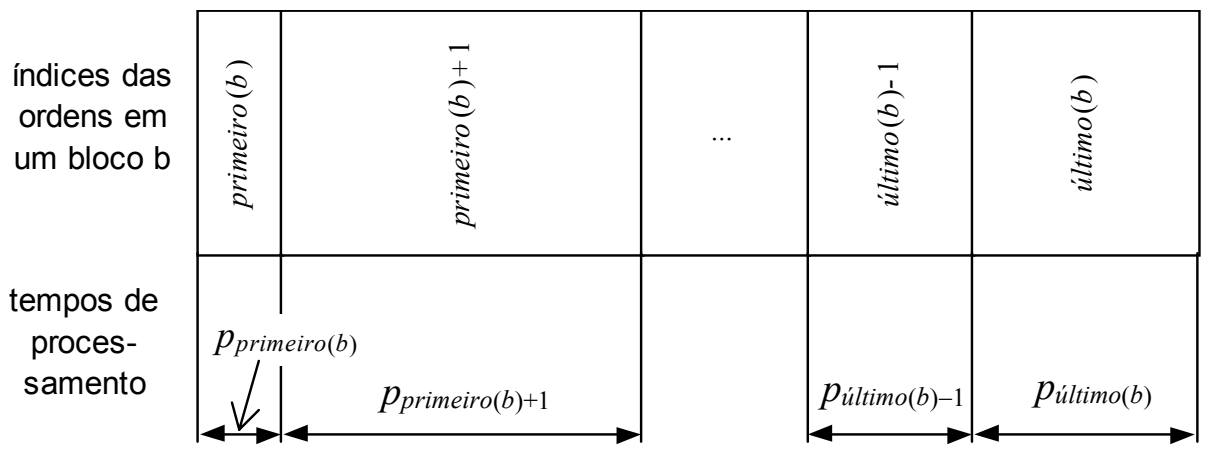

F ġura 4 :C onfiguração de um bbco $b$ qualquer com relação aos tem pos de processam ento e ńdice das ordens pertencentes ao mesmo

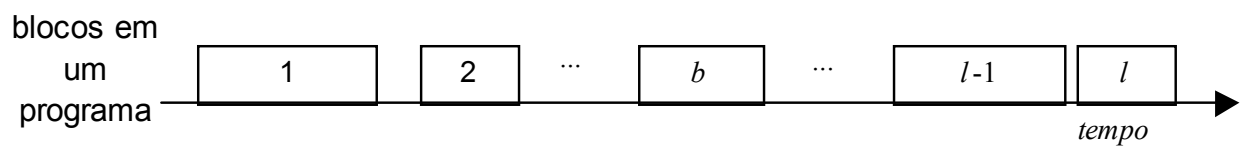

F ġura 5 :C onfiguração genérica dos bbcos de um program a parcílou complto 
Assume-se que um programa completo $\pi$ possua $l$ blocos $\{1,2, \ldots, l\}(1 \leq b \leq l$; $l \leq|J|$ ), como pode ser observado na Figura 5. No processamento do algoritmo, para se representar um bloco $b$, serão necessários apenas as definições dos indices extremos, ou seja, primeiro $(b)$ que é o índice da primeira ordem de $b$ e último $(b)$ que é o índice da última ordem de $b$. As ordens intermediárias são facilmente identificadas pois são relacionadas com a primeira e com a última.

As ordens de cada bloco $b$ são particionadas em 2 subconjuntos, denominados $\operatorname{Dim}(b)$ e $\operatorname{Aum}(b)$. Se $j \in \operatorname{Dim}(b)$ e o bloco for antecipado, o valor da função-objetivo diminui ou se mantém constante; se $j \in A u m(b)$ e o bloco for antecipado o valor da função-objetivo aumenta ou se mantém constante. $j \in \operatorname{Dim}(b)$ se $e_{j}>a_{j}$ e $j \in A u m(b)$ se $e_{j} \leq a_{j}$. Se $j \in \operatorname{Dim}(b)$, reduzindo-se $e_{j}$, reduz-se o atraso de $j$ e se $j \in A u m(b)$, reduzindo-se $e_{j}$, aumenta-se o adiantamento de $j$.

Para o desenvolvimento do algoritmo será necessária uma função que mede o quanto uma antecipação muda o valor da função-objetivo. Uma antecipação do bloco $b$ faz com que as ordens adiantadas aumentem a funçãoobjetivo em $H(b)=\sum_{j \in \operatorname{Aum}(b)}\left(h_{j}-v_{j}\right)$ por unidade movimentada. Nessa mesma movimentação, as ordens atrasadas fazem com que a função-objetivo diminua em $W(b)=\sum_{j \in \operatorname{Dim}(b)}\left(w_{j}+v_{j}\right)$ por unidade movimentada. Chamaremos $H(b)$ de potencial de aumento do custo com o adiantamento de $b$ e $W(b)$ de potencial de diminuição do custo com o adiantamento de $b$. Observe que para uma antecipação de $\Delta$ unidades, a diminuição (ou aumento caso o sinal seja negativo) na função-objetivo é equivalente a $\Delta\{W(b)-H(b)\}=\Delta\left\{\sum_{j \in \operatorname{Dim}(b)}\left(w_{j}+v_{j}\right)-\sum_{j \in \operatorname{Aum}(b)}\left(h_{j}-v_{j}\right)\right\}=\Delta\left\{\sum_{j \in \operatorname{Dim}(b)} w_{j}-\sum_{j \in \operatorname{Aum}(b)} h_{j}+\sum_{j \in b} v_{j}\right\}$.

\subsubsection{Visão geral do AIE}

A idéia central do algoritmo está na construção e movimentação de blocos, onde essa movimentação acontece sempre fazendo com que as ordens pertencentes ao mesmo sejam antecipadas. Sempre acontece uma antecipação do bloco pois as ordens adicionadas ao bloco estão sempre atrasadas ou no 
horário de início desejado. Se as datas de entrega forem suficientemente dispersas, cada bloco será formado por apenas uma ordem, pois todos os horários de início efetivos serão equivalentes aos horários de início desejados. Como isso obviamente não ocorre sempre, existem períodos de conflito, onde a capacidade disponivel na máquina não é suficiente para processar todas as ordens de modo que suas datas de entrega sejam atendidas. Quando isso acontece, os adiantamentos, atrasos e horários de término penalizados das ordens do bloco em consideração são avaliados procurando-se por uma oportunidade de diminuir o custo total do bloco, e por conseqüência do programa. Quando acontece o adiantamento dos blocos, as ordens adiantadas são mais adiantadas, as ordens que estavam na data exata passam a estar adiantadas e as ordens atrasadas deixam de estar atrasadas ou tem seu atraso diminuído.

Para esse fim, o algoritmo é iniciado fazendo com que a primeira ordem seja finalizada em seu horário de término ótimo, $C_{1}^{*}$. Isso pode não ser possivel, visto que a ordem já pode estar virtualmente atrasada - como a data de entrega desejada da ordem é muito cedo, mesmo que ela seja iniciada no instante inicial, ela não vai terminar em $C_{1}^{*}$. Verifica-se se a próxima ordem pode ser terminada em $C_{2}^{*}$. Aqui pode acontecer duas coisas: um novo bloco ser formado ou a ordem ser adicionada ao último bloco formado. Um novo bloco será formado caso o término da última ordem do último bloco seja anterior ao início desejado da ordem em consideração. Por outro lado, a ordem será incluída no último bloco formado, caso o término da última ordem do último bloco seja posterior ou igual ao horário de início desejado da ordem em consideração. Dessa forma, o início do processamento dessa última ordem será contíguo ao horário de término do processamento da ordem imediatamente anterior. Neste último caso, haverá uma ponderação entre todas as ordens pertencentes ao bloco formado com a nova ordem. Se a nova ordem adicionada estiver atrasada, e juntamente com os outros custos de atraso promover um custo de atraso maior do que os custos de adiantamento, então o bloco é movimentado para mais cedo enquanto o custo total diminui. Este procedimento descrito para a segunda ordem é realizado para todas as outras ordens até a última. 


\subsubsection{Detalhamento do AIE}

Para um melhor entendimento do algoritmo, ele pode ser considerado como tendo duas partes: a primeira, para construção de blocos e a segunda, para antecipação de blocos. Considere $t_{0}=0$. Formalmente, podemos dizer que a primeira parte do algoritmo - construção de blocos - tem início simplesmente programando-se $e_{1}$ (horário efetivo de início de $J_{1}$ ) o mais próximo de $a_{1}$ (horário desejado de início de $J_{1}$ ), isto é, $e_{1}=0$ se $a_{1}<0$ ou $e_{1}=a_{1}$ caso contrário. Genericamente, para um programa parcial $\pi_{j}^{A I E}$ já elaborado pelo AIE, programa-se $j+1$ conforme dois casos:

Caso 1: $e_{j}^{A I E}+p_{j} \leq a_{j+1}$. Programa-se $j+1$ para começar em $a_{j+1}$. Um novo bloco é criado com a ordem $j+1$ e a mesma passa a pertencer ao conjunto Aum(l) (onde $l$ é o índice do último bloco, isto é, o bloco criado para a inserção de $j^{+1)}$.

Caso 2: $e_{j}^{A I E}+p_{j}>a_{j+1}$. Programa-se $j+1$ para começar em $e_{j}^{A I E}+p_{j}$. Neste caso a ordem $j+1$ é inserida no bloco $l$ e no conjunto $\operatorname{Dim}(l)$.

Uma propriedade-chave, enunciada por GAREY et al. e mantida pelo algoritmo é que para cada bloco $b \subseteq \pi_{j}^{A I E}$, ou $W(b)<H(b)$ ou $e_{\text {primeiro(1) }}^{\text {AIE }}=0$ (quando $l=1$ ). O algoritmo pára a movimentação quando $W(b)<H(b)$ ocorre pela primeira vez pois há pelo menos uma ordem com término na data exata e a mesma pertence ao conjunto $\operatorname{Aum}(\boldsymbol{l})$. A propriedade-chave garante que o bloco esteja na posição de mínimo custo. Quando programa-se a próxima ordem, j+1, apenas o último bloco pode sofrer alguma alteração. Essa alteração pode fazer com que o último bloco tenha pelo menos uma das seguintes propriedades: ou

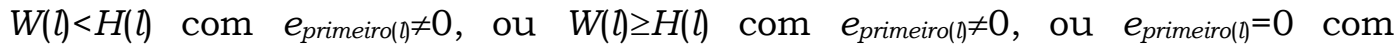
qualquer relação entre $W(l)$ e $H(l)$.

A segunda parte do algoritmo, de antecipação dos blocos, acontece considerando que se $W(l)<H(l)$ ou $e_{\text {primeiro( }()}=0$, não se toma nenhuma ação e o programa $\pi_{j+1}$ transforma-se em $\pi_{j+1}^{A I E}$. Por outro lado, se $W(l)=H(l)$ e $e_{\text {primeiro }(\eta \neq 0 \text {, }}$ pode-se movimentar o bloco $l$ inteiro, sem afetar o valor da função-objetivo do programa. Neste caso, o algoritmo programa o bloco para o mais cedo possivel. 
Caso contrário, se $W(l)>H(l)$ e $e_{\text {primeiro }(\eta \neq} \neq 0$, pode-se antecipar o bloco $l$ inteiro, fazendo com que o valor da função-objetivo do programa diminua. Essas movimentações são feitas até pelo menos uma das 3 hipóteses seguintes acontecer:

1. $e_{\text {primeiro( }(\mathfrak{l})}=0$. Ocorrerá somente se $l=1$. Caso ocorra, o bloco $l$ não pode ser movimentado para mais cedo pois ele estará começando no horário 0;

2. Para algum $j \in \operatorname{Dim}(l), e_{j}=a_{j}$; a ordem é transferida do conjunto $\operatorname{Dim}(l)$ para Aum(l) e $W(l)<H(l)$. Nesse caso, outras movimentações de $l$ só irão aumentar o valor da função-objetivo. Se a ordem for transferida de $\operatorname{Dim}(l)$ para $\operatorname{Aum}(l)$ e $W(l) \geq H(l)$, continua-se a movimentação da mesma maneira;

3. $e_{\text {primeiro }(l)}=e_{u \text { útimo }(l-1)}+p_{\text {último(l-1) }}$. O bloco $l$ é unido ao bloco $l-1$. Se $e_{\text {primeiro(l-1) }} \neq 0$ e $W(l-1)+W(l) \geq H(l-1)+H(l)$, continua-se a movimentação dos blocos unidos $l-1$ e $l$. Se $e_{\text {primeiro }(l-1) \neq 0}$ e $W(l-1)+W(l)<H(l-1)+H(l)$, deve-se parar a movimentação pois a função-objetivo tem o mínimo valor.

O programa resultante é $\pi_{j+1}^{A I E}$. O algoritmo faz sucessivas aplicações do procedimento acima formando os programas $\pi_{2}^{A I E}, \pi_{3}^{A I E}, \ldots, \pi_{|J|}^{A I E}$.

\subsubsection{Análise do AIE}

A demonstração que o algoritmo descrito proporciona um programa ótimo para uma seqüência predefinida no caso sem custos é apresentada em GAREY et al. (1988, p. 338). O corolário adiante prova que o algoritmo descrito aqui garante a otimização do problema em consideração.

Corolário 2.1. Para qualquer $j$, o programa parcial $\pi_{j}^{A I E}$ definido pelo AIE tem o menor valor de $g\left(\pi_{j}\right)=\sum_{i=1}^{j}\left(h_{i} E_{i}+w_{i} T_{i}+v_{i} C_{i}\right)$ dentre todos os programas possiveis para as primeiras $j$ ordens.

Demonstração: Como hipótese de indução, assumimos que em $j$ o corolário é verdadeiro, isto é, $g\left(\pi_{j}^{A I E}\right)=\min _{\pi_{j} \subseteq \Pi_{j}} g\left(\pi_{j}\right)$, onde $\Pi_{j}$ é o conjunto de todos 
os programas possíveis para as $j$ primeiras ordens. Para o programa vazio $\pi_{0}^{A I E}$, o corolário é verdadeiro. Portanto, só falta provar que para $j+1$ o corolário também é verdadeiro. Seja $\pi_{j+1}$ algum programa das primeiras $j^{j+1}$ ordens e seja $e_{k}$ e $e_{k}^{A I E}$ os horários efetivos de início da ordem $k$ em $\pi_{j}$ e $\pi_{j}^{A I E}$, respectivamente. Podemos considerar dois casos: um onde a ordem começa no horário desejado, $e_{j}^{A I E}+p_{j} \leq a_{j+1}$, e outro, onde a ordem não começa, $e_{j}^{A I E}+p_{j}>a_{j+1}$.

Caso 1. $e_{j}^{A I E}+p_{j} \leq a_{j+1}$. Este caso permite que o algoritmo programe $j+1$ de modo que $e_{j+1}^{A I E}=a_{j+1}$ e portanto, para $\pi_{j+1}^{A I E}$ a função-objetivo será $g\left(\pi_{j+1}^{A I E}\right)=g\left(\pi_{j}^{A I E}\right)+g_{j+1}\left(C_{j+1}^{*}\right)$. Levando em conta que $C_{j+1}^{*}=\arg \min g_{j+1}\left(C_{j+1}\right)$ por definição e que $g\left(\pi_{j}^{A I E}\right)=\min _{\pi_{j} \subseteq \Pi_{j}} g\left(\pi_{j}\right)$ pela hipótese de indução, podemos dizer com certeza que $g\left(\pi_{j+1}^{A I E}\right) \leq g\left(\pi_{j+1}\right)$, provando o corolário neste caso.

Caso 2. $e_{j}^{A I E}+p_{j}>a_{j+1}$. Como não é mais possivel ocorrer $e_{j+1}^{A I E}=a_{j}$, o algoritmo programa inicialmente $j+1$ de modo que $e_{j+1}^{A I E}=e_{j}^{A I E}+p_{j}$, avaliando o valor de $e_{\text {primeiro(l) }}^{\text {AIE }}$ e a relação entre $H(l)$ e $W(l)$

O bloco $l$ pode ser movimentado para mais tarde ou para mais cedo. Considerando a hipótese de indução, o bloco até a ordem $j$ está na posição ótima, portanto um postergamento faria a função-objetivo piorar. Ao adicionarmos a ordem $j+1$, que está numa região onde os custos são crescentes, a viabilidade de se movimentar o bloco inteiro para mais tarde é menor ainda.

Se $e_{\text {primeiro(l) }}^{A I E}=0$ o bloco não pode ser movimentado para mais cedo; como uma movimentação para mais tarde faz com que a função-objetivo aumente, o bloco está na posição ótima e o corolário está provado. Por outro lado, se $e_{\text {primeiro(l) }}^{\text {AIE }} \neq 0$, o bloco pode ser movimentado para mais cedo. Nas movimentações pode ocorrer a união dos blocos $l$ e $l-1$ diversas vezes. Sem perda de generalidade, vamos supor que não haja união dos blocos $l$ e $l-1$. 
Seja $\Delta$ uma antecipação que será definida mais adiante. Subdividiremos o caso 2 para que a prova fique mais clara:

Caso 2a. $H(l) \leq W(l)$ e $e_{\text {primeiro(l) }}^{A I E} \neq 0$. O algoritmo faz movimentações do bloco $l$ para mais cedo até que a relação $H(l)>W(l)$ seja verdadeira pela primeira vez. De forma contrária ao algoritmo, vamos supor que uma antecipação de $\Delta=\min \left\{\min _{j \in \operatorname{Dim}(l)}\left(e_{j}-a_{j}\right), e_{\text {primeio(l) }}^{\text {AIE }}\right\}$ - ou seja, a menor antecipação de modo que uma ordem tenha seu início em sua data de entrega desejada, ou não há mais hipótese de se adiantar o bloco, pois a primeira ordem está começando no instante inicial - promova um aumento no valor da função-objetivo. Para $\Delta=e_{\text {primeiro(l) }}^{\text {AIE }}$ podemos dizer que:

$$
\begin{gathered}
\sum_{k \in \operatorname{Aum}(l)}\left\{h_{k}\left(E_{k}+\Delta\right)\right\}+\sum_{k \in \operatorname{Dim}(l)}\left\{w_{k}\left(T_{k}-\Delta\right)\right\}+\sum_{k \in l}\left\{v_{k}\left(C_{k}-\Delta\right)\right\}>\sum_{k \in l}\left\{h_{k} E_{k}+w_{k} T_{k}+v_{k} C_{k}\right\} \\
\sum_{k \in l}\left\{h_{k} E_{k}+w_{k} T_{k}+v_{k} C_{k}\right\}+\sum_{\substack{i \in \operatorname{Aum}(l) \\
j \in \operatorname{Dim}(l)}}\left\{h_{i} \Delta-w_{j} \Delta-\left(v_{i}+v_{j}\right) \Delta\right\}>\sum_{k \in l}\left\{h_{k} E_{k}+w_{k} T_{k}+v_{k} C_{k}\right\},
\end{gathered}
$$

que simplificada se transforma em $\sum_{\substack{i \in \operatorname{Aum}(l) \\ j \in \operatorname{Dim}(l)}}\left\{h_{i}-w_{j}-\left(v_{i}+v_{j}\right)\right\}>0$ e portanto

$H(l)>W(l)$, mostrando uma incoerência com a hipótese de definição do caso 2 a. Para $\Delta=\min _{j \in \operatorname{Dim}(l)}\left(e_{j}-a_{j}\right)$ a prova é a mesma, com uma única diferença que a ordem que define $\Delta$ sai do conjunto $\operatorname{Dim}(l)$ e vai para $\operatorname{Aum}(l)$, fazendo assim com que $H(l)>W(l)$ se mantenha também, mostrando mais uma vez incoerência com a hipótese de definição do caso $2 \mathrm{a}$.

Caso 2b. $H(l)>W(l)$ e $e_{\text {primeiro(l) }}^{A I E} \neq 0$. Neste caso, o algoritmo não faz nenhuma movimentação. De forma contrária ao algoritmo, vamos supor que uma antecipação de $\Delta=\min \left\{\min _{j \in \operatorname{Dim}(l)}\left(e_{j}-a_{j}\right), e_{\text {primeiro(l) }}^{\text {AIE }}\right\}$ promova uma diminuição no valor da função-objetivo. Para $\Delta=e_{\text {primeiro(l) }}^{A I E}$ temos:

$$
\begin{gathered}
\sum_{k \in \operatorname{Aum}(l)}\left\{h_{k}\left(E_{k}+\Delta\right)\right\}+\sum_{k \in \operatorname{Dim}(l)}\left\{w_{k}\left(T_{k}-\Delta\right)\right\}+\sum_{k \in l}\left\{v_{k}\left(C_{k}-\Delta\right)\right\}<\sum_{k \in l}\left\{h_{k} E_{k}+w_{k} T_{k}+v_{k} C_{k}\right\} \\
\sum_{k \in l}\left\{h_{k} E_{k}+w_{k} T_{k}+v_{k} C_{k}\right\}+\sum_{\substack{i \in \operatorname{Aum}(l) \\
j \in \operatorname{Dim}(l)}}\left\{h_{i} \Delta-w_{j} \Delta-\left(v_{i}+v_{j}\right) \Delta\right\}<\sum_{k \in l}\left\{h_{k} E_{k}+w_{k} T_{k}+v_{k} C_{k}\right\},
\end{gathered}
$$


2. Algoritmo de inserção de espera para o problema de uma máquina com função-objetivo representada 32 pela soma de funções convexas do horário de término independentes para cada ordem

que simplificada se transforma em $\sum_{\substack{i \in \operatorname{Aum}(l) \\ j \in \operatorname{Dim}(l)}}\left\{h_{i}-w_{j}-\left(v_{i}+v_{j}\right)\right\}<0$ e portanto $H(l)<W(l)$, mostrando uma incoerência com a hipótese de definição do caso $2 \mathrm{~b}$. Para $\Delta=\min _{j \in \operatorname{Dim}(l)}\left(e_{j}-a_{j}\right)$ a prova é a mesma com uma única diferença que a ordem que define $\Delta$ sai do conjunto $\operatorname{Dim}(l)$ e vai para $\operatorname{Aum}(l)$, fazendo assim com que $H(l)>W(l)$ se mantenha, mostrando mais uma vez incoerência com a hipótese de definição. Terminamos aqui a prova para este último caso do corolário.

////

Quando a relação $W(b)=H(b)$ se mantiver, existirão infinitos programas ótimos; qualquer posição das ordens de $b$ que mantiverem a igualdade proporcionará um programa ótimo. Por uma questão de convenção assumida neste trabalho, o algoritmo irá programar o início do bloco o mais tarde possivel.

\subsection{Implementação computacional do AIE utilizando estruturas de filas de prioridade}

Uma implementação eficiente do algoritmo da seção anterior pode ser baseada na estrutura de dados denominada fila de prioridade. Sem a utilização das filas de prioridade, o tempo de solução do algoritmo no pior caso é $O\left(|J|^{2}\right)$, enquanto que com a utilização das mesmas é $O(|J| \log |J|)$. A diferenciação de ambos os casos se dá na forma de armazenar e manipular dados. No caso sem a utilização das filas de prioridade, podería-se utilizar matrizes para realizar as mesmas operações.

De acordo com TARJAN (1983, p. 33), uma fila de prioridade é uma estrutura de dados abstrata consistindo de uma coleção de itens, cada um dos quais possuindo um valor real associado denominado chave.

Para cada bloco de ordens $b$ é mantida uma fila de prioridade $P(b)$, que determinará o quanto cada um poderá ser movimentado. Em outras palavras, haverá uma fila de prioridade para cada bloco. Cada fila de prioridade deverá manter dois valores de cada item: o primeiro é o índice das ordens 
pertencentes a $\operatorname{Dim}(b)$; o segundo é o valor equivalente a $e_{j}-a_{j}$ (quantidade máxima que $e_{j}$ pode ser diminuída, enquanto diminui o atraso de $j$ ) para cada indice $j \in \operatorname{Dim}(b)$, doravante denominado chave da fila de prioridade.

O algoritmo foi implementado considerando seis operações com filas de prioridade. Para $n$ o número de itens da fila de prioridade, e considerando que as filas de prioridade sejam representadas por árvores binárias, os tempos de solução no pior caso (retirados de TARJAN, cap. 3) ${ }^{13}$ e as seis operações são definidas a seguir:

Operação 1. CriaFilaPrior $(P) . O(1)$. Cria uma fila de prioridade vazia denominada $P$. A criação de uma pilha com $n$ elementos demanda tempo $O(n)$;

Operação 2. EncontraMin $(P)$. $O(1)$. Encontra um item de mínima chave na fila de prioridade $P$ e apresenta essa chave sem remover o item da mesma;

Operação 3. ApagaMin $(P) . O(\log n)$. Encontra um item de mínima chave na fila de prioridade $P$. Apresenta seu índice e remove o item da mesma. Essa operação elimina o nó do primeiro nível da árvore e une os dois ramos que eram filhos do nó que foi eliminado, definindo o novo nó do primeiro nível;

Operação 4. Insere $(j, x, P) . O(1)+O(\log n)=O(\log n)$. Insere o item $j$ com chave $x$ na fila de prioridade $P$. A operação consiste em criar uma nova fila de prioridade com o item $j$ (com tempo $O(1)$ ) e depois unir essa fila com a fila $P(O(\log n))$;

Operação 5. Une $\left(P_{1}, P_{2}\right) \cdot O\left(\log \left(n_{1}+n_{2}\right)\right)=O(\log n)$. Une as filas de prioridade $P_{1}$ e $P_{2}$ de itens disjuntos (com $n_{1}$ e $n_{2}$ elementos respectivamente) em uma nova fila de prioridade que se transforma em $P_{1}$. A fila de prioridade $P_{2}$ torna-se vazia. Maiores detalhes podem ser encontrados em TARJAN (pp. 39-40);

Operação 6. AdicionaParaTodasChaves $(x, P)$. $O(1)$. Adiciona-se $x$ para todas as chaves dos itens pertencentes à fila de prioridade $P$. Neste

\footnotetext{
${ }^{13}$ TARJAN (cap. 3) diferencia dois tipos de filas de prioridade: $d$-heap e leftist heap. A diferença entre ambas é que o segundo tipo permite facilidades adicionais na operação de união de filas de prioridade. O padrão utilizado aqui é a fila de prioridade do tipo leftist.
} 
2. Algoritmo de inserção de espera para o problema de uma máquina com função-objetivo representada 34 pela soma de funções convexas do horário de término independentes para cada ordem

caso, a árvore deve manter como chave não seu valor em si, mas o incremento que um nó filho tem sobre o nó pai. Assim, o valor de uma chave específica num nó $y$ pode ser obtido somando-se os valores de todos os nós que estão no caminho entre o nó do primeiro nível e o nó $y$. Com isso, esta operação adiciona $x$ apenas ao nó raiz.

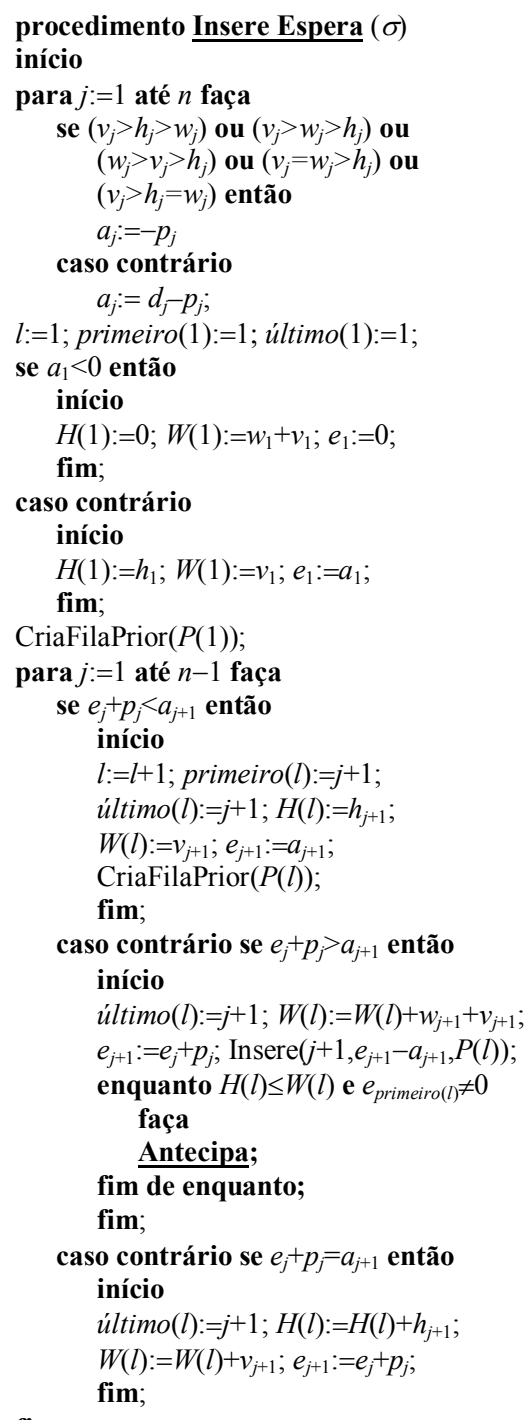

fim.

\author{
Uma seqüência completa é a entrada do procedimento. \\ Cálculo de todos os horários de inicio desejados. \\ Casos baseados na proposição 1 .
}

\begin{abstract}
Atribuição da ordem $j=1$ ao último bloco que também é o primeiro. Se o horário de início desejado é anterior ao instante inicial.
\end{abstract}

Define-se os custos do bloco e o horário efetivo de início de $j=1$.

Define-se os custos do bloco e o horário efetivo de início de $j=1$.

Cria-se a primeira fila de prioridade.

Cálculo dos horários de início das outras ordens.

Se o hor. de término de $j$ é anterior ao hor. de início desejado de $j+1$.

Cria-se uma nova fila, inserindo-se $j+1$ nela; atribui-se os custos ao bloco bem como o horário de início efetivo da ordem.

Se o hor. de término de $j$ é posterior ao hor. de início desejado de $j+1$.

; Insere-se a ordem em consideração no último bloco e altera-se seus custos, considerando 0 acréscimo da nova ordem.

Enquanto a soma dos custos de adiantamento for menor ou igual a soma dos custos de atraso mais os custos de horário de término das ordens pertencentes ao bloco, e houver possibilidade de antecipação utiliza-se o procedimento antecipa.

Se o hor. de término de $j$ é igual ao hor. de início desejado de $j+1$.

Acrescenta-se a ordem em consideração ao último bloco, alterando-se os custos do mesmo. Observe que não se utilizou a operação "Insere".

Final do procedimento.

F ġura 6 :P seudocódigo para construção de bbcos 
2. Algoritmo de inserção de espera para o problema de uma máquina com função-objetivo representada 35 pela soma de funções convexas do horário de término independentes para cada ordem

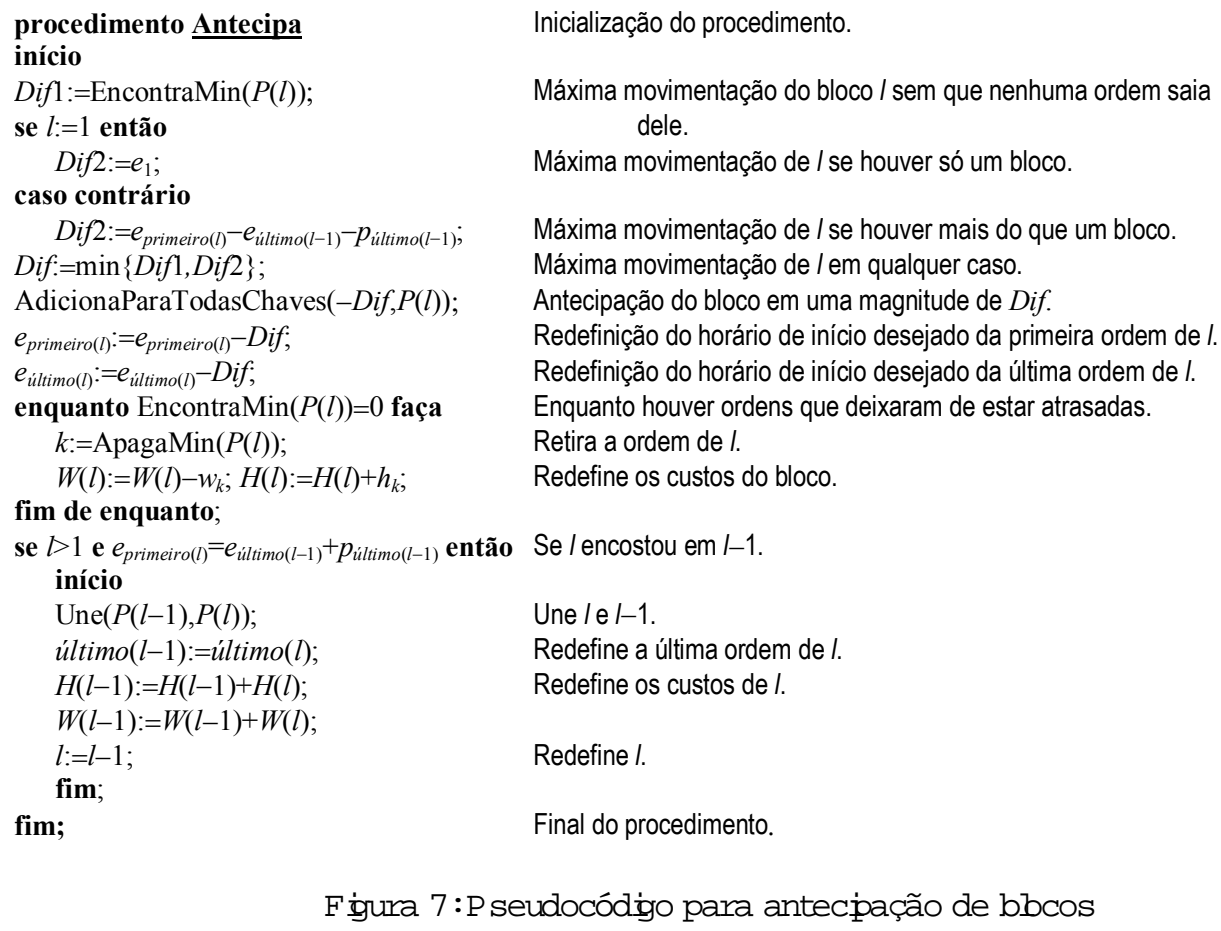

F giura 7:P seudocódigo para antecp̣ação de bbcos

O pseudocódigo utilizado para se programar uma seqüência de ordens qualquer foi elaborado com essas seis operações. Ele é dividido em duas partes: a de construção de blocos apresentado na Figura 6 e a de antecipação de blocos, apresentado na Figura 7.

Após o término do algoritmo, para a elaboração do programa final $\pi=\left\{e_{1}, e_{2}, \ldots, e_{|J|}\right\}$, podemos utilizar a seguinte equação:

$$
e_{j}=\left\{\begin{array}{l}
e_{\text {primeiro }(b)} \text { se } j=\text { primeiro }(b) \text { para } b \leq l, \\
e_{j-1}+p_{j-1} \text { caso contrário. }
\end{array}\right.
$$

No pior caso, o anel interno do procedimento de antecipação de blocos vai realizar $l=|J|$ operações ApagaMin $\left(P(l)\right.$ com tempo $O(\log J)$ cada uma ${ }^{14}$, onde $j$ é o número de elementos da fila de prioridade. O tempo total utilizado pode ser definido como $\sum_{j=1}^{|J|} \log j$. Considerando a concavidade da função $\log j$, e que $\log x=\ln x / \ln 2$, podemos dizer que 


$$
\sum_{j=1}^{|J|} \log j \leq \int_{1}^{|J|+1} \log x d x=\left.\frac{1}{\ln 2} x \ln x\right|_{1} ^{|J|+1}=O(|J| \log |J|) .
$$

Portanto, no pior caso, o tempo total demandando pelo procedimento Antecipa é de $O(|J| \log |J|)$. Se for esse o caso, o procedimento de Antecipa é utilizado apenas uma vez.

O anel principal do procedimento de construção de blocos é realizado $|J|-1$ vezes, e considerando-se que o procedimento Antecipa foi utilizado apenas uma vez, podemos dizer que em cada uma das $|J|-1$ vezes a operação Insere $(j, x, P(l))$ foi utilizada. Levando em conta que cada operação de inserção demande tempo $O(\log j)$ na j-ésima iteração, o tempo total utilizado pelo anel externo do procedimento de construção de blocos pode ser definido como $\sum_{j=1}^{|J-1|} \log j$. A solução é equivalente à equação (2.2) e o tempo pode ser definido como $O(|J| \log |J|)$.

Com isso temos que os dois procedimentos associados possuem tempo no pior caso de $O(|J| \log |J|)+O(|J| \log |J|)=O(|J| \log |J|)$. Como o início do procedimento de construção de blocos até a chegada do anel principal (após a linha que possui a operação CriaFilaPrior $(P(1))$ demanda tempo $O(|J|)$, podemos dizer que o tempo de solução do AIE no pior caso é $O(|J| \log |J|)$.

\subsection{Exemplo da utilização do AIE}

Seja um conjunto de ordens já seqüenciado, definido pela Tabela 2, com todas ordens disponiveis no instante zero. Queremos saber se a inserção de espera nessa seqüência dada pode promover uma diminuição no valor da função-objetivo.

Por uma questão de comparação, será calculado inicialmente o valor da função-objetivo da seqüência sem a inserção de espera. A Tabela 3 ilustra alguns passos intermediários para este caso.

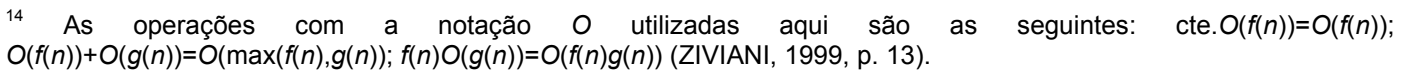


2. Algoritmo de inserção de espera para o problema de uma máquina com função-objetivo representada 37 pela soma de funções convexas do horário de término independentes para cada ordem

\begin{tabular}{cccccc}
\hline$j$ & $p_{j}$ & $d_{j}$ & $h_{j}$ & $w_{j}$ & $v_{j}$ \\
\hline 1 & 4 & 5 & 4 & 3 & 1 \\
2 & 5 & 8 & 4 & 1 & 3 \\
3 & 8 & 20 & 2 & 5 & 1 \\
4 & 4 & 23 & 3 & 2 & 3 \\
\hline
\end{tabular}

Tabeł 2 :D ados do exempb para inserção de espera

\begin{tabular}{ccccc}
\hline$j$ & $C_{j}$ & $E_{j}$ & $T_{j}$ & $h_{j} E_{j}+w_{j} T_{j}+v_{j} C_{j}$ \\
\hline 1 & 4 & 1 & 0 & 8 \\
2 & 9 & 0 & 1 & 28 \\
3 & 17 & 3 & 0 & 23 \\
4 & 21 & 2 & 0 & 69 \\
& & & total & 128 \\
\hline
\end{tabular}

Tabeł 3 :C álub do exem pb sem inserção de espera

O valor da função-objetivo em análise sem a inserção de espera é dado por $\sum_{j=1}^{4}\left(h_{j} E_{j}+w_{j} T_{j}+v_{j} C_{j}\right)=128$. A utilização do algoritmo com os passos intermediários utilizados na solução são apresentados a seguir:

Passo 1. Inicialização. $a_{1}=d_{1}-p_{1}=1, a_{2}=d_{2}-p_{2}=3, a_{3}=d_{3}-p_{3}=12, a_{4}=d_{4}-p_{4}=19, l=1$, primeiro $(1)=1, \quad$ último $(1)=1, \quad H(1)=h_{1}=4, \quad W(1)=v_{1}=1, \quad e_{1}=a_{1}=1$, CriaFilaPrior $(P(1))$;

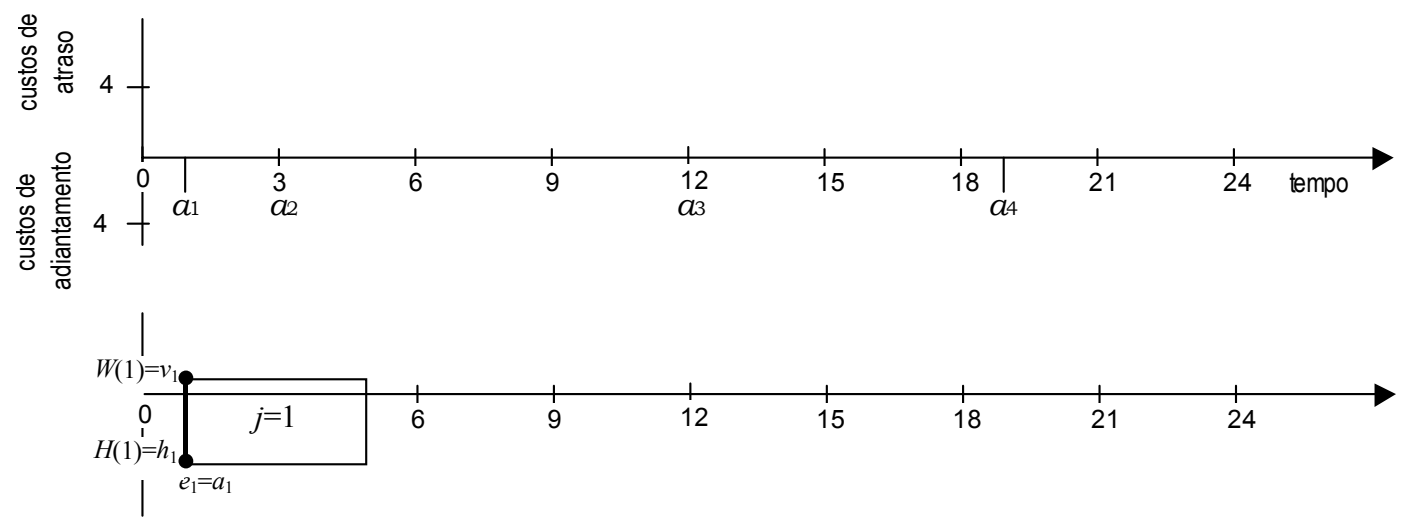

Fínura 8 :P asso 1 do exempb da utilização do A E 
Passo 2. Iteração 1. $j=1$, último $(1)=(j+1)=2, W(1)=W(1)+w_{j+1}+v_{j+1}=5, e_{2}=e_{1}+p_{1}=5$, Insere $(2,2, P(1))$. Como $H(1) \leq W(1)$, o procedimento antecipa é utilizado onde as seguintes operações são realizadas: $\operatorname{Difl}=\operatorname{EncontraMin}(P(1))=2$, Dif2 $=e_{1}=1, \quad$ Dif $=\min \{$ Dif $1, D i f 2\}=1, \quad$ AdicionaParaTodasChaves $(-1, P(1))$, $e_{1}=e_{1}-D i f=0, e_{2}=e_{2}-D i f=4$;
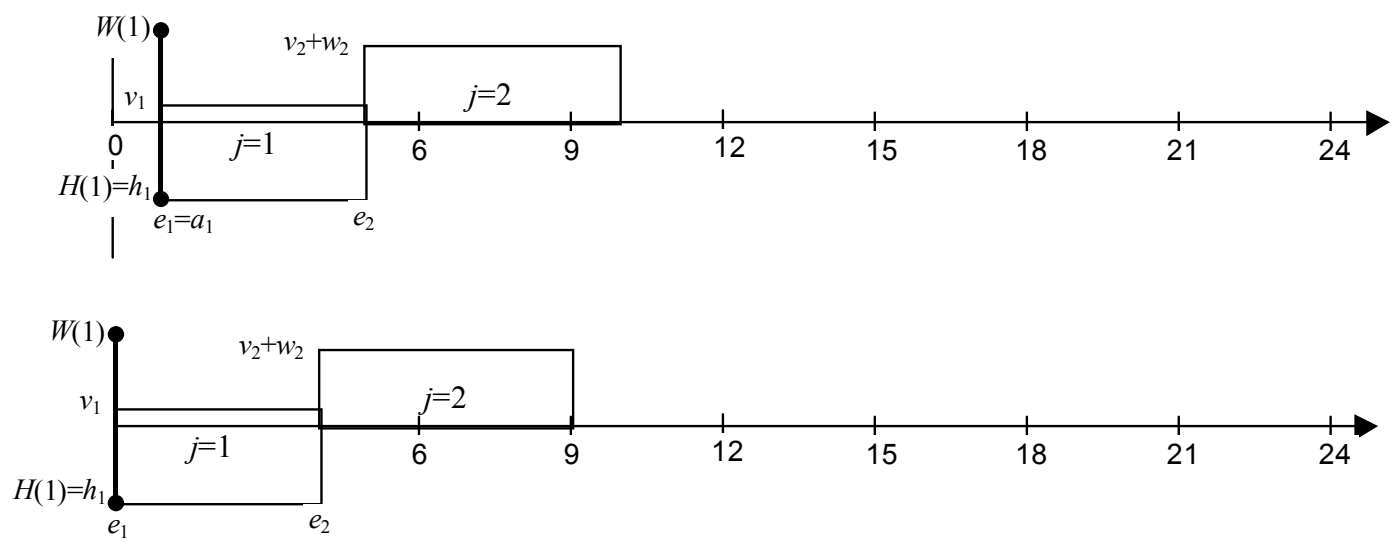

F ýura 9 :P asso 2 do exempb da utiłização do A E

Passo 3. Iteração 2. $j=2, l=l+1=2$, primeiro $(2)=j+1=3, \quad H(2)=h_{3}=2, \quad W(2)=v_{3}=1$, $e_{3}=a_{3}=12$, CriaFilaPrior $(P(2))$;

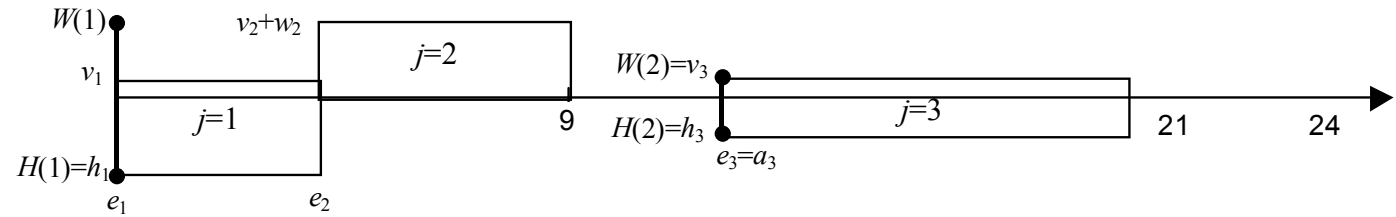

F íura 10 :P asso 3 do exempb da utilização do A E

Passo 4. Iteração 3. $j=3$, último(2) $=j+1=4, W(2)=W(2)+w_{4}+v_{4}=6, \quad e_{4}=e_{3}+p_{3}=20$, Insere $(4,1, P(2))$. $H(2) \leq W(2)$, o procedimento antecipa é utilizado mais uma vez. $\quad \operatorname{Dif1}=\operatorname{EncontraMin}(P(2))=1, \quad \operatorname{Dif2}=e_{3}-e_{2}-p_{2}=2$, 


$$
\begin{aligned}
& \operatorname{Dif}=\min \{\text { Dif } 1, \operatorname{Dif} 2\}=1, \text { AdicionaParaTodasChaves }(-1, P(2)), e_{3}=e_{3}-D i f=11, \\
& e_{4}=e_{4}-D i f=19, \operatorname{ApagaMin}(P(2))=4, W(2)=W(2)-w_{4}=4, H(2)=H(2)+h_{4}=5 ;
\end{aligned}
$$
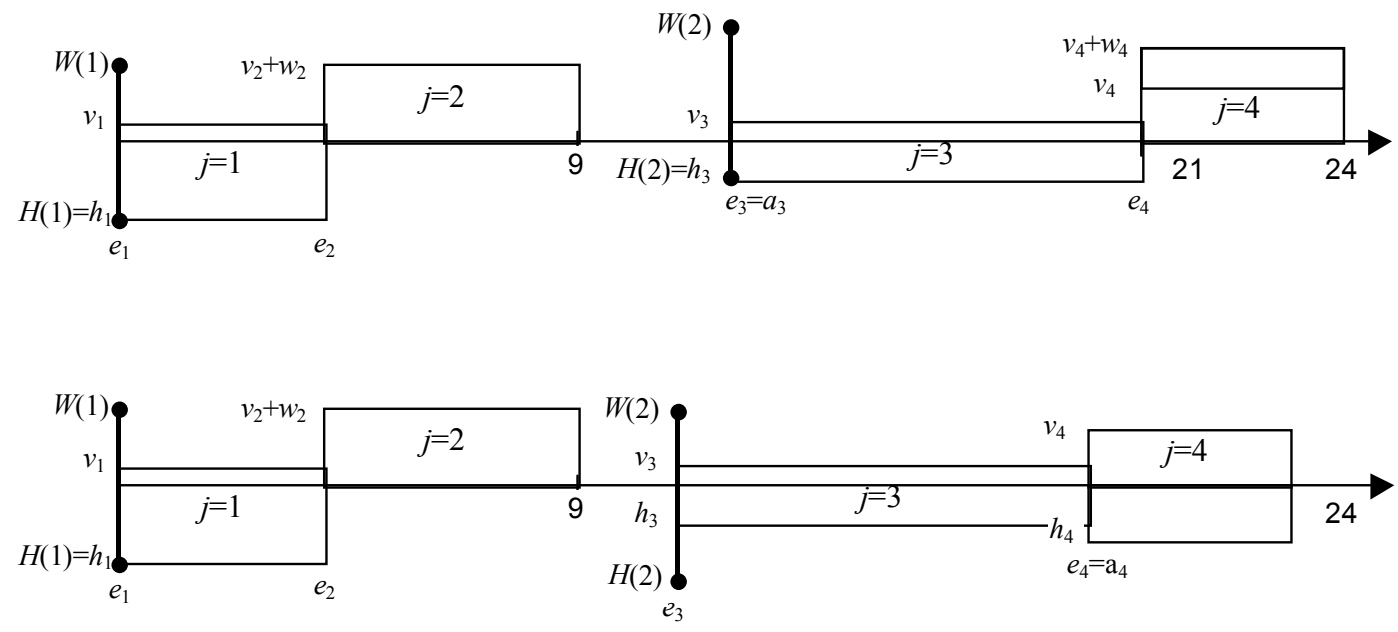

F ġura 11:P asso 4 do exempb da utilização do A E

Passo 5. Finalização. Fim.

Com os resultados gerados pelo AIE, juntamente com a base de dados da instância conforme Tabela 2, podemos construir a Tabela 4, que apresenta os resultados, inclusive com o valor da função-objetivo.

\begin{tabular}{ccccccc}
\hline$j$ & $e_{j}$ & $W_{j}$ & $C_{j}$ & $E_{j}$ & $T_{j}$ & $h_{j} E_{j}+w_{j} T_{j}+v_{j} C_{j}$ \\
\hline 1 & 0 & 0 & 4 & 1 & 0 & 8 \\
2 & 4 & 0 & 9 & 0 & 1 & 28 \\
3 & 11 & 2 & 19 & 1 & 0 & 21 \\
4 & 19 & 0 & 23 & 0 & 0 & 69 \\
& & & & & total & 126 \\
\hline
\end{tabular}

Tabela 4 :C ákub do exempb com inserção de espera

Os blocos existentes após o algoritmo ser finalizado são os seguintes: $B_{1}=\left\{J_{1}, J_{2}\right\}$ e $B_{2}=\left\{J_{3}, J_{4}\right\}$. Os blocos indicam que as ordens devem ser produzidas 
sem a inserção de espera entre as mesmas. O valor da função-objetivo neste

caso é $\sum_{j=1}^{4}\left(h_{j} E_{j}+w_{j} T_{j}+v_{j} C_{j}\right)=126$, que de acordo com o corolário 2.1 é o mínimo valor alcançado para a seqüência definida inicialmente.

\subsection{Programação da produção do problema de uma máquina via programação linear}

A programação linear pode ser utilizada para se resolver o problema tratado neste capítulo. Seguindo outras formulações de problemas parecidos, nossa formulação pode ser definida como:

$\min \sum_{j \in J}\left(h_{j} E_{j}+w_{j} T_{j}+v_{j} C_{j}\right)$

sujeito a:

(1) $C_{j-1}+W_{j}+p_{j}=C_{j} \quad(j \in J, j \neq 1)$

(2) $t_{0}+W_{j}+p_{j}=C_{j} \quad(j=1)$

(3) $C_{j}+E_{j}-T_{j}=d_{j} \quad(j \in J)$

(4) $\left\{E_{j}, T_{j}, W_{j}, C_{j}\right\} \in R_{+} \quad(j \in J)$

Como pode ser visto, a formulação é bastante simples, utilizando $5|J|+1$ valores constantes, $4|J|$ variáveis reais positivas e $2|J|$ restrições, excluindose as de não-negatividade. As restrições tipo (1) definem o horário de término das ordens. Elas consideram a recursividade do horário de término, ou seja, o horário de término da ordem $j+1$ é equivalente ao horário de término da ordem $j$, mais a espera que antecedeu sua realização e mais o tempo demandado para o seu processamento. A restrição tipo (2) é utilizada para não haver incoerência na restrição tipo (1) para a ordem $j=1$. A primeira ordem não tem um horário de término de uma ordem anterior que possa ser utilizado. Por essa razão introduziu-se to que identifica o instante de inicio da programação. As restrições tipo (3) mostram os relacionamentos entre os adiantamentos, atrasos e datas de entrega. São derivadas das equações de definição de adiantamento e atraso. Observe que em seu término, uma ordem $j$ ou vai estar adiantada, ou atrasada, ou no horário correto. Se ela estiver adiantada, o 
atraso é zero, $T_{j}=0$, e o adiantamento é equivalente a $E_{j}=d_{j}-C_{j}$. Portanto $C_{j}+E_{j}=d_{j}$, conforme equação do tipo (3) Se a ordem estiver atrasada, o adiantamento é nulo, $E_{j}=0$, e o atraso é equivalente a $T_{j}=C_{j}-d_{j}$. Portanto $C_{j}+T_{j}=d_{j}$. Se a ordem for terminada em seu horário exato, ambos, o atraso e o adiantamento são nulos, $T_{j}=E_{j}=0$. Assim, nossa equação do tipo (3) se transforma em $C_{j}=d_{j}$. As restrições tipo (4) são as de não-negatividade.

Dependendo da aplicação, a formulação de um problema de programação linear pode ser vantajosa em vista das facilidades e disponibilidades comerciais de softwares para a resolução desse tipo de problema. Além disso o problema entra num outro nível de entendimento e interpretação por parte do leitor. FRY et al. (1987) (para o problema deles) mencionam que essa formulação pode ser redefinida como um problema de rede que possui solução eficiente. Eles propuseram um procedimento de solução de um passo que resolve o problema em tempo $O\left(|J|^{2}\right)$.

\subsection{AIE para problemas com custos representados por funções convexas dos horários de término}

Nesta seção sugere-se um AIE que considera uma classe ampla de funções-objetivo. Para cada ordem, essa classe ampla será sintetizada como qualquer função cujos custos sejam representados por uma função convexa ${ }^{15}$ de seu horário de término. A função-objetivo em si será a soma das funções de custo de cada ordem.

\subsubsection{Preliminares}

No decorrer desta seção, $R$ representa o conjunto dos números reais.

\footnotetext{
${ }^{15}$ A não-consideração de uma classe mais ampla de funções, como funções quase-convexas ou pseudoconvexas por exemplo, acontece pela falta da propriedade de quase-convexidade da soma dessas funções. Aqui podería-se considerar qualquer classe de funções, desde que sua soma se mantivesse como uma função quase-convexa. Em realidade, essa restrição acontece pela dificuldade de convergência de um algoritmo para uma função que possua mais de um ponto de mínimo local estrito. Sob um ponto de vista mais teórico, nada impediria que a função da soma das funções dos horários de término tivesse mais de um mínimo local estrito; alguns procedimentos elaborados para se tratar desse tipo de problema (otimização global) já existem, como pode ser observado em RINNOOY KAN; TIMMER (1989).
} 
Faremos abaixo definições e provas importantes para o desenvolvimento do AIE adaptado à funções convexas dos horários de término.

Definição. (Conjunto convexo) (LUENBERGER, 1984, p. 464): Um conjunto $\Omega \subseteq R$ é dito convexo se para cada $x_{1}, x_{2} \in \Omega$, e cada número real $\alpha, 0 \leq \alpha \leq 1$, o ponto $\alpha x_{1}+(1-\alpha) x_{2} \in \Omega$.

Definição. (Função convexa) (LUENBERGER, p. 176): Uma função $g$ definida num conjunto convexo $\Omega$ é considerada como sendo convexa se, para cada $x_{1}, x_{2} \in \Omega \quad$ e cada número real $\alpha, \quad 0 \leq \alpha \leq 1$, a inequação $g\left(\alpha x_{1}+(1-\alpha) x_{2}\right) \leq \alpha g\left(x_{1}\right)+(1-\alpha) g\left(x_{2}\right)$ se mantém.

Lema 2.1. (Soma de funções convexas) Sejam $g_{1}$ e $g_{2}$ funções convexas no conjunto convexo $\Omega$. Então, $g_{1}+g_{2}$ é convexa em $\Omega$.

O lema 2.1 é importante aqui pois mostra que a soma de funções convexas possui apenas um ponto de mínimo. Como cada ordem utiliza uma função convexa para definir sua contribuição à função-objetivo, as posições dos blocos e por conseqüência dos programas completo e parcial também serão funções convexas dos horários de término. Dessa forma, procedimentos de busca não-linear irrestrita podem ser utilizados para a localização dos pontos que otimizam a função-objetivo.

Lema 2.2. Para $g(x)$ uma função convexa e $z^{[1]}$ um intervalo inicial de indecisão, o método da seção áurea, após $n$ iterações, define um intervalo $z^{[n]}$ onde se encontra o ponto de mínimo de $g(x)$. 
Demonstração: A demonstração é conseqüência direta da definição do método. Para a definição algorítmica do método, vide BAZARAA et al. (1993, pp. 270-2) por exemplo.

\subsubsection{Construção do AIE}

Seja $g_{j}\left(C_{j}\right)$ uma função convexa que descreve o valor do custo de $j \in J$ de acordo com seu horário de término. Vamos supor que o instante de início do horizonte de planejamento seja definido por to e que o horário de término de mínimo custo (horário de término desejado) seja definido como $C_{j}^{*}$.

Denominaremos $G(b)=\sum_{j \in b} g_{j}\left(C_{j}\right)$ a função-objetivo do bloco para cada bloco $b \in B$. Adicionalmente, vamos definir $G\left(b^{+}\right)$como o valor de $G(b)$ se $b$ fosse antecipado em um pequeno valor e $G\left(b^{-}\right)$analogamente para um pequeno postergamento. Considerando que nosso intervalo de indefinição seja definido por $z$, podemos dizer que $G\left(b^{+}\right)=\sum_{j \in b} g_{j}\left(C_{j}-\alpha z\right)$ e $G\left(b^{-}\right)=\sum_{j \in b} g_{j}\left(C_{j}+(1-\alpha) z\right)$, onde $0<\alpha<1$.

Do ponto de vista prático $\alpha$ é simplesmente um fator que faz com que a soma das movimentações para a direita e para a esquerda seja equivalente a $z$. Dessa forma, a movimentação para a direita pode ser diferente da movimentação para a esquerda.

No desenvolvimento do algoritmo vamos considerar cinco possiveis regiões em uma função convexa: as regiões de tipo 1, 2, 3, 4 e 5, conforme apresentado na Figura 12.

Considerando a convexidade da função-objetivo, podemos dizer que os cinco tipos de regiões representam que se o bloco estiver na região do:

- Tipo 1: antecipações adicionais são interessantes pois o bloco está numa região onde uma antecipação promove um decréscimo na função-objetivo; 

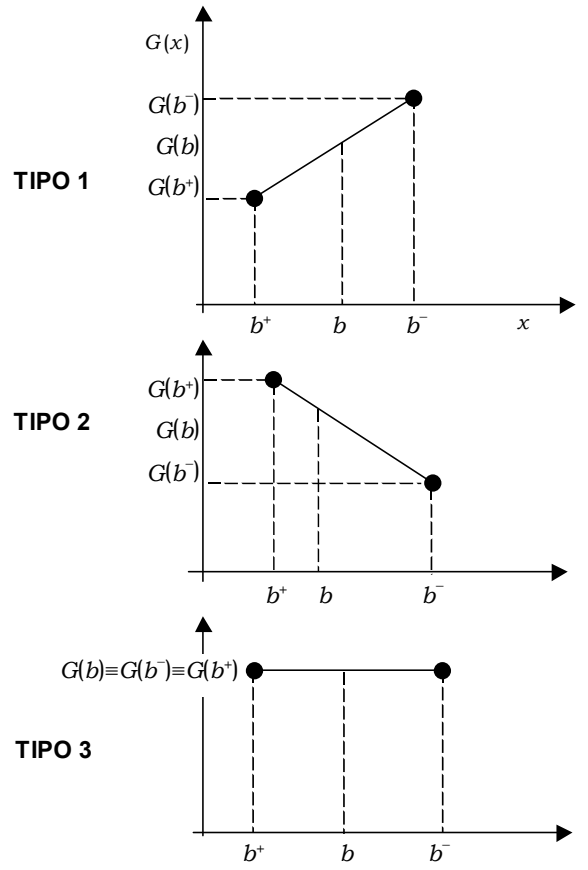

F ġura 12 :Regñes possíveis numa função convexa
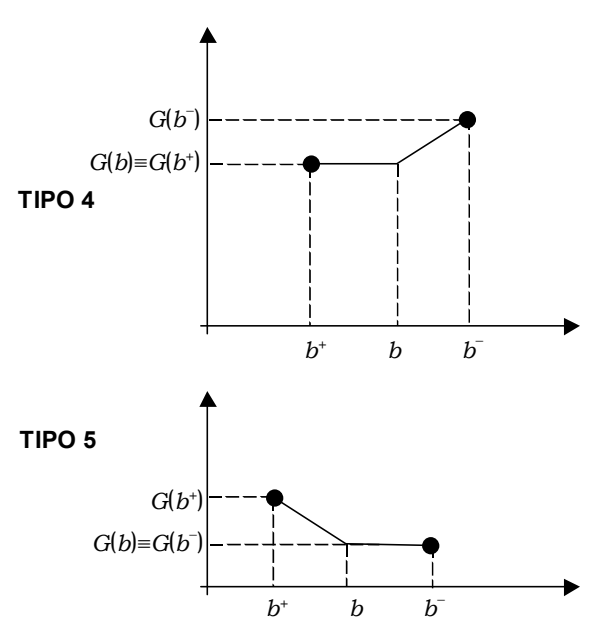

- Tipo 2: antecipações adicionais não são interessantes pois o bloco está numa região onde uma antecipação promove um aumento na função-objetivo;

- Tipo 3: antecipações adicionais ou aumentam ou não alteram a função-objetivo. Por essa razão opta-se por não se antecipar mais o bloco;

- Tipo 4: antecipações adicionais ou aumentam ou não alteram a função-objetivo. Por essa razão opta-se por não se antecipar mais o bloco;

- Tipo 5: antecipações adicionais aumentam o valor da função-objetivo.

A grosso modo, o algoritmo vai continuar trabalhando da mesma maneira. Existe um procedimento que vai gerando blocos e outro que vai antecipando os mesmos. Suponha que o algoritmo tenha realizado as antecipações $[n-1]$ e $[n]$. A Tabela 5 abaixo descreve o raciocínio utilizado na construção do algoritmo. 


\begin{tabular}{|c|c|c|c|}
\hline & \multicolumn{2}{|c|}{ Ponto } & \multirow[t]{2}{*}{ Conclusão } \\
\hline & {$[n-1]$} & {$[n]$} & \\
\hline \multirow{5}{*}{ Região } & tipo 1 & tipo 1 & Antecipar mais uma vez \\
\hline & tipo 1 & tipo 2 & A região de mínimo custo está compreendida entre $[n-1]$ e $[n]$ \\
\hline & tipo 1 & tipo 3 & O ponto de mínimo custo é $b$ de $[n]$ \\
\hline & tipo 1 & tipo 4 & O ponto de mínimo custo é $b$ de $[n]$ \\
\hline & tipo 1 & tipo 5 & O ponto de mínimo custo é $b$ de $[n]$ \\
\hline
\end{tabular}

Tabeł 5 :Rehções possíveis entre os tịos de regD̃es de uma função convexa em duas terações do abortmo

O algoritmo funcionará tomando as ações que atendam as conclusões apresentadas na Tabela 5. A seguir o algoritmo é descrito mais formalmente.

Suponha sem perda de generalidade que $t_{0}=0$. O algoritmo tem início programando-se a primeira ordem de modo que $g_{1}\left(C_{1}\right)$ seja mínima. Se $C_{1}^{*}<p_{1}$, então, $C_{1}^{A I E}=p_{1}$. Caso contrário, pode-se definir $C_{1}^{A I E}=C_{1}^{*}$. Considerando que um programa parcial já tenha sido elaborado até a ordem $j$, $\pi_{j}^{A I E}$, a j+1-ésima ordem pode ser programada de acordo com dois casos: um onde a ordem não pode ser programada com custo mínimo e outro onde a ordem pode.

Caso 1 (sem custo mínimo garantido): $C_{j}^{A I E}+p_{j+1}>C_{j+1}^{*}$. Programa-se $j+1$ de modo que $C_{j+1}^{A I E}=C_{j}+p_{j+1} \cdot j+1$ é inserida no bloco $l$.

Caso 2 (com custo mínimo garantido): $C_{j}^{A I E}+p_{j+1} \leq C_{j+1}^{*}$. Programa-se $j+1$ de modo que $C_{j+1}^{A I E}=C_{j+1}^{*}$. Cria-se um novo bloco com a ordem $j+1$.

A propriedade-chave agora se transforma em: $G(l) \leq G\left(l^{+}\right)$, isto é, uma antecipação adicional faz com que a função-objetivo do bloco aumente ou se mantenha. Se após o acréscimo da ordem $j+1$ ao programa $\pi_{j}^{A I E}$, a propriedade-chave é mantida, não se toma nenhuma ação. Por outro lado, se a propriedade-chave é violada, o bloco $l$ é movimentado para mais cedo enquanto pelo menos uma das condições abaixo não aconteça: 
Condição 1: $e_{\text {primeiro( }()}=0$. Ocorrerá somente se $l=1$. Caso ocorra, o bloco $l$ não pode ser movimentado para mais cedo pois ele estará começando no horário 0;

Condição 2: A desigualdade $G(l) \leq G\left(l^{+}\right)$torna-se verdadeira; o algoritmo constata que o bloco está na região de tipo 2, 3, 4 ou 5. Neste caso, se o bloco estiver na região do tipo 2 significa que uma antecipação um pouco menor poderia fazer com que a função-objetivo diminuísse. Em outras palavras, duas iterações consecutivas, $[n-1]$ e $[n]$, terem avaliado as regiões como sendo do tipo 1 e 2 respectivamente. Caso ocorra, deverá haver uma busca na região pertencente ao intervalo $\left[C_{\text {primeiro(l) }}^{[n]}, C_{\text {primeiro(l) }}^{[n-1]}\right]$, de modo que o ponto de mínimo dentro de uma indecisão aceitável seja localizado.

Observe que pelas antecipações, os blocos $l$ e $l-1$ podem ser unidos $(k \leftarrow l \cup l-1)$ diversas vezes. A união não leva a modificações no algoritmo descrito, visto que o bloco unido tem o mesmo tratamento do bloco $l$ inicial.

Suponha que $\Delta^{[n]}=\min _{j \in \operatorname{Dim}(b)}\left(e_{j}-a_{j}\right)$ seja a antecipação, após $n$ movimentações, que fez com que a condição 2 se tornasse válida, posicionando o bloco numa região de tipo 2. O intervalo de indecisão $\left[C_{\text {primeiro(l) }}^{[n]}, C_{\text {primeiro(l) }}^{[n-1]}\right]$, com $z^{[1]}=C_{\text {primeiro(l) }}^{[n-1]}-C_{\text {primeiro(l) }}^{[n]}$, contém o ponto de mínimo custo do bloco $l$. A utilização de um procedimento de busca unidimensional em $Z^{[1]}$ pode encontrar um intervalo menor de indecisão acerca de qual a posição do bloco que gera o mínimo custo. A saída do procedimento será a antecipação ótima $\Delta^{*}$ que substitui a antecipação $\Delta^{[n]}$.

Para tanto, utilizaremos um procedimento de busca unidimensional bastante conhecido, denominado método da seção áurea (LUENBERGER, pp. 199-200). No método da seção áurea, após $m$ iterações, o intervalo de indecisão se reduz a $z^{[m]}=(2 /(1+\sqrt{5}))^{m-1} z^{[1]}$. Considerando que o intervalo de

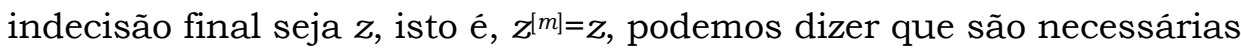

$$
m=1+\frac{\ln \left(z / z^{[1]}\right)}{\ln (2 /(1+\sqrt{5}))}
$$

iterações para que o procedimento seja finalizado. 
Se for o caso, após a localização de $\Delta^{*}$, o programa resultante é $\pi_{j+1}$. O algoritmo faz sucessivas aplicações do procedimento acima formando os programas $\pi_{2}^{A I E}, \pi_{3}^{A I E}, \ldots, \pi_{|J|}^{A I E}$.

O teorema abaixo, que é um caso geral do corolário 2.1 já apresentado, garante a otimalidade do algoritmo.

Teorema 2.1. Suponha que para um programa parcial $\pi_{j}^{A I E}$ calculado pelo AIE, o valor mínimo da função-objetivo de seus blocos esteja em um intervalo de indecisão $z$. Considerando que dentro de $z$ todos os blocos forneçam o mesmo valor da função-objetivo, $\pi_{j}^{A I E}$ leva ao menor valor de $g\left(\pi_{j}\right)=\sum_{i=1}^{j} g_{i}\left(C_{i}\right)$ dentre todos os programas possiveis para as primeiras $j$ ordens. ${ }^{16}$

Demonstração: Grande parte da prova apresentada aqui é análoga à prova do corolário 2.1. Como hipótese de indução, assumimos que em $j$ o teorema é verdadeiro, isto é, $g\left(\pi_{j}^{A I E}\right)=\min _{\pi_{j} \subseteq \Pi_{j}} g\left(\pi_{j}\right)$, onde $\Pi_{j}$ é o conjunto de todos os programas possiveis para as $j$ primeiras ordens. Para o programa vazio $\pi_{0}^{A I E}$, o teorema é verdadeiro. Portanto, só falta provar que para uma iteração qualquer, $j+1$, o teorema também é verdadeiro. Seja $C_{k}$ e $C_{k}^{A I E}$ os horários de término da ordem $k$ em $\pi_{j}$ e $\pi_{j}^{A I E}$, respectivamente. Podemos considerar dois casos: um onde a ordem pode terminar no horário desejado, $C_{j}^{A I E}+p_{j+1} \leq C_{j+1}^{*}$, e outro, onde a ordem não pode, $C_{j}^{A I E}+p_{j+1}>C_{j+1}^{*}$.

Caso 1. $C_{j}^{A I E}+p_{j+1} \leq C_{j+1}^{*}$. Este caso permite que o algoritmo programe j+1 de modo que $C_{j+1}^{A I E}=C_{j+1}^{*}$, e portanto, para $\pi_{j+1}^{A I E}$ a função-objetivo será

\footnotetext{
${ }^{16}$ Do ponto de vista prático, $z$ é facilmente justificável visto que os horários de término geralmente não são penalizados numa base contínua. A especificação do desejo de término sempre vai acontecer num intervalo de tempo. A solicitação de entrega de um produto acontece no dia 5 por exemplo, e não na hora 12,34 do dia 5 . Esse intervalo, que pode ser um dia, uma hora, ou qualquer outro intervalo, especifica que sob o ponto de vista do custo do programa, é indiferente qualquer que seja o término dentro desse intervalo pré-especificado.
} 
$g\left(\pi_{j+1}^{A I E}\right)=g\left(\pi_{j}^{A I E}\right)+g_{j+1}\left(C_{j+1}^{*}\right)$. Levando em conta que $C_{j+1}^{*}=\arg \min g_{j+1}\left(C_{j+1}\right)$ por definição e que $g\left(\pi_{j}^{A I E}\right)=\min _{\pi_{j} \subseteq \Pi_{j}} g\left(\pi_{j}\right)$ pela hipótese de indução, podemos dizer com certeza que $g\left(\pi_{j+1}^{A I E}\right) \leq g\left(\pi_{j+1}\right)$. Portanto, o teorema é verdadeiro neste caso.

Caso 2. $C_{j}^{A I E}+p_{j+1}>C_{j+1}^{*}$. Como não é mais possivel ocorrer $C_{j+1}^{A I E}=C_{j+1}^{*}$, o algoritmo programa inicialmente $j+1$ de modo que $C_{j+1}^{A I E}=C_{j}^{A I E}+p_{j+1}$, avaliando o valor de $e_{\text {primeiro(l) }}^{A I E}$ e a relação entre $G(l)$ e $G\left(l^{+}\right) \cdot j+1$ é inserida no bloco $l$. Considerando a hipótese de indução e a convexidade de $g_{j+1}\left(C_{j+1}\right)$, podemos dizer que $g_{j+1}\left(C_{j+1}^{A I E}\right) \leq g_{j+1}\left(C_{j+1}^{A I E}+\varepsilon\right)$ onde $C_{j+1}^{*}<C_{j+1}^{A I E} \leq C_{j+1}^{A I E}+\varepsilon$. Com essa consideração, sabemos que $g\left(\pi_{j+1}\right)$ só pode ser diminuída caso haja uma antecipação $\Delta$ do bloco $l$. Sem perda de generalidade, vamos supor que as antecipações não gerem união dos blocos $l$ e $l-1$.

Se em algum momento $e_{\text {primeiro(1) }}^{\text {AIE }}=0$, o algoritmo não faz mais movimentações e o teorema prova a otimalidade do mesmo pois não há uma antecipação $\Delta$ que possa fazer com que o valor da função-objetivo diminua. Por outro lado, se nas movimentações $e_{\text {primeiro(1) }}^{\text {AIE }} \neq 0$, o algoritmo antecipa o bloco $l$ até que aconteça um dos dois subcasos abaixo:

Subcaso 2a. A desigualdade $G(l) \leq G\left(l^{+}\right)$torna-se verdadeira, sendo que na antecipação corrente, $[n]$, avaliou-se a região da função-objetivo e constatou-se que ela é equivalente ao tipo 3,4 ou 5 . Pela convexidade de $G(l)=\sum_{j \in l} g_{j}\left(C_{j}\right)$, a desigualdade é suficiente para garantir a que o mínimo esteja compreendido no intervalo $z$ desde que a soma das amplitudes das movimentações à direita $\mathrm{e}$ à esquerda seja no máximo z. O teorema está provado para este subcaso.

Subcaso 2b. A desigualdade $G(l) \leq G\left(l^{+}\right)$torna-se verdadeira, sendo que na antecipação corrente, $[n]$, avaliou-se a região da função-objetivo e constatou-se que ela é equivalente ao tipo 2. Pelo tipo de construção do algoritmo, na antecipação [n-1] a região era do tipo 1, e por conseqüência, houve uma inversão do sinal da derivada da função-objetivo entre as iterações $[n-1]$ e $[n]$. Haverá uma busca utilizando o método da seção áurea na região pertencente ao intervalo $\left[C_{\text {primeiro(l) }}^{A I E[n]}, C_{\text {primeiro(l) }}^{A I E[n-1]}\right]$. Considerando o lema 2.2, pode-se dizer que 
acontecerão $k$ iterações até que $z^{[k]} \leq z$. Isso termina a prova do teorema. ////

\subsubsection{Implementação computacional e questões relacionadas}

Seguindo as mesmas linhas das seções anteriores apresenta-se abaixo o pseudocódigo do AIE para ordens com funções-objetivo representadas pela soma de funções convexas dos horários de término. O procedimento agora é chamado InsereEspera2, conforme Figura 13, e tem como procedimento auxiliar o procedimento Antecipa2, conforme Figura 14.

Além das 6 operações com filas de prioridades descritas anteriormente neste capítulo, adicionamos mais duas outras operações:

Operação 7: DefineTipoRegiãoEm $(-x)$. $O(n)$, onde $n$ é o número de ordens do bloco. A operação calcula $G(l)$ e $G\left(l^{+}\right)$com uma antecipação de $x$ e avalia o tipo de região.

Operação 8: SeçãoÁurea $(a, b, f, z) \cdot O\left(\log \left(d_{\max } / z\right)\right)$. O método da seção áurea

vai demandar $n=1+\log (z / \Delta) / \log (2 /(1+\sqrt{5})) \quad=1+\log (\Delta / z) / \log ((1+\sqrt{5}) / 2)$ $=O(\log (\Delta / z))$ (onde $\Delta$ é uma antecipação) iterações até que o valor de indecisão seja $z$. A maior antecipação possivel será $d_{\text {max }}$; ponto mais distante onde o algoritmo colocaria a ordem de modo que houvesse antecipações. Utiliza o método da seção áurea para a definição da posição de mínimo custo para o bloco. Dada uma função $f$, e o intervalo $[a, b]$ onde a busca deve ser realizada, a operação localiza, com uma precisão de $z$, a posição que leva o bloco a ter mínimo custo.

O código computacional do método da seção áurea é bastante comum e pode ser encontrado em diversas fontes como por exemplo em PRESS et al. (1992, pp. 390-5).

No pseudocódigo não se introduziu uma definição de $\alpha$ pois ela é dependente de características do problema a ser analisado. Além dessa dependência do problema, o cálculo de $\alpha$ não oferece maiores complicações nem tem um impacto significativo no tempo computacional do algoritmo. 
2. Algoritmo de inserção de espera para o problema de uma máquina com função-objetivo representada 50 pela soma de funções convexas do horário de término independentes para cada ordem

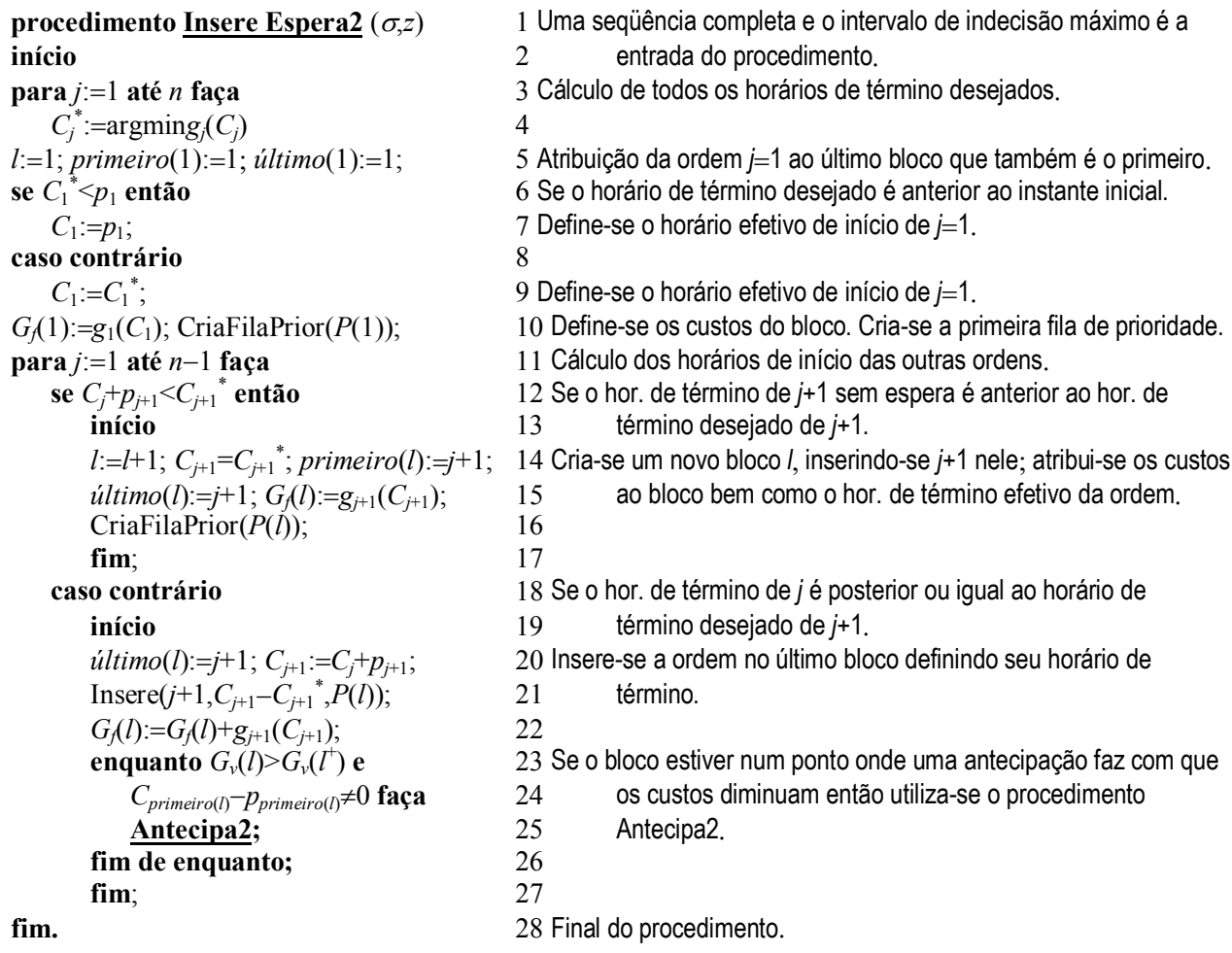

F ġura 13 :P seudocódigo para inserção de espera em seqüêncí predefinda; custos das ordens representados por funções convexas dos horárìs de tém ṅo

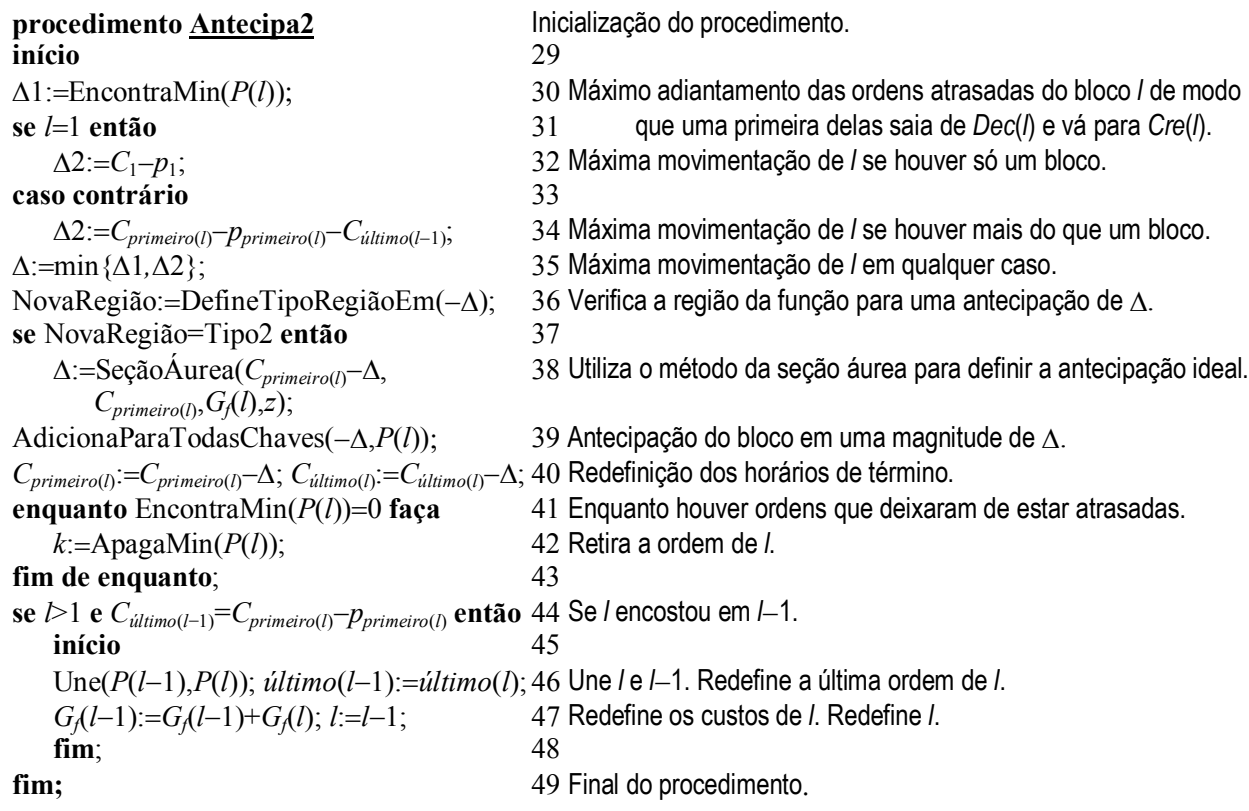


O leitor pode verificar que $G(l)$ ora é usada como $G_{f}(l)$ e ora como $G_{\nu}(l)$. A diferença entre ambas é que a primeira representa a função $G(l)$ e a segunda o valor numérico da função $G(l)$. Embora não haja uma explicitação, $g_{j}\left(C_{j}\right)$ segue o mesmo padrão nas operações de atribuição, ou seja, se $x:=G_{f}(l)+g_{j}\left(C_{j}\right)$, estamos querendo dizer que a função $g_{j}\left(C_{j}\right)$ está sendo acrescentada à função $G_{f}(l)$, enquanto que se a operação for do tipo $x:=G_{v}(l)+g_{j}\left(C_{j}\right)$, estamos querendo dizer que o valor de $g_{j}\left(C_{j}\right)$ está sendo adicionado a $G_{v}(l)$.

Proposição 2.3. O tempo computacional do algoritmo sugerido é de $O\left(|J| \max \left\{|J|, \log \left(d_{\max } / z\right)\right\}\right)$, onde $d_{\max }$ é a maior data de entrega, $|J|$ é o número de ordens e $z$ é a precisão com que o procedimento de busca vai definir a região ótima.

Demonstração: Desconsiderando as linhas 36, 37, 38, 41, 42 e 43, o tempo de execução do procedimento Antecipa2 pode ser considerado como $O(1)$. O tempo para a realização do método da seção áurea (linhas 37 e 38), como visto anteriormente, é $O\left(\log \left(d_{\max } / z\right)\right)$ e o tempo para realização da operação DefineTipoRegiãoEm $(x)$ demanda $O(j)$ considerando que o bloco contenha $j$ ordens. No pior caso, as operações serão utilizadas tantas vezes quanto o procedimento Antecipa2 o for. O procedimento ApagaMin (1. 41, $42 \mathrm{e}$ 43) possui tempo $O(\log j)$ para $j$ ordens na pilha. No pior caso, o procedimento Antecipa2 será utilizado $|J|-1$ vezes. Assim, o tempo total demandado pode ser definido como

$$
\begin{aligned}
\sum_{j=1}^{|J|-1}\left\{\log \left(d_{\max } / z\right)+j\right\} & =(|J|-1) \log \left(d_{\max } / z\right)+\frac{(|J|-1)|J|}{2} \\
& =O\left(|J| \max \left\{|J|, \log \left(d_{\max } / z\right)\right\}\right) .
\end{aligned}
$$

Se o procedimento Antecipa2 foi utilizado $|J|-1$ vezes, a operação Insere (1. 21) também o foi. O tempo de execução das linhas 3 a 10 é $O(|J|)$ e das linhas 12 a 22 é $O(|J| \log |J|)$ (considerando a equação (2.2)), portanto o tempo total do procedimento Insere Espera2 é

$$
O(|J| \log |J|)+O\left(|J| \max \left\{|J|, \log \left(d_{\max } / z\right)\right\}\right)=O\left(|J| \max \left\{|J|, \log \left(d_{\max } / z\right)\right\}\right),
$$

conforme queriamos demonstrar. 
2. Algoritmo de inserção de espera para o problema de uma máquina com função-objetivo representada 52 pela soma de funções convexas do horário de término independentes para cada ordem

A ordem do tempo no pior caso poderia ser um pouco melhorada em alguns casos se considerássemos que a realização dos $|J|-1$ métodos da seção áurea demanda tempo $\sum_{j=1}^{|J|-1}\left\{\log \left(d_{j} / z\right)\right\}$ ao invés de $\sum_{j=1}^{|J|-1}\left\{\log \left(d_{\max } / z\right)\right\}$. Observe que no caso particular onde $d_{\max }=d_{j} \quad(\forall j), \quad \sum_{j=1}^{|J|-1}\left\{\log \left(d_{j} / z\right)\right\}$ $=\sum_{j=1}^{|J|-1}\left\{\log \left(d_{\max } / z\right)\right\}$

A proposição mostra portanto que o algoritmo tem tempo de solução polinomial com o tamanho de entrada, pois depende de $\log \left(d_{\max }\right)$, ou mais formalmente, o tempo de solução é limitado por uma função polinomial do número de bits necessários para especificar uma instância do problema em representação binária ${ }^{17}$.

\footnotetext{
${ }^{17}$ Considerando que $[x]$ represente a parte inteira de $x$, o número de bits $w(n)$ necessários para representar um número inteiro $n$ em um registro é dado por $w(n)=[\log |n|]+1$, se $n \neq 0$ e $w(n)=1$ caso contrário. Se o algoritmo dependesse de $d_{\max }$ ao invés de $\log \left(d_{\max }\right)$ ele seria pseudopolinomial, ou seja, polinomial caso a instância seja especificada em representação unária. Outros detalhes com relação a um caso parecido podem ser encontrados em LAWLER (1977).
} 


\section{Variação de capacidade no problema de programação de uma máquina}

Fazendo um contraponto à vasta disponibilidade de estudos relacionados aos problemas de adiantamento e atraso, está o problema de programação da produção com variação de capacidade. Essa consideração, incomum na literatura que trata da teoria da programação, foi enunciada por CONWAY et al. (1967, p. 5) como sua restrição 1. O conceito de restrição para CONWAY et al. era uma simplificação imposta aos estudos teóricos, de modo que o ambiente real pudesse ser modelado com maior facilidade. Desde então, poucos estudos foram feitos considerando a retirada dessa restrição. No capítulo 1 forneceu-se uma revisão acerca de trabalhos que trataram do tema.

$\mathrm{Na}$ realidade, a motivação para a realização desta parte da tese não foi teórica, mas sim prática. Nos ambientes produtivos é muito comum a utilização de horas-extras de modo a diminuir possiveis custos, em especial os custos de atraso, como por exemplo os de multa aplicados por montadoras de veículos em fornecedores de autopeças. O advento da mentalidade de produção tipo JIT levou à preocupações semelhantes quando a entrega é antecipada. Uma outra situação real, onde a variação de capacidade é muito comum acontece quando existe empréstimo - ou alocação - de funcionários de setores ou recursos-não-gargalo a recursos ou setores-gargalo.

Este capítulo foi desenvolvido tendo em mente que a utilização de capacidade adicional pode ser feita objetivando-se dois resultados:

- Diminuir o atraso. Quando uma ordem for atrasar, utiliza-se a horaextra para eliminar o atraso;

- Diminuir o adiantamento. Ao invés de adiantarmos uma ordem, podemos postergar seu processamento. Depois utilizamos horasextras de modo que o término da ordem seja mais tarde.

Supondo um sistema de programação da produção constituído, a implementação da abordagem proposta neste capítulo é relativamente simples. Para um programa elaborado pelo referido sistema, o algoritmo aqui desenvolvido define em quais os intervalos e em que quantidade a capacidade adicional seria efetivamente utilizada. No decorrer do capítulo essas definições 
de como o algoritmo funciona e quais suas considerações ficarão mais claras.

\subsection{Conceitos preliminares e definição do problema}

As definições e conceitos utilizados aqui são os mesmos que os apresentados na seção 2.1, a menos que especificado de forma contrária. Sejam $J=\{1,2, \ldots\}, \quad M=\{1,2, \ldots\}$ e $T=\{1,2, \ldots\}$ conjuntos finitos de indices que representam ordens, máquinas e intervalos de tempo respectivamente. Uma operação $m j$ é caracterizada pela realização da ordem $j \in J$ na máquina $m \in M$. Cada ordem $j$ é caracterizada pela quadrupla $\left(h_{j}, w_{j}, p_{j}, d_{j}\right)$, representando respectivamente: custo de adiantamento, custo de atraso, tempo de processamento e data de entrega.

As operações são caracterizadas pela dupla $\left(p_{m j}, d_{m j}\right)$, representando respectivamente tempo de processamento e data de entrega da operação $m$ da ordem $j$. Cada intervalo de tempo $t \in T$ é caracterizado pela tripla $\left(i_{t}, f_{t}, o_{t}\right)$ que representa os instantes de início e término, e o custo por unidade de tempo associado a $t$. Na realidade, o que define o tamanho de $t$ é o custo associado ao mesmo. Para uma quantidade $O_{t}$ de capacidade adicional inserida no intervalo de tempo $t$, o custo será $o_{t} O_{t}$. O conjunto $T$ será particionado em dois subconjuntos disjuntos $S$ e $N$, denominados capacidade normal e capacidade adicional. Pela definição de partição, sabe-se que $S \cup N=T$ e $S \cap N=\varnothing$. Quando uma capacidade adicional for efetivamente utilizada, os intervalos de $N$ passam a pertencer a um novo conjunto denominado $O \subseteq N$.

A Figura 15 apresenta esquematicamente os conjuntos de intervalos de tempo definidos anteriormente. $A \backslash B$ representa a diferença entre os conjuntos $A$ e $B$. A Figura 16 exemplifica uma instância mostrando um gráfico de Gantt de intervalos de tempo. Perceba que habitualmente o problema de programação da produção considera que haja apenas o subconjunto $S$ e que seus intervalos de tempo sejam concatenados. De uma maneira geral, quando houver a criação de um turno de trabalho novo por exemplo, há uma expansão do subconjunto $S$ e uma diminuição do subconjunto $N$. Os relacionamentos e definições dos subconjuntos são feitas de acordo com as estratégias de gestão de capacidade da empresa. 


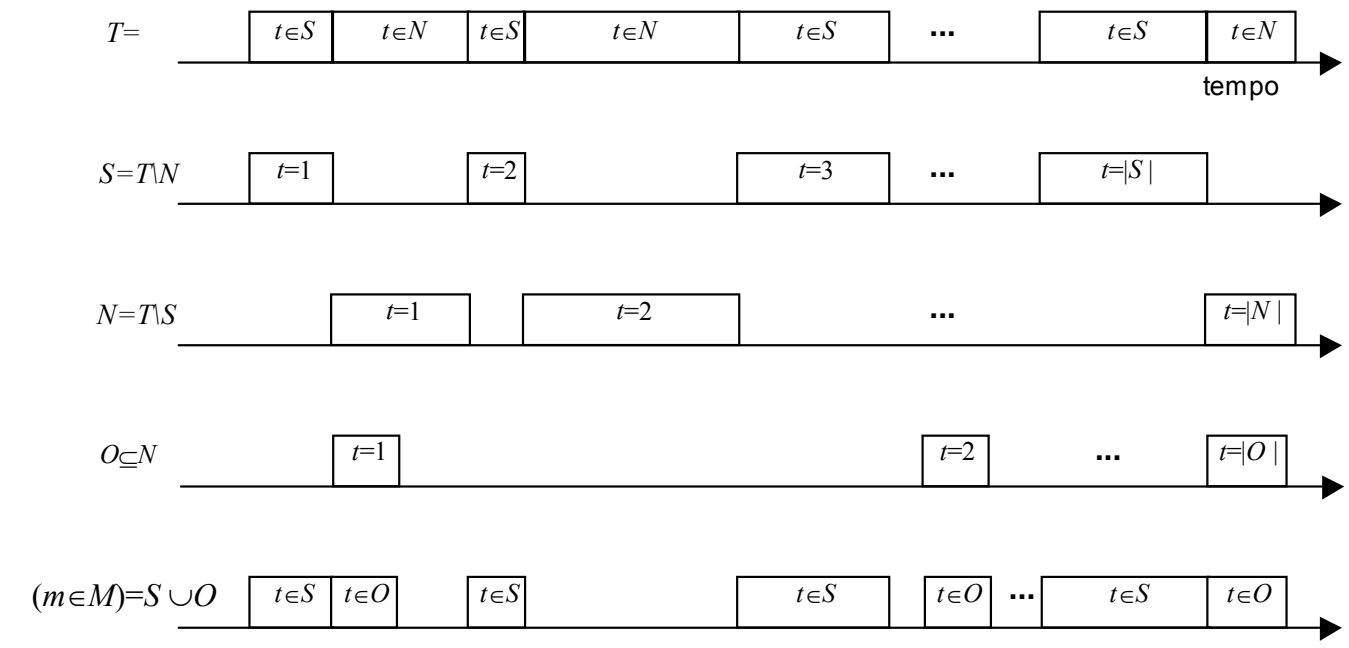

F ýra 15 :C onjuntos e subconyintos rekcínados aos intervabs de tempo

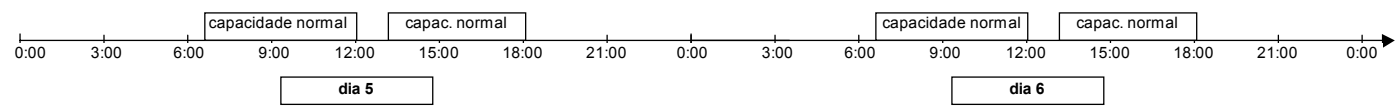

F giura 16 :G ráfico de $G$ antt de uma instâncí mostrando os intervabs de tempo de capacilade normal

Como mais de uma ordem pode ser realizada em um intervalo de tempo de capacidade adicional, vamos associar o intervalo de tempo com cada ordem que é realizada em $t$. Por essa razão chamaremos $O_{j t}$ de quantidade de capacidade adicional em $t$ que foi utilizada no processamento de $j$ e $W_{t}$ o tempo do intervalo $t$ em que a capacidade adicional não foi utilizada. A Figura 17 mostra os conceitos envolvidos.

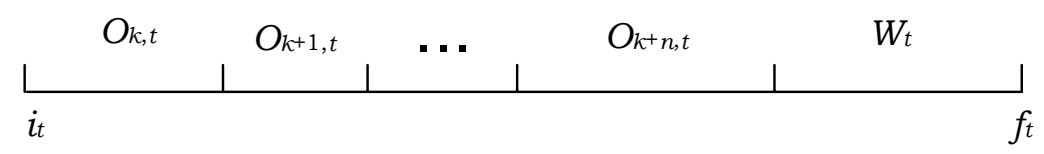

F giura $17: V$ aráveis relacínadas aos intervabs de capacilade adicinal 
Com isso podemos dizer que $f_{t}-i_{t}=W_{t}+\sum_{j \in A \subseteq J} O_{j t}$, onde $A$ é o conjunto de ordens que foram processadas no intervalo $t$. Se não houver utilização de capacidade adicional em $t, f_{t}-i_{t}=W_{t}$.

Uma consideração importante e que o leitor deve manter em mente é que estaremos trabalhando com calendários e por essa razão, as datas de entrega e horários de término serão definidos de modo apropriado. Podemos pensar em diversas maneiras de como considerar os intervalos de tempo na modelagem. Vamos expandir o conceito de tempo de processamento contemplando ambas, a capacidade normal e a capacidade adicional. Os tempos de processamentos são definidos como $p_{j}=p_{j}^{S}+\sum_{t \in N} O_{j t}$, onde $p_{j}^{S}$ é o processamento (em tempo) que foi realizado em um intervalo de capacidade normal e $\sum_{t \in N} O_{j t}$ é o processamento que foi realizado em um intervalo de capacidade adicional. Para uma ordem qualquer, considerando que to seja o instante inicial do horizonte de planejamento, o horário de término pode ser definido como

$$
C_{j}=\left\{\begin{array}{l}
t_{0}+W_{j}+p_{j}^{S}+\sum_{\left\{t \in N: f_{t} \leq C_{j}\right\}} W_{t}+\sum_{\left\{t \in N: i_{t} \leq C_{j}\right\}} O_{j t} \text { para } j=1 \\
C_{j-1}+W_{j}+p_{j}^{S}+\sum_{\left\{t \in N: C_{j-1}<f_{t} \leq C_{j}\right\}} W_{t}+\sum_{\left\{t \in N:\left(C_{j-1}, C_{j}\right] \cap\left[i_{t}, f_{t}\right] \neq \varnothing\right\}} O_{j t} \text { caso contrário. }
\end{array}\right.
$$

Apesar de não haver o sobrescrito em $W_{j}$ e $W_{t}$, está implícito que o primeiro caso é o tempo de espera acontecido em intervalos de capacidade normal e o segundo em intervalos de capacidade adicional.

A construção e a forma da equação (3.1) não é muito simples, e por essa razão desenvolve-se abaixo uma explicação mais detalhada. A maior dificuldade provavelmente está na definição dos limites dos somatórios. A Figura 18 mostra os possiveis relacionamentos entre os intervalos de processamento das ordens e os intervalos de capacidade adicional.

Para $J_{1}, C_{1}$ é dependente do início do horizonte de planejamento, $t_{0}$; do tempo de espera utilizado antes de seu processamento, $W_{1}$; do tempo de processamento que aconteceu em intervalos de tempo pertencentes à capacidade normal, $p_{1}^{S}$; dos intervalos de tempo de capacidade adicional que ficaram no intervalo $\left[t_{0}, C_{1}\right]$ e que não foram utilizados no processamento de $J_{1}$, 
$\sum_{\left\{t \in N: f_{t} \leq C_{1}\right\}} W_{t}$; e dos intervalos de tempo de capacidade adicional que ficaram no intervalo $\left[t_{0}, C_{1}\right]$ e que foram utilizados no processamento de $J_{1}, \sum_{\left\{t \in N: i_{t} \leq C_{1}\right\}} O_{1 t}$. Cada somatório utiliza limites diferentes pela possibilidade de $J_{1}$ ser finalizada em um intervalo de capacidade adicional $t^{*}$. Se for esse o caso, $W_{t^{*}}$ não deve ser utilizada para o cálculo de $C_{1}$, enquanto que $O_{1 t^{*}}$ deve; observe a Figura 17 para que a explicação fique mais clara.

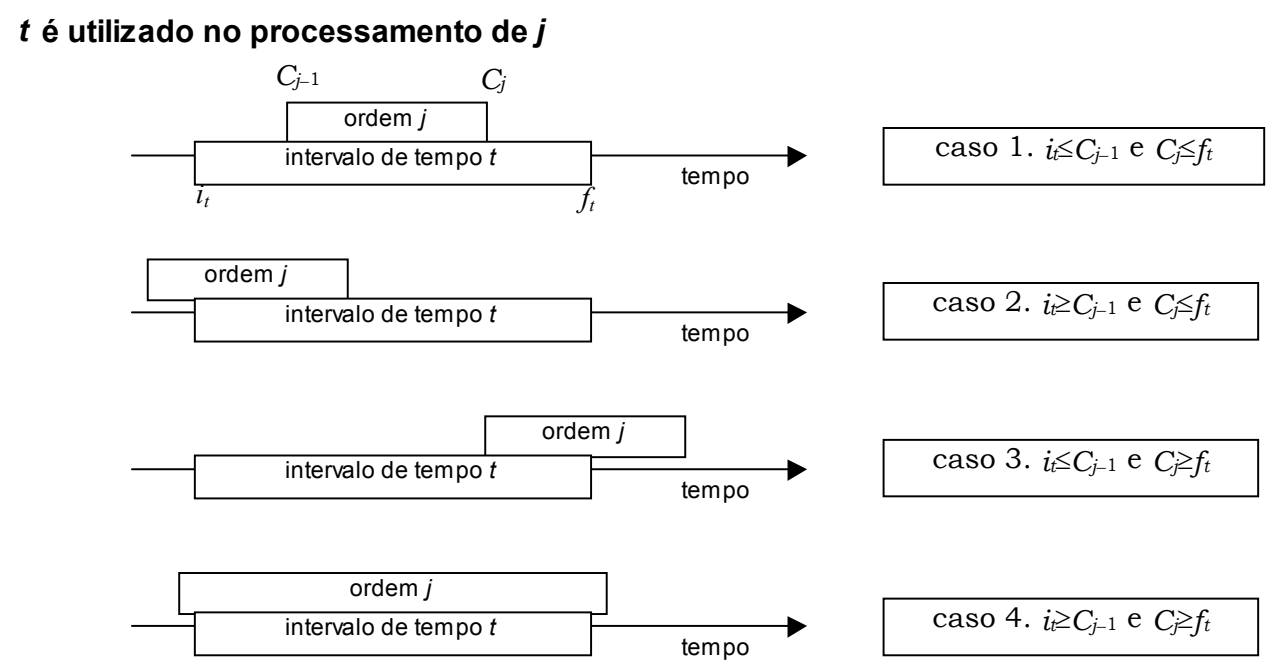

$t$ não é utilizado no processamento de $j$

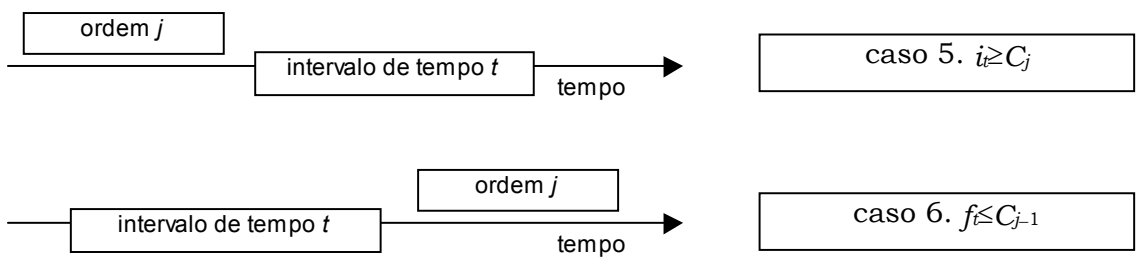

F íura 18 :Rehcinamentos possíveis entre intervabs de processam ento de ordens e ntervabs de tempo

Para $J_{j}, C_{j}$ é dependente do horário de término da ordem anterior, $C_{j-1}$; do tempo de espera em intervalos de capacidade normal utilizado antes de seu processamento, $W_{j}$; do tempo de processamento que aconteceu em intervalos 
de tempo pertencentes à capacidade normal, $p_{j}^{S}$; dos intervalos de tempo de capacidade adicional que ficaram no intervalo $\left(C_{j-1}, C_{j}\right]$ e que não foram utilizados no processamento de $J_{j}, \sum_{\left\{t \in N: C_{j-1}<f_{t} \leq C_{j}\right\}}$; e dos intervalos de tempo de capacidade adicional que ficaram no intervalo $\left(C_{j-1}, C_{j}\right]$ e que foram utilizados no processamento de $J_{j}, \sum_{\left\{t \in N:\left(C_{j-1}, C_{j}\right] \cap\left[i_{t}, f_{t}\right] \neq \varnothing\right\}} O_{j t} \cdot\left(C_{j-1}, C_{j}\right] \cap\left[i_{t}, f_{t}\right] \neq \varnothing$ é equivalente aos casos 1, 2, 3 e 4 da Figura 18. A observação feita para $J_{1}$ com relação ao possivel término num intervalo de capacidade adicional também é válida aqui.

Para um intervalo $t$, o total de capacidade adicional utilizado pode ser definido como $O_{t}=\sum_{j \in J} O_{j t}$. Para o caso de uma única máquina, nossa funçãoobjetivo vai ser definida como

$$
\min \sum_{j \in J}\left(h_{j} E_{j}+w_{j} T_{j}\right)+\sum_{t \in N} o_{t} O_{t}
$$

ao

$$
\text { passo que }
$$

para

múltiplas

máquinas, $\min \sum_{m \in M}\left\{\sum_{j \in J}\left(h_{j} E_{m j}+w_{j} T_{m j}\right)+\sum_{t \in N} o_{m t} O_{m t}\right\}$.

\subsection{Primeiro exemplo: idéia geral da solução proposta}

O exemplo apresentado nesta seção tenta fornecer ao leitor uma idéia geral do raciocínio utilizado para a construção do algoritmo.

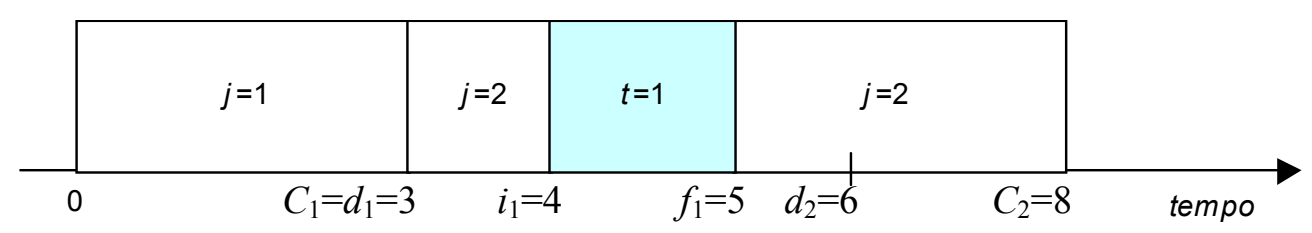

F giura 19 :P rim eiro exempb antes da inserção de capacìlade 


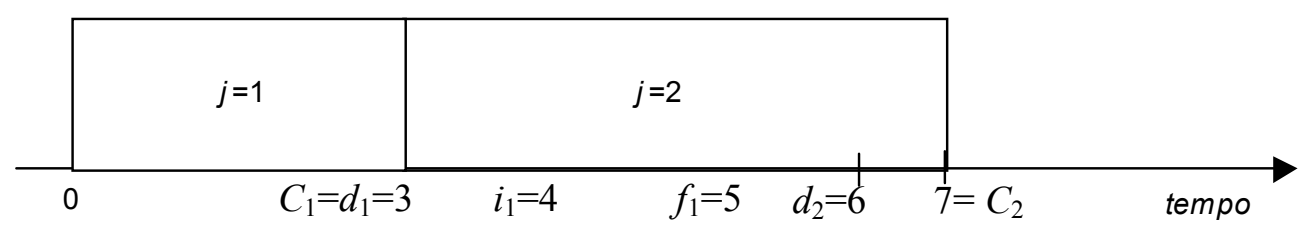

Fịura 20 :P rin eiro exem pb após a inserção de capacílade

Vamos supor um exemplo bem simples, onde existam 2 ordens e apenas um intervalo de capacidade adicional disponivel. Considere que $\left(p_{1}, d_{1}, w_{1}, h_{1}\right)=(3,3,6,8), \quad\left(p_{2}, d_{2}, w_{2}, h_{2}\right)=(4,6,6,8) \quad$ e $\quad\left(i_{1}, f_{1}, o_{1}\right)=(4,5,2)$. Fazendo a programação e utilizando o AIE, a Figura 19 apresenta o resultado alcançado.

$j=1$ não pode ser antecipada pois está começando no instante inicial. $j=2$ está atrasada em duas unidades de tempo, sendo que o custo desse atraso é $w_{2} \cdot T_{2}=6.2=12$. Observe que a utilização da capacidade adicional existente em $t=1$ pode fazer com que o custo total do programa diminua pois $o_{1}=2$. Então, a grosso modo, o que deve ser feito (e que o AIC faz) é trocar o custo de 6 unidades de atraso pelo custo de 2 unidades de utilização de capacidade adicional, promovendo uma economia de 4 unidades de custo. Dessa forma, o resultado é apresentado na Figura 20.

Neste ponto não se utiliza capacidade adicional pois não há mais capacidade adicional disponivel. Portanto o AIC é finalizado.

\subsection{Outros estudos correlacionados realizados previamente}

Ao que tudo indica, o primeiro estudo publicado de forma irrestrita que trata da hipótese da inserção de capacidade na programação da produção pertence a HOLLOWAY; NELSON (1974). Os autores trabalharam com o problema genérico de programação - não há uma configuração específica para as máquinas - onde, inicialmente, o objetivo é a minimização da utilização de horas-extras, sujeito às restrições de que todas as datas de entrega sejam satisfeitas e que todas as relações de precedência entre operações de uma mesma ordem sejam atendidas. Basicamente, a abordagem deles programa a fábrica de acordo com alguma regra de despacho com a utilização de uma 
quantidade ilimitada de horas-extras, fazendo assim com que não haja atraso. Depois disso, utilizam procedimentos melhorativos, onde considera-se que as horas-extras são limitadas e por conseqüência procuram diminuir sua utilização a patamares viáveis.

O trabalho tem continuidade com a geração de soluções Pareto-ótimas para a elaboração de fronteiras eficientes ${ }^{18}$ no problema atraso total $\mathrm{X}$ horasextras. Com essas curvas, o administrador pode ponderar as decisões entre níveis aceitáveis de atraso e de utilização de horas-extras. O trabalho sugere procedimentos análogos de implementação para o caso de chegadas dinâmicas de ordens. Como característica restritiva no estudo, pode-se citar a falta de uma preocupação com os custos de atraso e de horas-extras.

Um outro estudo, mais teórico, que trabalha com um tema análogo, pertence a GELDERS; KLEINDORFER (1974). Nesse estudo, GELDERS; KLEINDORFER trabalham com o seqüenciamento do conjunto de ordens em uma máquina com a possibilidade de utilização de horas-extras. Para П o conjunto de todas as seqüências possiveis, o problema abordado pelos autores pode ser definido como $\min \sum_{j \in\{J \subseteq \Pi\}}\left(w_{j} T_{j}+v_{j} C_{j}\right)+o \sum_{t \in N} O_{t}$, onde $J \subseteq \Pi$ representa uma seqüência qualquer dentre todas as possiveis para o conjunto de ordens disponíveis. Observe que, de maneira contrária ao tratado nesta tese, o problema possui função-objetivo regular ${ }^{19}$ e portanto a inserção de espera não pode fazer com que o valor da função-objetivo melhore. Dessa forma, a capacidade adicional que vai sendo utilizada é a que está disponível o mais cedo possivel.

GELDERS; KLEINDORFER sugerem a utilização do branch-and-cut para a solução do problema. Como de costume, o esforço dos autores se concentra na definição de bons limitantes com a finalidade de diminuir o tamanho do espaço de busca. Desconsiderando os nós eliminados pelos limitantes, a

${ }^{18}$ De acordo com WINSTON (1995, p. 751), as definições de Pareto-otimalidade e fronteiras eficientes são as seguintes:

Definição: Uma solução viável B domina uma solução viável $A$ em um problema de múltiplos objetivos se B é no mínimo tão boa quanto $A$ com relação a todos os objetivos e é estritamente melhor do que $A$ com relação a pelo menos um objetivo.

Definição: Soluções Pareto-ótimas são o conjunto de todas as soluções viáveis não-dominadas.

Definição: Se todas as soluções Pareto-ótimas são inseridas num gráfico, o gráfico é chamado uma fronteira eficiente.

${ }_{19}$ Uma função-objetivo regular é aquela que considera sempre preferível acabar uma atividade mais cedo, ao invés de mais tarde. Matematicamente, conforme CONWAY et al. (1967, p.12), é um valor a ser minimizado que pode ser expresso como uma função dos horários de término $M=f\left(C_{1}, C_{2}, \ldots, C_{|J|}\right)$ e que aumenta se no mínimo um dos horários de 
estrutura de solução varia todos os valores possiveis de $\sum_{t \in N} O_{t}$, onde para cada um desses valores, um procedimento tipo branch-and-cut é utilizado para se minimizar $\sum_{j \in\{J \subseteq \Pi\}}\left(w_{j} T_{j}+v_{j} C_{j}\right)$.

Mesmo com grande genialidade na criação dos procedimentos, um ponto que pode limitar em muitos casos a abordagem sugerida é que o programa gerado é preemptive-resume ${ }^{20}$.

Num outro trabalho que complementa o trabalho citado fazendo a implementação computacional dos procedimentos, GELDERS; KLEINDORFER (1975, p. 316) mencionam que os problemas resolvidos não excederam 12! elementos (por exemplo 12 niveis de horas-extras e 11 ordens) para um limite de 1 minuto de tempo computacional.

\subsection{Formulação do problema de programação da produção com capacidade variável via programação matemática}

A programação matemática pode ser utilizada para formular o problema de programação da produção de uma máquina descrito na seção 3.1. Embora seja sugerido um procedimento com tempo de solução polinomial mais adiante, a formulação via programação matemática pode deixar mais claros tanto o problema quanto os conceitos envolvidos.

A formulação abaixo define nosso problema:

(F1) $\min \sum_{j \in J}\left(h_{j} E_{j}+w_{j} T_{j}\right)+\sum_{t \in N}\left\{o_{t}\left(\sum_{j \in J} O_{j t}\right)\right\}$

sujeito a:

(1) $C_{j-1}+W_{j}+p_{j}^{S}+\sum_{\left\{t \in N: C_{j-1}<f_{t} \leq C_{j}\right\}} W_{t}+\sum_{\left\{t \in N:\left(C_{j-1}, C_{j}\right] \cap\left[i_{i}, f_{t}\right] \neq \varnothing\right\}} O_{j t}=C_{j} \quad(j \in J, j \neq 1)$

(2) $t_{0}+W_{j}+p_{j}^{S}+\sum_{\left\{t \in N: f_{t} \leq C_{j}\right\}} W_{t}+\sum_{\left\{t \in N: i_{t} \leq C_{j}\right\}} O_{j t}=C_{j} \quad(j=1)$

término aumenta; ou seja, se $M^{\prime}=f\left(C_{1}{ }^{\prime}, C_{2}{ }^{\prime}, \ldots, C_{\mid J}{ }^{\prime}\right)$, então $M^{\prime}>M$ só se $C_{j}^{\prime}>C_{j}$ para no mínimo um $j, 1 \leq j \leq|J|$.

${ }_{20}$ Uma tradução aceitável para preemption-resume é interrupção com retomada, isto é, uma ordem cujo processamento é interrompido pode ser finalizada posteriormente sem haver alteração no tempo de processamento da mesma. Em qualquer caso onde haja um tempo de preparação da máquina, quer seja esse tempo dependente da seqüência ou não, não se pode assumir a modelagem sugerida. 
(3) $C_{j}+E_{j}-T_{j}=d_{j}$

$(j \in J)$

(4) $W_{t}+\sum_{j \in J} O_{j t}=f_{t}-i_{t}$

(5) $p_{j}^{S}+\sum_{t \in N} O_{j t}=p_{j}$

$(j \in J)$

(6) $E_{j}, T_{j}, W_{j}, C_{j}, O_{j t}, W_{t} \in R_{+}$

$(j \in J, t \in N)$

A formulação apresentada utiliza $4|J|+3|N|+1$ valores constantes, $(5+|N|)|J|+|N|$ variáveis reais e $3|J|+|N|$ restrições, excluindo-se as de nãonegatividade. Na função-objetivo, $\sum_{t \in N}\left\{o_{t}\left(\sum_{j \in J} O_{j t}\right)\right\}$ representa o custo total da capacidade adicional utilizada. Observe que ela é equivalente à equação (3.2). A modificação aconteceu para que o modelo considerasse a hipótese de se processar mais de uma ordem em cada intervalo de capacidade adicional disponível.

As restrições tipo (1) e (2) definem os horários de término das ordens; são derivadas da equação (3.1). As restrições tipo (3) mostram os relacionamentos entre os adiantamentos, atrasos e datas de entrega. São derivadas das equações de definição de adiantamento e atraso. Explicações mais detalhadas da definição das mesmas podem ser encontradas na seção 2.7. As restrições tipo (4) especificam que o intervalo de capacidade adicional seja utilizado ou no processamento das ordens ou como tempo de espera. Considera a hipótese de várias ordens serem feitas em apenas um intervalo. Restrições tipo (5) relacionam o tempo de processamento em capacidade normal e adicional. As restrições tipo (6) são as de não-negatividade.

As restrições tipo (1) e (2) são especialmente dificeis pois dependem do valor de variáveis para serem construídas. A solução não é trivial embora existam modelagens na literatura bastantes parecidas como por exemplo o corte misto-inteiro de Gomory (NEMHAUSER; WOLSEY, 1988, p. 250). Uma forma de se safar dessa dificuldade é utilizar variáveis 0-1 associadas que permitem o mesmo resultado na formulação. Por outro lado a solução fica ainda mais dificil pois, além da introdução das variáveis 0-1, algumas restrições passam a ser não-lineares. Isso traz a necessidade da elaboração de procedimentos específicos para sua solução pois os procedimentos mais convencionais de solução não garantiriam a otimização global do problema. 
Com a finalidade de implementarmos uma solução em programação matemática mais adiante, apresentamos abaixo as transformações necessárias. Sejam $Y_{j t}$ e $X_{j t}$ variáveis 0-1 definidas como segue:

$$
\begin{gathered}
Y_{j t}=\left\{\begin{array}{l}
1 \text { se } C_{j-1}<f_{t} \leq C_{j} \text { para }\{j \in J, j \neq 1\} \\
1 \text { se } f_{t} \leq C_{j} \text { para } j=1 \\
0 \text { caso contrário, }
\end{array}\right. \\
X_{j t}=\left\{\begin{array}{l}
1 \text { se }\left(C_{j-1}, C_{j}\right] \cap\left[i_{t}, f_{t}\right] \neq \varnothing \text { para }\{j \in J, j \neq 1\} \\
1 \text { se } i_{t} \leq C_{j} \text { para } j=1 \\
0 \text { caso contrário. }
\end{array}\right.
\end{gathered}
$$

Utilizando essas variáveis na modelagem, a formulação pode ser redefinida como segue:

(F2) $\min \sum_{j \in J}\left(h_{j} E_{j}+w_{j} T_{j}\right)+\sum_{t \in N}\left\{o_{t}\left(\sum_{j \in J} O_{j t}\right)\right\}$

sujeito a:

(1) $C_{j-1}+W_{j}+p_{j}^{S}+\sum_{t \in N} W_{t} Y_{t}+\sum_{t \in N} O_{j t} X_{j t}=C_{j} \quad(j \in J, j \neq 1)$

(2) $t_{0}+W_{j}+p_{j}^{S}+\sum_{t \in N} W_{t} Y_{t}+\sum_{t \in N} O_{j t} X_{j t}=C_{j} \quad(j=1)$

(3) $C_{j}+E_{j}-T_{j}=d_{j} \quad(j \in J)$

(4) $W_{t}+\sum_{j \in J} O_{j t}=f_{t}-i_{t} \quad(t \in N)$

(5) $Y_{t}, X_{j t} \in\{0,1\} \quad(j \in J, t \in N)$

(6) $E_{j}, T_{j}, W_{j}, C_{j}, O_{j t}, W_{t} \in R_{+} \quad(j \in J, t \in N)$

Em F2, embora tenha havido a introdução de variáveis 0 -1, a construção das restrições tipo (1) e (2) não depende mais do valor de uma variável, simplificando em alguma medida a solução do problema. De qualquer forma, ambas, F1 e F2, podem ser implementadas, sendo que a escolha da melhor vai depender apenas do software e do método utilizado na solução.

Com a utilização de um software ${ }^{21}$ de programação matemática que se

21 Atualmente, diversos softwares com alta capacidade de solução e a preços relativamente baixos são disponíveis para esse fim. A LINDO Systems (http://www.lindo.com) por exemplo, comercializava em 10/10/1999 um software com capacidade ilimitada no número de variáveis e restrições (o limite é definido pela memória do computador) a 
utiliza de planilhas eletrônicas para a manipulação do modelo, F2 pode ser implementada diretamente. Apesar disso, não se garante a localização do ótimo global devido às não-linearidades das restrições. Para a localização do ótimo global devem ser desenvolvidos procedimentos específicos.

Na próxima seção será desenvolvido um algoritmo com tempo de solução polinomial que resolve o mesmo problema.

\subsection{Algoritmo de programação de uma máquina com possibilidade de inserção de capacidade no problema com função-objetivo do tipo $\sum_{j \in J}\left(h_{j} E_{j}+w_{j} T_{j}\right)+\sum_{t \in N} o_{t} O_{t}$}

O algoritmo descrito nesta seção, denominado Algoritmo de Inserção de Capacidade (AIC), considera que haja uma seqüência de ordens predefinida e que essa seqüência tenha sido programada de acordo com o AIE de GAREY et al. (1988), com sua devida adaptação ao caso onde existam custos de adiantamento e atraso. COLIN; SHIMIZU (2000) fazem essa adaptação e o capitulo anterior trata de um caso mais genérico ainda.

A idéia central do AIC é avaliar, bloco a bloco, o programa gerado pelo AIE. Nessa avaliação, o AIC pondera entre os custos ocorridos de adiantamento e atraso e uma possivel utilização de capacidade adicional para a realização das ordens, sabendo que essa capacidade adicional também possui custos associados. Dependendo do resultado dessa ponderação, as ordens podem ter seus horários de início e/ou término alterados, permitindo assim que novos blocos sejam formados.

Para ordens que estejam adiantadas deseja-se inserir capacidade após - término das mesmas, fazendo com que seus términos possam ser postergados, ao passo que para ordens que estejam atrasadas, deseja-se inserir capacidade antes do término das mesmas, fazendo com que seus términos possam ser antecipados.

US $\$ 4.995,00$. Dentre os softwares, os especialmente interessantes são os que funcionam como suplemento (subrotina) de planilhas eletrônicas comuns. A formulação é feita dentro da planilha e o software soluciona o problema utilizando algoritmos de programação linear, inteira e não-linear. Para detalhes de uma implementação em um problema de tamanho médio, vide COLIN et al. (1999). 
Seja $b \subseteq B$ um bloco qualquer, no qual o AIC irá trabalhar. Seja uma ordem $j \in b$. De maneira diferente do capitulo anterior, $j \in A u m(b)$ se $a_{j}>e_{j}$; $j \in \operatorname{Dim}(b)$ se $e_{j}>a_{j}$ e $j \in A u m D i m(b)$ se $e_{j}=a_{j}$.

Seja $K=\{1,2, \ldots\}$ um conjunto finito de índices e $b_{k} \subseteq b$ um bloco parcial $k \in K$, formado pelo máximo número de ordens concatenadas pertencentes ao bloco $b$ e que pertençam ao mesmo conjunto $(\operatorname{Aum}(b), \operatorname{Dim}(b)$ ou $\operatorname{AumDim}(b))$. A Tabela 6 mostra todas as configurações possíveis dos blocos parciais dentro de um bloco qualquer. Por exemplo, a coluna $b>1,|K|=1, b_{1}$ com apenas um $\mathrm{X}$ significa que para o caso de um bloco diferente do primeiro $(b>1)$, com apenas um bloco parcial $(|K|=1)$, haverá apenas a hipótese de $b_{1} \subseteq \operatorname{AumDim}(b)$. Neste exemplo especificamente, $b_{1}=b$ e $b_{1}=\operatorname{AumDim}(b)$.

\begin{tabular}{|c|c|c|c|c|c|c|c|c|c|c|c|c|}
\hline & \multicolumn{6}{|c|}{$b=1$} & \multicolumn{6}{|c|}{$b>1$} \\
\hline & \multirow{2}{*}{$\begin{array}{c}|K|=1 \\
b_{1}\end{array}$} & \multicolumn{2}{|c|}{$|K|=2$} & \multicolumn{3}{|c|}{$|K| \geq 3(i \in K ; i \neq 1,|K|)$} & \multirow{2}{*}{$\begin{array}{c}|K|=1 \\
b_{1}\end{array}$} & \multicolumn{2}{|c|}{$|K|=2$} & \multicolumn{3}{|c|}{$|K| \geq 3(i \in K ; i \neq 1,|K|)$} \\
\hline & & $b_{1}$ & $b_{2}$ & $b_{1}$ & $b_{I}$ & $b_{|K|}$ & & $b_{1}$ & $b_{2}$ & $b_{1}$ & $b_{i}$ & $b_{|K|}$ \\
\hline $\operatorname{Aum}(b)$ & & $\mathrm{X}$ & & $\mathrm{X}$ & $\mathrm{X}$ & & & $\mathrm{X}$ & & $\mathrm{X}$ & $\mathrm{X}$ & \\
\hline AumDim(b) & $\mathrm{X}$ & $\mathrm{x}$ & $\mathrm{X}$ & $\mathrm{X}$ & $\mathrm{X}$ & $\mathrm{x}$ & $\mathrm{X}$ & $\mathrm{X}$ & $\mathrm{X}$ & $\mathrm{X}$ & $\mathrm{X}$ & $\mathrm{X}$ \\
\hline $\operatorname{Dim}(b)$ & $\mathrm{X}$ & $\mathrm{X}$ & $\mathrm{X}$ & $\mathrm{X}$ & $\mathrm{X}$ & $\mathrm{X}$ & & & $\mathrm{X}$ & & $\mathrm{X}$ & $\mathrm{X}$ \\
\hline
\end{tabular}

Tabeh 6 : C onfigurações possíreis para os bbcos parcíis pertencentes ao bbco b

O raciocínio que se segue é fundamental para o desenvolvimento do AIC. Suponha que exista um bloco $b$ com diversos blocos parciais e que nesse bloco haja apenas um intervalo de tempo $t$ onde capacidade adicional pode ser utilizada. Em $t$ devemos fazer considerações acerca da movimentação das ordens de $b$ levando em conta a hipótese de se utilizar a capacidade adicional para diminuir os adiantamentos ou atrasos. Se for para a diminuição dos atrasos, apenas as ordens que estão terminando após $t$ deverão ser consideradas, ao passo que se for para a diminuição dos adiantamentos, apenas as ordens que estão terminando antes de $t$ deverão ser consideradas.

Tomando como base o raciocínio descrito acima, chamaremos a função $H\left(C_{\text {primeiro }\left(b_{k}\right)}, i_{t}\right)=\left\{\sum_{j \in \operatorname{Aum}(b)} h_{j}-\sum_{j \in\{\operatorname{Dim}(b) \cup \operatorname{AumDim}(b)\}} w_{j}: C_{\text {primeiro }\left(b_{k}\right)} \leq C_{j}<i_{t} ; b_{k} \subseteq \operatorname{Aum}(b)\right\}$ 
de diminuição do adiantamento com o postergamento das ordens com término pertencentes ao intervalo $\left[C_{\left.\text {primeiro(b } b_{k}\right)}, i_{t}\right)$ e

$$
W\left(i_{t}, C_{\text {ültimo }\left(b_{k}\right)}\right)=\left\{\sum_{j \in \operatorname{Dim}(b)} w_{j}-\sum_{j \in\{\operatorname{Aum}(b) \cup \operatorname{AumDim}(b)\}} h_{j}: i_{t}<C_{j} \leq C_{\text {ültimo }\left(b_{k}\right)} ; b_{k} \subseteq \operatorname{Dim}(b)\right\}
$$

de diminuição do atraso com a antecipação das ordens com término pertencentes ao intervalo $\left(i_{t}, C_{\text {último }\left(b_{k}\right)}\right]$.

Podemos dizer que para $\tau$ um instante qualquer, os valores de $H\left(\tau, i_{t}\right)$ e $W\left(i_{t}, \tau\right)$ especificam o quanto a movimentação das ordens que possuem horários de término pertencentes aos intervalos $\left[\tau, i_{t}\right)$ e $\left(i_{t}, \tau\right]$ podem alterar a funçãoobjetivo por unidade de movimentação. Pelo tipo de construção do algoritmo, desejamos encontrar os argumentos que maximizam $H\left(\tau, i_{t}\right)$ e $W\left(i_{t}, \tau\right)$. Vale lembrar mais uma vez que a posição de inserção de capacidade é dependente do estado das ordens que estão próximas à posição de inserção: para um grupo de ordens atrasadas, deseja-se inserir capacidade antes do término das mesmas e para um grupo de ordens adiantadas, deseja-se inserir capacidade após o término das mesmas. Como pode ser visto na definição das funções, uma ordem que tem seu término na data exata será considerada adiantada ou atrasada, dependendo se o cálculo é de $H\left(\tau, i_{t}\right)$ ou $W\left(i_{t}, \tau\right)$. Os lemas a seguir mostram que os intervalos $\left[C_{\text {primeiro }\left(b_{k}\right)}, i_{t}\right)$ e $\left(i_{t}, C_{\text {ultimo }\left(b_{k}\right)}\right]$ definem os máximos $H\left(\tau, i_{t}\right)$ e $W\left(i_{t}, \tau\right)$

Lema 3.122. Suponha que um intervalo de tempo definido por $\left[\tau, i_{t}\right)$ seja pertencente ao intervalo de processamento do bloco $b . H\left(\tau, i_{t}\right)$ terá o máximo valor quando $\tau=C_{\text {primeiro }\left(b_{k}\right)}$, onde $b_{k}$ é um bloco parcial de ordens adiantadas que tem pelo menos uma ordem terminada antes de $i_{t}$.

Demonstração: Vamos supor dois casos para serem analisados: $\tau \in \operatorname{Aum}(b)$ e $\tau \in\{\operatorname{Dim}(b) \cup \operatorname{AumDim}(b)\}$.

\footnotetext{
${ }^{22}$ Para um intervalo $t$ que pode ser utilizado como capacidade adicional, o lema 3.1 define os intervalos (começando em $\tau$ ) dentro do bloco $b$ que propiciam as melhores movimentações com relação à diminuição dos custos de adiantamento. O lema 3.2 é análogo ao lema 3.1 só que trata dos custos de atraso.
} 
Caso 1: $\tau \in \operatorname{Aum}(b)$. Se $\tau \in A u m(b)$, podemos dizer que $\tau \in b_{k}$, onde $b_{k}$ é um bloco parcial de ordens adiantadas de $b$. Tomando como base a equação (3.3) e considerando que

$$
\begin{gathered}
H\left(C_{\text {último }\left(b_{k}\right)-0}, i_{t}\right)=H\left(C_{\text {primeiro }\left(b_{k+1}\right)}, i_{t}\right)+\sum_{n=0}^{0} h_{\text {ultimo }\left(b_{k}\right)-n}, \\
H\left(C_{\text {último }\left(b_{k}\right)-1}, i_{t}\right)=H\left(C_{\text {primeiro }\left(b_{k+1}\right)}, i_{t}\right)+\sum_{n=0}^{1} h_{\text {último }\left(b_{k}\right)-n}, \\
H\left(C_{\text {último }\left(b_{k}\right)-2}, i_{t}\right)=H\left(C_{\text {primeiro }\left(b_{k+1}\right)}, i_{t}\right)+\sum_{n=0}^{2} h_{\text {último }\left(b_{k}\right)-n}, \\
\vdots \\
H\left(C_{\text {último }\left(b_{k}\right)-m}, i_{t}\right)=H\left(C_{\text {primeiro }\left(b_{k+1}\right)}, i_{t}\right)+\sum_{n=0}^{m} h_{\text {último }\left(b_{k}\right)-n},\left|b_{k}\right|>m \geq 0,
\end{gathered}
$$

podemos dizer que no máximo valor de $m$, isto é, $m=\left|b_{k}\right|-1$, $H\left(C_{\text {último }\left(b_{k}\right)-m}, i_{t}\right)=H\left(C_{\text {primeiro }\left(b_{k}\right)}, i_{t}\right)$ também alcança seu valor máximo, provando esta parte do lema.

Caso 2: $\tau \in\{\operatorname{Dim}(b) \cup A u m \operatorname{Dim}(b)\}$. Vamos supor sem perda de generalidade que $\tau \in b_{k-n}$, onde $n$ representa um número de blocos parciais que não estejam adiantados e que estão antes de $b_{k}$. A prova acontece considerando que o intervalo $\left[\tau, C_{\text {ultimo(b-n }}\right)$ faz com que o valor de $H\left(\tau, i_{t}\right)$ diminua, mostrando assim incoerência na sua utilização. Portanto, $H\left(C_{\text {primeiro }\left(b_{k}\right)}, i_{t}\right)>H\left(C_{\text {primeiro }\left(b_{k-n}\right)}, i_{t}\right)$, provando assim o lema.

Lema 3.2. Suponha que um intervalo de tempo definido por $\left(i_{t}, \tau\right]$ seja pertencente ao intervalo de processamento do bloco $b . W\left(i_{t}, \tau\right)$ terá o máximo valor quando $\tau=C_{\text {último }\left(b_{k}\right)}$, onde $b_{k}$ é um bloco parcial de ordens atrasadas que tem pelo menos uma ordem terminada depois de $i_{t}$.

Demonstração: A demonstração é análoga à demonstração do lema 3.1. 
O algoritmo é inicializado com uma entrada que é um programa definido pelo AIE. Com isso, podemos perceber que a entrada possui pelo menos um bloco onde esse(s) bloco(s) possui(em) pelo menos uma ordem cada.

O algoritmo começa trabalhar no primeiro bloco, indo progressivamente de um em um. Em cada bloco o algoritmo define blocos parciais e, utilizando esses blocos parciais, vai fazendo várias passadas, avaliando a viabilidade de se inserir capacidade adicional. Para garantir a otimização, o algoritmo trabalha progressivamente indo dos pontos mais viáveis de inserção de capacidade adicional para os menos viáveis. Para isso, em cada ponto viável, o algoritmo faz ponderações avaliando qual seria o ganho em se utilizar uma capacidade adicional. Em cada possivel intervalo de inserção de capacidade, esse ganho é calculado pela diferença entre a diminuição dos custos de adiantamento ou atraso, dependendo do caso, e o aumento no custo devido a inserção de capacidade adicional. A avaliação e inserção de capacidade adicional é feita até que acabe a capacidade adicional disponivel para ser utilizada, ou que em todos os pontos não haja viabilidade em se inserir capacidade adicional devido ao aumento do custo total.

Seja $a:=b$ a operação de atribuição do valor $b$ à variável $a$ e $A \leftarrow B$ a operação de atribuição do conjunto $B$ ao conjunto $A$, ou seja, $A(a)$ é definido como o $B(b)$, mantendo $B(b)$ inalterado. As variáveis que mantiverem um asterisco $\left(^{*}\right)$ serão associadas às posições e movimentações ótimas. Com a finalidade de termos um pouco mais de concisão notacional, define-se $t \in N_{b}=\left\{t \in N: e_{\text {primeiro(b) }} \leq i_{t} \leq C_{u}\right.$ uttimo(b) $\}$, isto é, os intervalos de tempo pertencentes ao bloco $b$. Com essas novas considerações, o algoritmo pode ser apresentado mais formalmente a seguir.

\section{A LG ORIMO DE NSERÇ ÃO DE CAPACDADE A I)}

Passo 1. Inicialização. Comece com um programa definido pelo AIE.

Passo 2. Iteração $b$. Para cada $b \subseteq B$, faça:

Passo 2.1. Localização dos intervalos. Defina todos os $t \in N_{b}$. Defina os blocos parciais existentes em $b$, verificando a qual conjunto eles pertencem: se a $\operatorname{Aum}(b), \operatorname{Dim}(b)$ ou $\operatorname{AumDim}(b)$. Se $j \in \operatorname{AumDim}(b)(\forall j \in b)$, então comece uma nova iteração indo para o passo 2. 
Passo 2.2. Localização do melhor intervalo. Para cada $t \in N_{b}$, calcule $H\left(C_{\text {primeiro }\left(b_{k}\right)}, i_{t}\right)-o_{t} \quad$ para todo $\quad\left\{b_{k} \subseteq \operatorname{Aum}(b): C_{\text {primeiro }\left(b_{k}\right)} \leq i_{t}\right\} \quad$ e $W\left(i_{t}, C_{\text {último }\left(b_{k}\right)}\right)-o_{t}$ para todo $\left\{b_{k} \subseteq \operatorname{Dim}(b): C_{u ́ \text { ultimo }\left(b_{k}\right)} \geq i_{t}\right\}$. Localize o $i_{t^{*}}$ e o $b_{k}^{*} \quad$ cujo $\quad L^{*}=\max \left\{H^{*}, W^{*}\right\}, \quad$ onde $H^{*}=\max \left\{H\left(C_{\text {primeiro }\left(b_{k}\right)}, i_{t}\right)-o_{t}: C_{\text {primeiro }\left(b_{k}\right)}<i_{t}, i_{t} \in N_{b}\right\} \quad$ e $W^{*}=\max \left\{W\left(i_{t}, C_{\text {último }\left(b_{k}\right)}\right)-o_{t}: C_{\text {último }\left(b_{k}\right)}>i_{t}, i_{t} \in N_{b}\right\}$. Se $H^{*}=W^{*}$, então $L^{*}=H^{*}$.

Passo 2.3. Inserção de capacidade no programa. Se $L^{*} \leq 0$, então comece uma nova iteração indo para o passo 2. Caso contrário, se $L^{*}=H^{*}$, calcule $\lambda=\left\{\min \left(C_{j}^{*}-C_{j}\right): C_{\text {primeiro }\left(b_{k}^{*}\right)} \leq C_{j} \leq i_{t^{*}} ; j \in A u m(b)\right\}$, ou se $L^{*}=W^{*}$ e $L^{*} \neq H^{*}, \quad$ calcule $\quad \lambda=\left\{\min \left(C_{j}-C_{j}^{*}\right): i_{t^{*}}<C_{j} \leq C_{\text {último }\left(b_{k}^{*}\right)} ; j \in \operatorname{Dim}(b)\right\} . \quad \mathrm{A}$ capacidade a ser inserida com início em $i_{t^{*}}$ é definida como $O_{t^{*}}=\min \left\{\lambda, f_{t^{*}}-i_{t^{*}}\right\}$. Recalcule os horários de término do programa que foram alterados.

Passo 2.4. Redefinição dos conjuntos capacidade adicional e capacidade adicional efetivamente utilizada. $O \leftarrow O \cup\left(O_{t^{*}}, t^{*}\right)$. Se $O_{t^{*}} \neq f_{t^{*}}-i_{t^{*}}$, então $i_{t^{*}}:=i_{t^{*}}+O_{t^{*}}$, caso contrário, $N_{b} \leftarrow N_{b} \backslash t^{*}$.

Passo 2.5. Redefinição dos blocos do programa.

Passo 2.5.1. Se $L^{*}=H^{*}$ e $C_{\text {primeiro }\left(b_{k}^{*}\right)} \neq C_{\text {primeiro(b) }}$, então particione o bloco $b$ em dois outros blocos. Para $i>b(i \in B), i:=i+1 . \quad C_{\text {último(b+1) }}:=C_{\text {último(b) }}$, $C_{\text {último(b) }}:=C_{\text {último }\left(b_{k-1}^{*}\right)}, C_{\text {primeiro( }(b+1)}:=C_{\text {primeiro }\left(b_{k}^{*}\right)}$. Reconfigure os blocos $b \mathrm{e}$ $b+1$ de modo que as características $W(b)<H(b)$ ou $e_{\text {primeiro }(b)}=0$ e $W(b+1)<H(b+1)$ se mantenham.

Passo 2.5.2. Se $L^{*}=W^{*}, L^{*} \neq H^{*}$ e $C_{\text {ultimo }\left(b_{k}^{*}\right)} \neq C_{u \text { ultimo }(b)}$, então particione o bloco $b$ em dois outros blocos. Para $i>b \quad(i \in B), \quad i=i+1$. $C_{\text {último }(b+1)}:=C_{\text {último }(b)}, \quad C_{\text {primeiro }(b+1)}:=C_{\text {primeiro }\left(b_{k+1}^{*}\right)}, \quad C_{\text {último(b) }}:=C_{\text {último }\left(b_{k}^{*}\right)}$. Reconfigure os blocos $b$ e $b+1$ de modo que as características $W(b)<H(b)$ ou $e_{\text {primeiro }(b)}=0$ e $W(b+1)<H(b+1)$ se mantenham. 


$$
\begin{aligned}
& \text { Passo 2.5.3. Se } L^{*}=H^{*} \text { e } C_{\text {primeiro }\left(b_{k}^{*}\right)}=C_{\text {primeiro(b) }} \text { ou se } L^{*}=W^{*} \text { e } \\
& C_{\text {último }\left(b_{k}^{*}\right)}=C_{\text {último }(b)} \text {, então reconfigure o bloco } b \text { de modo que as } \\
& \text { características } W(b)<H(b) \text { ou } e_{\text {primeiro }(b)}=0 \text { se mantenham. }
\end{aligned}
$$

Passo 2.5.4. Retorne para o passo 2.1.

Passo 3. Término. Fim.

O passo 2 é realizado em cada bloco, indo do primeiro ao último. Para um bloco $b$, o passo 2.1 define os intervalos de tempo candidatos à inserção de capacidade e os blocos parciais existentes em $b$.

O passo 2.2 calcula implicitamente todas (de acordo com os lemas $3.1 \mathrm{e}$ 3.2) as possibilidades de inserção de capacidade no bloco em análise e localiza a melhor delas. Para o caso onde $H^{*}=W^{*}$, define-se arbitrariamente que $L^{*}=H^{*}$, ou seja, a capacidade adicional vai ser inserida para diminuir o adiantamento.

O passo 2.3 avalia se uma capacidade adicional deve ser utilizada, e, se o for, define em que quantidade. Ela será ou o intervalo de tempo disponivel inteiro, ou um intervalo que faça com que se mude o ganho por unidade de movimentação, isto é, se mude $L^{*}$, perdendo assim a garantia de estarmos na movimentação mais vantajosa. Nada impede que nesse último caso, num passo futuro, a capacidade adicional seja inserida como continuidade do passo corrente. Nesse passo, mais uma vez, toma-se o cuidado de se considerar a hipótese $H^{*}=W^{*}$.

No passo 2.4 acrescenta-se o intervalo de capacidade adicional definido no passo 2.3 ao conjunto de capacidades adicionais que serão efetivamente utilizadas. Se o intervalo completo foi utilizado, o mesmo é retirado do conjunto de intervalos candidatos - intervalos disponiveis -; caso não tenha sido utilizado por completo, mantém-se o intervalo alterando-se apenas seu horário de início.

No passo 2.5 é feita a adaptação do bloco que foi alterado, mantendo-se as condições descritas na construção do $\operatorname{AIE}\left(H(b)>W(b)\right.$ ou $\left.e_{\text {primeiro(b) }}=0\right)$. Pode haver divisão do bloco em dois, conforme descrito nos passos 2.5.1 e 2.5.2. O passo 2.5.3 representa os casos onde o bloco não se divide. Não há 
reconfiguração do mesmo pois as características $H(b)>W(b)$ ou $e_{\text {primeiro(b) }}=0$ se mantém.

\subsection{Análise da otimalidade do Algoritmo de Inserção de Capacidade (AIC)}

Assim como na seção anterior, vamos considerar que o programa de entrada do AIC tenha sido definido pelo AIE. Mais uma vez não se considera a hipótese de alteração da seqüência.

Como visto anteriormente, o AIE minimiza a função-objetivo $\sum_{j \in J}\left(h_{j} E_{j}+w_{j} T_{j}\right)$. A prova agora tem que considerar que o AIC minimiza a função-objetivo definida por $\sum_{j \in J}\left(h_{j} E_{j}+w_{j} T_{j}\right)+\sum_{t \in N} o_{t} O_{t}$.

Um ponto-chave para a otimização da função-objetivo é considerar que as capacidades são adicionadas sempre internamente a um bloco, portanto fazendo com que os intervalos de tempo dos outros blocos sejam mantidos sem qualquer alteração.

Uma outra forma de se entender esse ponto-chave é considerar que a capacidade tem um relacionamento direto com o tempo de processamento. $\mathrm{O}$ aumento da capacidade tem o mesmo efeito da diminuição do tempo de processamento. O mesmo problema tratado aqui nesta tese provavelmente poderia ser resolvido considerando a hipótese de se diminuir o tempo de processamento das ordens, onde a diminuição promove um custo adicional.

Seja $\pi$ um programa viável qualquer, П o conjunto de todos os programas viáveis possiveis de serem gerados para a seqüência definida preliminarmente e $g\left(\pi^{*}\right)=\min _{\pi \subseteq \Pi} g(\pi)$ o valor da função-objetivo do programa ótimo. A proposição abaixo mostra um resultado importante para a minimização da funçãoobjetivo.

Proposição 3.1. Supondo que os blocos de um programa tenham sido programados de acordo com o AIE, a inserção de capacidade em um bloco $b \subseteq B$ não precisa considerar os outros blocos $i \subseteq B \backslash b$, e nem altera seus 
horários de início e de término. Isso faz com que a otimização individualizada de cada bloco leve a otimização do programa contendo todos os blocos. Mais formalmente,

$$
\begin{aligned}
g\left(\pi^{*}\right) & =\min \sum_{b \subseteq B} G(b) \\
& =\sum_{b \subseteq B}\left\{\min _{C_{j}, O_{t}}\left\{\sum_{j \in b}\left(h_{j} E_{j}+w_{j} T_{j}\right)+\sum_{t \in N_{b}} o_{t} O_{t}\right\}\right\} .
\end{aligned}
$$

Demonstração: Levando em conta que entre blocos existe, por definição, intervalos de espera, não haverá interesse em que um bloco considere a capacidade adicional pertencente a um outro bloco. Suponha dois blocos, o bloco $b$ e o bloco $b+1$. Suponha que estejamos interessados na inserção de capacidade no bloco $b$, onde essa capacidade tem um custo muito maior do que a capacidade de $b+1$, sendo portanto, num primeiro momento, mais interessante utilizar a capacidade de $b+1$ do que de $b$. Mesmo levando em consideração o baixo custo da capacidade adicional de $b+1$, podemos dizer que é mais interessante utilizarmos o período de espera entre $b$ e $b+1$ do que a capacidade adicional de $b+1$, supondo que a capacidade adicional possua um custo $o_{t}>0$. Como o AIE foi utilizado anteriormente e portanto a posição dos blocos é ótima, não há viabilidade em se utilizar os períodos de espera entre os blocos. O raciocínio pode ser generalizado por indução para um caso qualquer.

A prova de que a inserção de capacidade num bloco não altera os horários dos outros blocos pode ser obtida levando em conta que quando isso acontece, o horizonte de tempo interno ao bloco é expandido.

Suponha haver $N$ iterações até que o AIC termine a inserção de capacidade em um determinado bloco $b$. Cada iteração - isto é, inserção de capacidade - será representada por um indice entre colchetes, $[n](n=1, \ldots, N)$. Para a n-ésima iteração do AIC, a função-objetivo terá uma diminuição equivalente a $\Delta\left(b_{[n]}, O_{t_{[n]}^{*}}\right)=L_{b_{[n]}}^{*} O_{t_{[n]}^{*}}$, onde $b_{[n]}$ representa o estado do bloco $b$ após $n$ iterações. O AIC encontra os valores $O_{t_{[n]}^{*}}$ para os quais $\sum_{n=1}^{N} \Delta\left(b_{[n]}, O_{t_{[n]}^{*}}\right)$ seja máxima. 
Para a prova que o algoritmo otimiza a função-objetivo do problema em análise, podemos considerar que o algoritmo trabalha seqüencialmente, como um procedimento de solução de um problema de múltiplos estágios. Podemos considerar que cada inserção de capacidade gera um estado em nosso programa, lembrando que as inserções de capacidade são afetadas pelas inserções de capacidade já realizadas.

Como nosso algoritmo trabalha seqüencialmente, otimizando funçõesobjetivo parciais, e não a função-objetivo completa, a decomposição de funções será importante para a nossa prova. Em especial, as condições de Mitten descritas adiante (MITTEN, 1964 e NEMHAUSER, 1966) se aplicam ao nosso caso.

Definição. (Condições de Mitten) Para $g_{1}$ e $g_{2}$ funções de valores reais, as condições de Mitten podem ser definidas como segue:

Separabilidade. $g(\cdot)$ é separável se

$$
\begin{aligned}
g\left[h_{1}\left(y_{1}, x_{1}\right), h_{2}\left(y_{2}, x_{2}\right), \ldots,\right. & \left.h_{k}\left(y_{k}, x_{k}\right)\right]= \\
& g_{1}\left[h_{1}\left(y_{1}, x_{1}\right), g_{2}\left(h_{2}\left(y_{2}, x_{2}\right), h_{3}\left(y_{3}, x_{3}\right), \ldots, h_{k}\left(y_{k}, x_{k}\right)\right)\right] ;
\end{aligned}
$$

Monotonicidade. $g_{1}$ é uma função monotonamente não-decrescente de $g_{2}$ para todo $h_{i}(i=1, \ldots, k)$.

Teorema 3.1. (Decomposição) Para funções de valores reais $h_{i}(i=1, \ldots, k)$,

$$
\begin{aligned}
\max _{x_{1}, x_{2}, \ldots, x_{k}} g\left[h_{1}\left(y_{1}, x_{1}\right), h_{2}\left(y_{2}, x_{2}\right), \ldots, h_{k}\left(y_{k}, x_{k}\right)\right] \\
\quad=\max _{x_{1}} g_{1}\left[h_{1}\left(y_{1}, x_{1}\right), \max _{x_{2}, x_{3}, \ldots, x_{k}} g_{2}\left(h_{2}\left(y_{2}, x_{2}\right), h_{3}\left(y_{3}, x_{3}\right), \ldots, h_{k}\left(y_{k}, x_{k}\right)\right)\right],
\end{aligned}
$$

se as condições de Mitten se aplicam à função $g(\cdot)$.

Demonstração: A demonstração pode ser encontrada em NEMHAUSER (seção 2.9). 
Em cada passo, o AIC procura pela decisão que minimiza a funçãoobjetivo no instante da tomada de decisão considerando um passo, conforme pode ser visto no "passo 2.2" do AIC, sem se importar se a decisão atual pode prejudicar uma otimização global; as decisões são ótimas para subproblemas. Esse procedimento, embora aparentemente míope, leva a otimização global, conforme pode ser visto adiante.

Teorema 3.2. O processo de decisão seqüencial utilizado pelo AIC leva à otimização do problema em análise.

Demonstração: Pode haver dois casos de alteração dos blocos considerados pelo AIC: a inserção de capacidade em um bloco pode promover sua divisão ou não. Esta prova é para o caso onde aconteçam múltiplas inserções sem que o bloco se divida. Observe que esta mesma prova se aplica ao caso onde acontece um certo número de inserções e o bloco se divide.

Como após cada inserção de capacidade, o AIC reotimiza os adiantamentos e atrasos ponderados, podemos considerar que nosso problema seja definir uma seqüência de valores de capacidades a serem adicionadas $O_{t_{11]}^{*}}, O_{t_{[2]}^{*}}, \ldots, O_{t_{[N]}^{*}}$, de modo que a diminuição da função-objetivo seja máxima. Para $f_{[N]}\left(b_{[N]}\right)$ a diminuição máxima da função-objetivo após o AIC ter inserido capacidade no bloco $b$, nosso problema pode ser reespecificado como

$$
f_{[N]}\left(b_{[N]}\right)=\max _{O_{t[1]}, O_{t[2]}, \ldots, O_{t[N]}} \sum_{n=1}^{N} \Delta\left(b_{[N+1-n]}, O_{t_{[N+1-n]}}\right) \text {, }
$$

ou de forma mais elegante,

$$
f_{[N]}\left(b_{[N]}\right)=\max _{O_{t]}}\left\{\Delta\left(b_{[N]}, O_{t_{[N]}}\right)+f_{[N-1]}\left(b_{[N-1]}\right)\right\} \operatorname{com} f_{[1]}\left(b_{[1]}\right)=\max _{O_{t_{11}}}\left\{\Delta\left(b_{[1]}, O_{t_{[1]}}\right)\right\} .
$$

Como uma função de múltiplas somas é separável e $f_{[M]}\left(b_{[M]}\right)$ é uma função monotonamente não-decrescente de $f_{[N-1]}\left(b_{[N-1]}\right)$, as condições de Mitten se aplicam e portanto o teorema 3.1 também. Assim, $f_{[M]}\left(b_{[N]}\right)$ pode ser rescrita como

$$
f_{[N]}\left(b_{[N]}\right)=\max _{O_{t_{[N]}}}\left\{\Delta\left(b_{[N]}, O_{t_{[N]}}\right)+\max _{O_{t[N-1]}}\left\{\Delta\left(b_{[N-1]}, O_{t_{[N-1]}}\right)+\ldots+\max _{O_{\left.t^{1}\right]}}\left\{\Delta\left(b_{[1]}, O_{t_{[1]}}\right)\right\} \ldots\right\}\right\},
$$


evidenciando-nos claramente como o algoritmo toma as decisões ótimas na escolha de $O_{t_{[n]}^{*}}=\arg \max _{O_{t_{[n]}}}\left\{\Delta\left(b_{[n]}, O_{t_{[n]}}\right)\right\} \quad(n=1, \ldots, N)$ para determinar $f_{[N]}\left(b_{[M]}\right) . \quad / / / /$

Lema 3.3. (Inserção de capacidade ótima no passo) Para um bloco inicial $b$ definido pelo AIE, o AIC minimiza a função-objetivo $\sum_{j \in b}\left(h_{j} E_{j}+w_{j} T_{j}\right)+\sum_{t \in N_{b}} o_{t} O_{t}$ para um limite 23 de inserção de capacidade de $O_{t^{*}}=\min \left\{\lambda, f_{t^{*}}-i_{t^{*}}\right\}$, por intermédio da inserção de capacidade adicional e movimentação dos blocos.

Demonstração: Suponha um bloco $b$ qualquer que tenha sido definido pelo AIE. O AIC pode inserir capacidade ou não.

Caso 1. AIC não insere capacidade. O AIC não vai inserir capacidade caso $L^{*} \leq 0$. Se isso acontecer é porque para $t \in N_{b}$, não há nenhum agrupamento de blocos parciais que faça com que a soma de seus custos seja maior do que ot e portanto não há um ponto onde seja vantajoso utilizar capacidade adicional. Como o AIE minimiza $\sum_{j \in b}\left(h_{j} E_{j}+w_{j} T_{j}\right)$, se não houver valor de ot que faça $\sum_{j \in b}\left(h_{j} E_{j}^{A I C}+w_{j} T_{j}^{A I C}\right)+\sum_{t \in N_{b}} o_{t} O_{t}<\sum_{j \in b}\left(h_{j} E_{j}+w_{j} T_{j}\right)$, a função-objetivo está minimizada para o bloco $b$.

Caso 2. AIC insere capacidade. O AIC vai inserir capacidade caso $L^{*}>0$. O algoritmo define que a quantidade de capacidade a ser inserida é $O_{t^{*}}=\min \left\{\lambda, f_{t^{*}}-i_{t^{*}}\right\}$, ou seja, a máxima quantidade de capacidade adicional de modo que $L^{*}$ não tenha seu valor alterado.

Caso 2a. $L^{*}=H^{*}$. Neste caso, $\lambda=\left\{\min \left(C_{j}^{*}-C_{j}\right): C_{\text {primeiro }\left(b_{k}^{*}\right)} \leq C_{j} \leq i_{t^{*}}\right\}$. Vamos supor que ao invés de $O_{t^{*}}$ seja inserida uma quantidade $\delta$ de capacidade adicional. Pode haver 4 casos: (1) Se $\delta<O_{t^{*}}=\lambda$, então $\Delta(b, \delta)<\Delta\left(b, O_{t^{*}}\right)$ e portanto a função-objetivo fica maior. (2) Se $\delta>O_{t^{*}}=\lambda$,

${ }^{23}$ A especificação do limite aconteceu para não haver confusão entre a otimização da função-objetivo num bloco com vários passos e a otimização da função-objetivo considerando um passo apenas. 
então pelo menos uma ordem passou de $\operatorname{Aum}(b)$ para $\operatorname{AumDim}(b)$ ou $\operatorname{Dim}(b)$, fazendo com que o valor de $L^{*}$ diminua, perdendo assim a garantia de ser a melhor movimentação. (3) Se $\delta<O_{t^{*}}=f_{t^{*}}-i_{t^{*}}$, o raciocínio é análogo ao caso (1). (4) Se $\delta>O_{t^{*}}=f_{t^{*}}-i_{t^{*}}$, há inconsistência na hipótese pois $\delta \leq f_{t^{*}}-i_{t^{*}}$, visto que $f_{t^{*}}-i_{t^{*}}$ é o intervalo completo. Após isso, o algoritmo movimenta o (os) bloco (s) de modo que $\sum_{j \in b}\left(h_{j} E_{j}+w_{j} T_{j}\right)$ seja mínima, provando o caso 2a.

Caso 2b. $L^{*}=W^{*}$. Neste caso, $\lambda=\left\{\min \left(C_{j}-C_{j}^{*}\right): i_{t^{*}}<C_{j} \leq C_{\text {ultimo }\left(b_{k}^{*}\right)}\right\}$. A prova é equivalente ao caso 2a. Os 4 caso são os seguintes: (1) Se $\delta<O_{t^{*}}=\lambda$, então $\Delta(b, \delta)<\Delta\left(b, O_{t^{*}}\right)$ e portanto a função-objetivo fica maior. (2) Se $\delta>O_{t^{*}}=\lambda$, então pelo menos uma ordem passou de $\operatorname{Dim}(b)$ para $\operatorname{AumDim}(b)$ ou $\operatorname{Aum}(b)$, fazendo com que o valor de $L^{*}$ diminua, perdendo assim a garantia de ser a melhor movimentação. (3) O raciocínio é análogo ao caso (1). (4) Idem a (4) do caso 2a. Após isso, o algoritmo movimenta o(s) bloco(s) de modo que $\sum_{j \in b}\left(h_{j} E_{j}+w_{j} T_{j}\right)$ seja mínima. Isso termina a prova do lema para este último caso possivel.

/ / /

Utilizando os resultados descritos anteriormente, podemos finalmente provar a otimalidade do AIC com o teorema adiante.

Teorema 3.3. Após o término do AIC, há um programa ótimo dentre todos os possiveis de serem gerados para a seqüência inicial de ordens $J$, considerando a capacidade adicional disponível.

Demonstração: O lema 3.3 juntamente com o teorema 3.2 mostram que acontece uma inserção de capacidade ótima em cada bloco avaliado pelo AIC. Considerando a proposição 3.1 (que mostra que a inserção de capacidade otimizada em cada bloco leva a otimização do programa) e que o AIC trabalha iterativamente de bloco em bloco, podemos deduzir que o teorema é verdadeiro. 
Observe que não há necessariamente apenas um ótimo, especialmente quando $H(b)=W(b)$ para algum $b \subseteq B$. Pelo tipo de problema, devido a continuidade da variável tempo, quando existir mais do que um ótimo, haverá infinitos programas que possuem custo mínimo.

\subsection{Implementação computacional do AIC}

Esta seção propõe pseudocódigos para a implementação do AIC sugerido na seção 3.4. Serão utilizadas operações equivalentes às operações descritas no capítulo 2 e também algumas operações matriciais. Para cada bloco parcial a ser gerado, será mantida uma matriz que vai possuir as mesmas características das filas de prioridade utilizadas nos blocos.

Como o algoritmo é relativamente grande, optou-se por utilizar procedimentos auxiliares que são descritos a seguir. Nos próximos 8 procedimentos, $n$ representa o número de elementos da fila de prioridade $P \mathrm{e}$ $m$ representa o número de intervalos de capacidade adicional que são pertencente ao intervalo de processamento das ordens contidas em $P$.

Procedimento 1. LocalizaIntervalos $(P) . O(m)$. Procedimento que localiza os intervalos de capacidade adicional que são pertencentes ao intervalo de tempo utilizado pelas ordens pertencentes à matriz $P$ e apresenta-os, gerando um conjunto de intervalos.

Procedimento 2. DefineBlocosParciais $(P)$. $O(n)$. Procedimento que define os blocos parciais para o bloco que é representado pela matriz $P$.

Procedimento 3. LocalizaMelhorInserção(P). $O(n m)$. Procedimento que localiza a melhor inserção a ser realizada em $P$, apresentando três valores como saída: O intervalo de melhor inserção, o bloco parcial que permite a melhor inserção e o máximo valor do ganho por unidade de movimentação.

Procedimento 4. CalculaIntervaloMáx $(a, b)$. $O(n)$. Procedimento que calcula o intervalo de movimentação máximo entre os instantes $a$ e $b$, de modo que as ordens não mudem de conjuntos.

Procedimento 5. Insere $(a, b, P) . O(\log n)$. Procedimento que insere os itens de chave $a$ e $b$ na fila de prioridade $P$. 


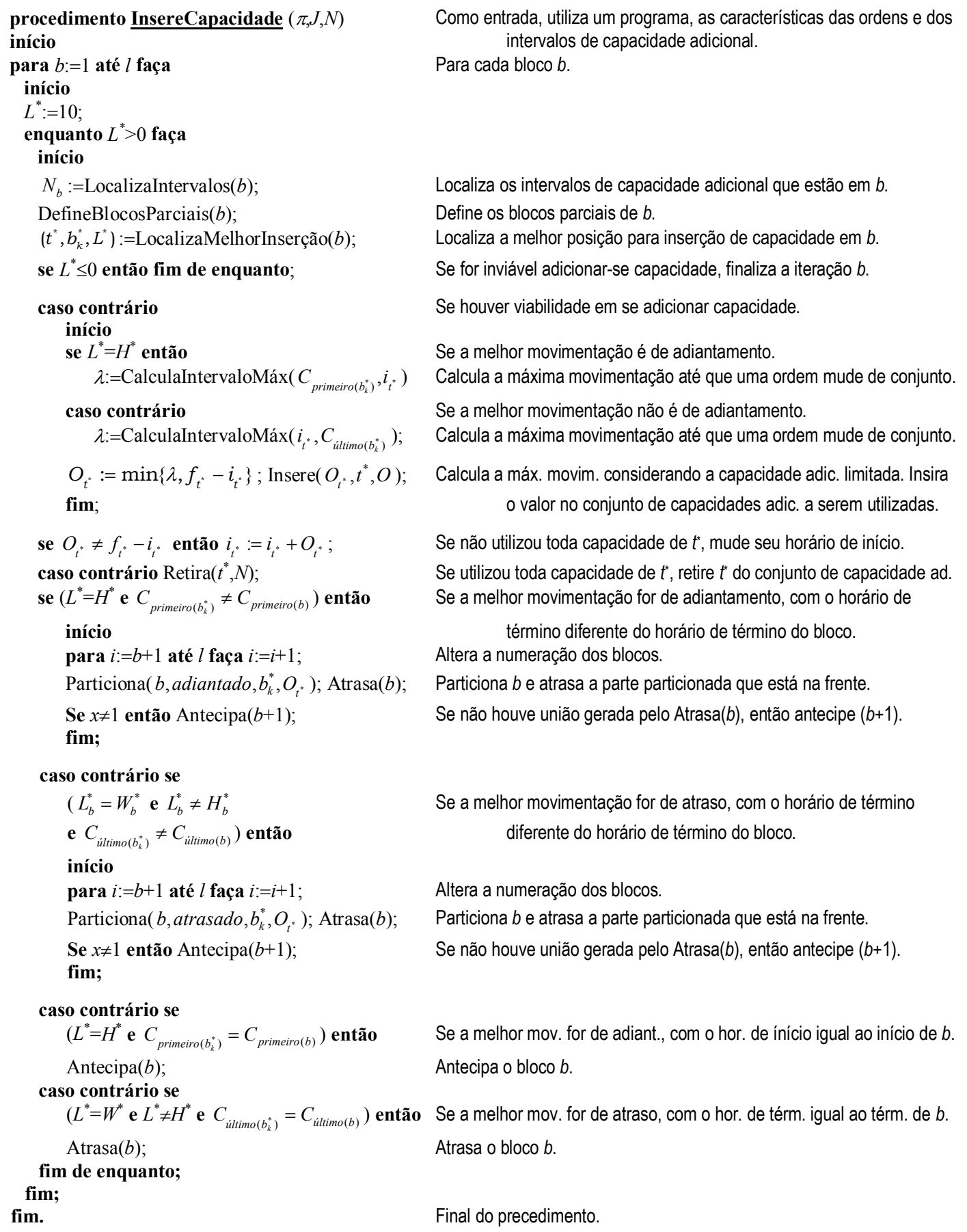

Fìura 21:P seudocódigo do A I

Procedimento 6. Retira $(a, P)$. $O(\log n)$. Retira o elemento $a$ da fila de prioridade $P$, onde a fila de prioridade $P$ é caracterizada por uma tripla ordenada. 
Procedimento 7. Particiona $\left(P_{1}, a, P_{2}, b\right)$. $O(n)$. A fila de prioridade $P_{1}$ é transformada em duas outras filas de prioridade. A partição da fila de prioridade $P_{1}$ considera que o bloco parcial de valor ótimo representado pela fila de prioridade $P_{2}$ esteja a (ou atrasado ou adiantado), e utiliza uma quantidade de capacidade adicional $b$.

Procedimento 8. Atrasa $(P) . O(n \log n)$. Atrasa a fila de prioridade $P$. O procedimento é equivalente ao procedimento antecipa, apresentado na Figura 7. Deixa a fila de prioridade $P$ com as propriedades de $W(P)<H(P)$ ou $e_{\text {primeiro }(P)}=0$. Neste procedimento existe uma variável $x$ de saída que indica se houve ou não união de blocos. Se $x=1$, houve união, caso contrário, não houve.

A Figura 21 apresenta o pseudocódigo do AIC utilizando todos os procedimentos descritos anteriormente.

Após o término do algoritmo, todas as ordens de $J$ estarão inseridas em $l$ blocos. O programa final é elaborado de acordo com os horários de término e as capacidades adicionais utilizadas definidas pelo AIC. As capacidades adicionais que serão efetivamente utilizadas são definidas como os intervalos $\left[i_{t}, i_{t}+O_{t}\right]$ para cada $t \in O$.

O procedimento do anel interno que mais demanda tempo no algoritmo apresentado anteriormente é o 3, com tempo $O\left(|b|\left|N_{b}\right|\right.$ ) (isto é, o número de ordens vezes o número de intervalos de capacidade adicional do bloco). No pior caso o comando de controle "enquanto" será realizado $|b|\left|N_{b}\right|$ vezes. Portanto, para cada bloco, o tempo será definido como $O\left(|b|^{2}\left|N_{b}\right|^{2}\right)$. Como haverá $l$ blocos, o tempo total pode ser definido como $\sum_{b=1}^{l}\left\{|b|^{2}\left|N_{b}\right|^{2}\right\}$. Queremos saber quando a soma tem seu maior valor para definir o limitante de tempo. Para deixar mais clara a solução, chamaremos $|b|$ de $x_{b}$ e $\left|N_{b}\right|$ de $y_{b}$. O valor máximo da soma pode ser encontrado por intermédio dos multiplicadores de Lagrange (LUENBERGER, 1984, cap. 10). Para tanto, podemos dizer que o problema seja

$$
\begin{gathered}
\max _{l, x_{b}, y_{b}} \sum_{b=1}^{l}\left(x_{b}^{2} y_{b}^{2}\right) \\
\text { sujeito a } \sum_{b=1}^{l} x_{b}-|J|=0
\end{gathered}
$$




$$
\begin{aligned}
& \sum_{b=1}^{l} y_{b}-|T|=0 \\
& x_{b} \geq 1, y_{b} \geq 0 \quad(b=1, \ldots, l) .
\end{aligned}
$$

Num primeiro momento os dois últimos grupos de restrições podem ser desconsiderados. Se a solução com a desconsideração atender às restrições, então a solução é ótima, ou seja, as restrições não estão ativas.

A função Lagrangeana, $L$, associada ao problema acima é definida como

$$
L=\sum_{b=1}^{l}\left(x_{b}^{2} y_{b}^{2}\right)+\lambda_{1}\left(\sum_{b=1}^{l} x_{b}-|J|\right)+\lambda_{2}\left(\sum_{b=1}^{l} y_{b}-|T|\right),
$$

e por conseqüência: $\frac{\partial L}{\partial x_{b}}=2 x_{b} y_{b}^{2}+\lambda_{1}=0 \quad(b=1, \ldots, l), \quad \frac{\partial L}{\partial y_{b}}=2 x_{b}^{2} y_{b}+\lambda_{2}=0$ $(b=1, \ldots, l), \frac{\partial L}{\partial \lambda_{1}}=\sum_{b=1}^{l} x_{b}-|J|=0$ e $\frac{\partial L}{\partial \lambda_{2}}=\sum_{b=1}^{l} y_{b}-|T|=0$. A solução não pode ser encontrada pelo método convencional de solução de sistemas de equações pois temos $2 l+3$ variáveis $\left(x_{b}, y_{b}, l, \lambda_{1}, \lambda_{2}\right)(b=1, \ldots, l)$ e $2 l+2$ equações. Com uma análise mais detalhada do sistema de equações podemos perceber que $x_{1} y_{1}^{2}=x_{2} y_{2}^{2}=\ldots=x_{l} y_{l}^{2}$ e $x_{1}^{2} y_{1}=x_{2}^{2} y_{2}=\ldots=x_{l}^{2} y_{l}$. Considerando que $x_{b}$ e $y_{b}$ são inteiros, a única solução possível para qualquer valor de $l$ é $x_{1}=x_{2}=\ldots=x_{l}=x$ e $y_{1}=y_{2}=\ldots=y_{l}=y$. Dessa forma as equações $\sum_{b=1}^{l} x_{b}-|J|=0$ e $\sum_{b=1}^{l} y_{b}-|T|=0$ podem ser transformadas em $x=|J| / l$ e $y=|T| / l$ atendendo às restrições $x_{b} \geq 1$ e $y_{b} \geq 0$. Assim $\max \sum_{b=1}^{l}\left(x_{b}^{2} y_{b}^{2}\right)=\sum_{b=1}^{l}\left(\left(\frac{|J|}{l}\right)^{2}\left(\frac{|T|}{l}\right)^{2}\right)=\frac{|J|^{2} \cdot|T|^{2}}{l^{3}}$.

Como $1 \leq l \leq|J|$, podemos dizer que o tempo de solução computacional do AIC no pior caso é definido por

$$
\sum_{b=1}^{l}\left\{|b|^{2}\left|N_{b}\right|^{2}\right\}=\frac{|J|^{2} \cdot|T|^{2}}{l^{3}}=O\left(|J|^{2} \cdot|T|^{2}\right) .
$$

\subsection{Exemplos de funcionamento do AIC}

Nesta seção são apresentados dois exemplos de funcionamento do AIC. Anteriormente, na seção 3.2, apresentou-se um caso bem simples que tenta 
ser bastante intuitivo. O segundo exemplo mostrado nesta seção é um pouco mais complexo e tenta mostrar mais detalhadamente o funcionamento do AIC. O terceiro mostra um caso onde acontece a divisão de um bloco após a inserção de capacidade adicional.

\subsubsection{Segundo exemplo: noção geral de funcionamento com detalhamento}

Seja um conjunto de ordens já seqüenciado $J$, com características definidas na Tabela 7 . A Tabela 8 fornece as características dos intervalos de capacidade adicional associados ao conjunto de ordens e disponiveis para serem utilizados. Todas as ordens estão disponíveis em $t_{0}=0$.

Vamos avaliar o programa gerado nos dois casos: o primeiro sem e o segundo com a utilização a utilização de capacidade adicional.

\begin{tabular}{ccccc}
\hline$j$ & $p_{j}$ & $d_{j}$ & $h_{j}$ & $w_{j}$ \\
\hline 1 & 40 & 50 & 4 & 3 \\
2 & 50 & 70 & 4 & 6 \\
3 & 60 & 220 & 5 & 5 \\
4 & 20 & 250 & 3 & 2 \\
\hline
\end{tabular}

Tabeł 7:D ados das ordens do segundo exempb para ńserção de capacìlade

\begin{tabular}{cccc}
\hline$t$ & $i_{t}$ & $f_{t}$ & $o_{t}$ \\
\hline 1 & 25 & 29 & 1 \\
2 & 42 & 45 & 2 \\
3 & 74 & 95 & 2 \\
4 & 180 & 190 & 4 \\
5 & 228 & 248 & 1 \\
\hline
\end{tabular}

Tabeh 8 :D ados dos nitervabs de tempo disponíreis do segundo exempb para ńserção de capacilade

Por uma questão de comparação será calculado inicialmente o valor da função-objetivo do programa sem a inserção de espera, sem a utilização de capacidade adicional e com as ordens começando o mais cedo possivel. A 
Tabela 9 ilustra o resultado alcançado. Observe que os horários de término são calculados de acordo com a equação (3.1).

\begin{tabular}{ccccc}
\hline$j$ & $C_{j}$ & $E_{j}$ & $T_{j}$ & $h_{j} E_{j}+w_{j} T_{j}$ \\
\hline 1 & 47 & 3 & 0 & 12 \\
2 & 118 & 0 & 48 & 288 \\
3 & 178 & 42 & 0 & 210 \\
4 & 208 & 42 & 0 & 126 \\
& & & total & 636 \\
\hline
\end{tabular}

Tabel 9 :C ákub do segundo exempb sem possbilidade de niserção de espera

Vamos agora utilizar o AIE para elaborar o programa, desconsiderando a hipótese de se utilizar a capacidade adicional que está disponível. Inicialmente $j=1$ é programada para ser finalizada em sua data de entrega pois há folga e ela pode ser iniciada em $e_{1}=3$. Portanto $W_{1}=3$. Mesmo iniciando $j=2$ imediatamente após $j=1$ ser finalizada, isto é, $e_{2}=C_{1}, j=1$ é finalizada atrasada. Como o $\left(H(1)=h_{1}=4\right) \leq\left(W(1)=w_{2}=6\right)$, o bloco $b=1$ composto das ordens $j=1$ e $j=2$ é antecipado enquanto a inequação for verdadeira ou o horário inicial seja 0 e portanto não haja mais possibilidade de se adiantar o bloco. Aqui o bloco é antecipado até que $e_{1}=0$.

Como $j=3$ está relativamente folgada, ela consegue ser finalizada em $d_{3}$, isto é, $C_{3}=d_{3}=220$. Por conseqüência, $e_{3}=150, W_{3}=32, H(2)=h_{3}=5$ e $W(2)=0$. Como o $a_{4}<C_{3}, j=4$ é introduzida em bloco $b=2$, sendo finalizada em $C_{4}=260$ e fazendo com que $W(2)=w_{4}=2$. Como $(H(2)=5)>(W(2)=2)$, o bloco não é antecipado e o programa está finalizado.

\begin{tabular}{cccccc}
\hline$j$ & $W_{j}$ & $C_{j}$ & $E_{j}$ & $T_{j}$ & $h_{j} E_{j}+w_{j} T_{j}$ \\
\hline 1 & 0 & 47 & 3 & 0 & 12 \\
2 & 0 & 118 & 0 & 48 & 288 \\
3 & 32 & 220 & 0 & 0 & 0 \\
4 & 0 & 260 & 0 & 10 & 20 \\
& & & & total & 320 \\
\hline
\end{tabular}

Tabeł 10 :C álub do segundo exempb com possbililade de ṅserção de espera

A Tabela 10 apresenta resumidamente os resultados alcançados. Podemos perceber que existem dois blocos definidos como: $B_{1}=\left\{J_{1}, J_{2}\right\}$ e $B_{2}=\left\{J_{3}, J_{4}\right\}$. 
Utilizando o pseudocódigo do AIC definido na Figura 21, resolvemos o mesmo problema com a possibilidade de inserção de capacidade. A entrada do algoritmo vai ser o programa definido pelo AIE, conforme Tabela 10. Alguns dos passos intermediários são apresentados abaixo:

Passo 1. Iteração 1. $b:=1 . N_{1}:=\{t=1, t=2, t=3\}$.

Definição dos blocos parciais de $b$ : Para $j:=1, J_{1} \in b_{1} \subseteq A u m(b)$; Para $j:=2$, $J_{2} \in b_{2} \subseteq \operatorname{Dim}(b)$.

Localização do melhor intervalo de $b$ : (Será feita uma busca no bloco $b$ identificando a posição de melhor inserção)

Para $t:=1$ :

$\left\{b_{k} \subseteq \operatorname{Aum}(b): C_{\text {primeiro }\left(b_{k}\right)} \leq i_{t}\right\}:=\varnothing$; (Não há viabilidade nessa hipótese pois não há nenhuma ordem no bloco $b$ com término adiantado que está localizada antes de $i_{1}$ )

$\left\{b_{k} \subseteq \operatorname{Dim}(b): C_{\text {ultimo }\left(b_{k}\right)} \geq i_{t}\right\}:=b_{2}, W\left(i_{1}, C_{2}\right)-o_{1}:=6-4-1:=1 ;$ (Considerou-se $b_{2}$ pois esse bloco parcial, que possui apenas a ordem $j=2$, está com o término atrasado e $t=1$ está localizado antes do término da ordem, portanto fazendo com que seja possivel antecipar seu término)

Para $t:=2$ :

$\left\{b_{k} \subseteq \operatorname{Aum}(b): C_{\text {primeiro }\left(b_{k}\right)} \leq i_{t}\right\}:=\varnothing ;$

$\left\{b_{k} \subseteq \operatorname{Dim}(b): C_{\text {último }\left(b_{k}\right)} \geq i_{t}\right\}:=b_{2}, W\left(i_{2}, C_{2}\right)-o_{2}:=6-4-2:=0$;

Para $t:=3$ :

$\left\{b_{k} \subseteq \operatorname{Aum}(b): C_{\text {primeiro }\left(b_{k}\right)} \leq i_{t}\right\}:=\varnothing ;$

$\left\{b_{k} \subseteq \operatorname{Dim}(b): C_{\text {último }\left(b_{k}\right)} \geq i_{t}\right\}:=b_{2}, W\left(i_{3}, C_{2}\right)-o_{3}:=6-2:=4$;

$H^{*}=\max \left\{H\left(C_{\text {primeiro }\left(b_{k}\right)}, i_{t}\right)-o_{t}: C_{\text {primeiro }\left(b_{k}\right)} \leq i_{t}, i_{t} \in N_{b}\right\}:=\varnothing ;$

$W^{*}=\max \left\{W\left(i_{t}, C_{\text {último }\left(b_{k}\right)}\right)-o_{t}: C_{\text {último }\left(b_{k}\right)} \geq i_{t}, i_{t} \in N_{b}\right\}:=\max \{1,0,4\}:=4$;

$\left(t^{*}, b_{k}^{*}, L^{*}\right):=\left(3, b_{2}, 4\right)$;

Inserção de capacidade: (Avalia-se quanta capacidade adicional vai ser utilizada no intervalo escolhido)

$\lambda:=$ CalculaInterMáx $\left(i_{3}, C_{2}\right)=\left\{\min \left(C_{j}-C_{j}^{*}\right): 74<C_{j} \leq 118 ; j \in \operatorname{Dim}(1)\right\}$

$=\min (118-70)=48$; 
$O_{3}:=\min \left\{\lambda, f_{3}-i_{3}\right\}=\min \{48,95-74\}=21$;

$C_{2}:=C_{2}-O_{3}:=118-21:=97$;

Redefinição dos conjuntos de capacidade adicional e capacidade efetivamente utilizada:

$O:=O \cup\left\{O_{t^{*}}, t^{*}\right\}:=\varnothing \cup\left\{O_{3}, 3\right\}:=\{21,3\} ;$

$N_{1}:=\{t=1, t=2, t=3\} \backslash\{t=3\}:=\{t=1, t=2\}$

Passo 1. Iteração 2. $b:=1 . N_{1}:=\{t=1, t=2\}$.

Definição dos blocos parciais de $b$ : Para $j:=1, J_{1} \in b_{1} \subseteq A u m(b)$; Para $j:=2$, $J_{2} \in b_{2} \subseteq \operatorname{Dim}(b)$.

Localização do melhor intervalo de $b$ :

Para $t:=1$ :

$\left\{b_{k} \subseteq \operatorname{Aum}(b): C_{\text {primeiro }\left(b_{k}\right)} \leq i_{t}\right\}:=\varnothing ;$

$\left\{b_{k} \subseteq \operatorname{Dim}(b): C_{\text {último }\left(b_{k}\right)} \geq i_{t}\right\}:=b_{2}, W\left(i_{1}, C_{2}\right)-o_{1}:=6-4-1:=1$;

Para $t:=2$ :

$\left\{b_{k} \subseteq \operatorname{Aum}(b): C_{\text {primeiro }\left(b_{k}\right)} \leq i_{t}\right\}:=\varnothing ;$

$\left\{b_{k} \subseteq \operatorname{Dim}(b): C_{\text {último }\left(b_{k}\right)} \geq i_{t}\right\}:=b_{2}, W\left(i_{2}, C_{2}\right)-o_{2}:=6-4-2:=0$;

$W^{*}=\max \left\{W\left(i_{t}, C_{\text {último }\left(b_{k}\right)}\right)-o_{t}: C_{\text {último }\left(b_{k}\right)} \geq i_{t}, i_{t} \in N_{b}\right\}:=\max \{1,0\}:=1 ;$

$\left(t^{*}, b_{k}^{*}, L^{*}\right):=\left(1, b_{2}, 1\right)$

Inserção de capacidade:

$\lambda:=$ CalculaInterMáx $\left(i_{1}, C_{2}\right)=\left\{\min \left(C_{j}-C_{j}^{*}\right): 25<C_{j} \leq 97 ; j \in \operatorname{Dim}(1)\right\}$

$=\min (97-70)=27$;

$O_{1}:=\min \left\{\lambda, f_{1}-i_{1}\right\}=\min \{27,29-25\}=4$;

$C_{1}:=C_{1}-O_{1}:=47-4:=43$;

$C_{2}:=C_{2}-O_{1}:=97-4:=93$;

Redefinição dos conjuntos de capacidade adicional e capacidade efetivamente utilizada:

$O:=O \cup\left\{O_{t^{*}}, t^{*}\right\}:=\{21,3\} \cup\left\{O_{1}, 1\right\}:=\{4,1 ; 21,3\} ;$

$N_{1}:=\{t=1, t=2\} \backslash\{t=1\}:=\{t=2\} ;$

Passo 1. Iteração 3. $b:=1 . N_{1}:=\{t=2\}$.

Definição dos blocos parciais de $b$ : Para $j:=1, J_{1} \in b_{1} \subseteq A u m(b)$; Para $j:=2$, $J_{2} \in b_{2} \subseteq \operatorname{Dim}(b)$. 
Localização do melhor intervalo de $b$ :

Para $t:=2$ :

$\left\{b_{k} \subseteq \operatorname{Aum}(b): C_{\text {primeiro }\left(b_{k}\right)} \leq i_{t}\right\}:=\varnothing ;$

$\left\{b_{k} \subseteq \operatorname{Dim}(b): C_{\text {último }\left(b_{k}\right)} \geq i_{t}\right\}:=b_{2}, W\left(i_{2}, C_{2}\right)-o_{2}:=6-4-2:=0$;

$W^{*}=\max \left\{W\left(i_{t}, C_{\text {ultimo }\left(b_{k}\right)}\right)-o_{t}: C_{\text {ultimo }\left(b_{k}\right)} \geq i_{t}, i_{t} \in N_{b}\right\}:=\max \{0\}:=0 ;$

$\left(t^{*}, b_{k}^{*}, L^{*}\right):=\left(2, b_{2}, 0\right)$

Como $L^{*} \leq 0$, então vá para o próximo bloco;

Passo 2. Iteração 4. $b:=2 . N_{2}:=\{t=4, t=5\}$.

Definição dos blocos parciais de $b$ : Para $j:=3, J_{3} \in b_{1} \subseteq$ AumDim(b); Para $j:=4, J_{4} \in b_{2} \subseteq \operatorname{Dim}(b)$.

Localização do melhor intervalo de $b$ :

Para $t:=4$ :

$\left\{b_{k} \subseteq \operatorname{Aum}(b): C_{\text {primeiro }\left(b_{k}\right)} \leq i_{t}\right\}:=\varnothing ;$

$\left\{b_{k} \subseteq \operatorname{Dim}(b): C_{\text {ultimo }\left(b_{k}\right)} \geq i_{t}\right\}:=b_{2}, W\left(i_{4}, C_{4}\right)-o_{4}:=2-5-4:=-7$;

Para $t:=5$ :

$\left\{b_{k} \subseteq \operatorname{Aum}(b): C_{\text {primeiro }\left(b_{k}\right)} \leq i_{t}\right\}:=\varnothing ;$

$\left\{b_{k} \subseteq \operatorname{Dim}(b): C_{\text {último }\left(b_{k}\right)} \geq i_{t}\right\}:=b_{2}, W\left(i_{5}, C_{4}\right)-o_{5}:=2-1:=1 ;$

$H^{*}=\max \left\{H\left(C_{\text {primeiro }\left(b_{k}\right)}, i_{t}\right)-o_{t}: C_{\text {primeiro }\left(b_{k}\right)} \leq i_{t}, i_{t} \in N_{b}\right\}:=\varnothing ;$

$W^{*}=\max \left\{W\left(i_{t}, C_{\text {ultimo }\left(b_{k}\right)}\right)-o_{t}: C_{\text {último }\left(b_{k}\right)} \geq i_{t}, i_{t} \in N_{b}\right\}:=\max \{-7,1\}:=1 ;$

$\left(t^{*}, b_{k}^{*}, L^{*}\right):=\left(5, b_{2}, 1\right)$;

Inserção de capacidade:

$\lambda:=$ CalculaInterMáx $\left(i_{5}, C_{4}\right)=\left\{\min \left(C_{j}-C_{j}^{*}\right): 228<C_{J} \leq 260 ; j \in \operatorname{Dim}(2)\right\}$

$=\min (260-250)=10$;

$O_{5}:=\min \left\{\lambda, f_{5}-i_{5}\right\}=\min \{10,248-228\}=10$;

$C_{4}:=C_{4}-O_{5}:=260-10:=250$;

Redefinição dos conjuntos de capacidade adicional e capacidade efetivamente utilizada:

$O:=O \cup\left\{O_{t^{*}}, t^{*}\right\}:=\{4,1 ; 21,3\} \cup\left\{O_{5}, 10\right\}:=\{4,1 ; 21,3 ; 10,5\} ;$

$i_{5}:=i_{5}+O_{5}:=228+10:=238$;

Passo 2. Iteração $5 . b:=2 . N_{2}:=\{t=4, t=5\}$. 
Definição dos blocos parciais de $b$ : Para $j:=3, J_{3} \in b_{1} \subseteq$ AumDim(b); Para $j:=4, J_{4} \in b_{1} \subseteq \operatorname{AumDim}(b)$.

Avalie o próximo bloco; (como todas as ordens do bloco estão terminando em suas datas desejadas, o bloco está programado)

Passo 3. Finalização. Fim.

Com os resultados gerados pelo AIC, podemos construir a Tabela 11, que se relaciona com as ordens, e a Tabela 12, que se relaciona com os intervalos de capacidade adicional.

\begin{tabular}{ccc}
\hline$t$ & $O_{t}$ & $o_{t} O_{t}$ \\
\hline 1 & 4 & 4 \\
2 & 0 & 0 \\
3 & 21 & 42 \\
4 & 0 & 0 \\
5 & 10 & 10 \\
& total & 56 \\
\hline
\end{tabular}

Tabeł $12:$ C ustos de utilização de capacìlade adicinaldo segundo exempb

Assim, a função-objetivo para o programa gerado pelo AIC pode ser calculada, e é equivalente a $\sum_{j \in J}\left(h_{j} E_{j}+w_{j} T_{j}\right)+\sum_{t \in N} o_{t} O_{t}=222$. Como pode ser observado, o valor é menor que os dois outros casos apresentados anteriormente, e de acordo com as provas apresentadas neste capítulo, é o valor ótimo para o problema em consideração. 


\subsubsection{Terceiro exemplo: divisão de bloco}

Neste terceiro exemplo, deseja-se mostrar um caso onde acontece a divisão de um bloco. A instância é apresentada nas tabelas a seguir. Todas as ordens estão disponíveis em $t_{0}=0$.

Vamos avaliar o programa gerado nos dois casos: o primeiro sem e o segundo com a utilização de capacidade adicional.

\begin{tabular}{ccccc}
\hline$j$ & $p_{j}$ & $d_{j}$ & $h_{j}$ & $w_{j}$ \\
\hline 1 & 1 & 2 & 10 & 10 \\
2 & 1 & 2 & 2 & 2 \\
3 & 0,5 & 6 & 1 & 1 \\
4 & 1 & 3 & 2 & 2 \\
5 & 1 & 6 & 10 & 10 \\
\hline
\end{tabular}

Tabel 13 :D ados das ordens do terceiro exempb

\begin{tabular}{cccc}
\hline$t$ & $i_{t}$ & $f_{t}$ & $o_{t}$ \\
\hline 1 & 3,25 & 3,75 & 0,5 \\
\hline
\end{tabular}

Tabeh 14 :D ados do intervab de tempo disponíveldo terceiro exempb

\begin{tabular}{cccccc}
\hline$j$ & $W_{j}$ & $C_{j}$ & $E_{j}$ & $T_{j}$ & $h_{j} E_{j}+w_{j} T_{j}$ \\
\hline 1 & 1 & 2 & 0 & 0 & 0 \\
2 & 0 & 3 & 0 & 1 & 2 \\
3 & 0 & 4 & 2 & 0 & 2 \\
4 & 0 & 5 & 0 & 2 & 4 \\
5 & 0 & 6 & 0 & 0 & 0 \\
& & & & total & 8 \\
\hline
\end{tabular}

Tabeh 15 :C ákub do terceiro exempb com possbililade de inserção de espera

Utilizando o AIE para elaborar o programa, desconsiderando a hipótese de se utilizar a capacidade adicional, temos o resultado na Tabela 15.

Utilizando o pseudocódigo do AIC definido na Figura 21, resolvemos a mesma instância com a possibilidade de inserção de capacidade. A entrada do algoritmo vai ser o programa definido pelo AIE, conforme Tabela 15. Alguns dos passos intermediários são apresentados abaixo: 
Passo 1. Iteração 1. $b:=1 . N_{1}:=\{t=1\}$.

Definição dos blocos parciais de $b$ : Para $j:=1, J_{1} \in b_{1} \subseteq$ AumDim(b); Para $j:=2, J_{2} \in b_{2} \subseteq \operatorname{Dim}(b)$; Para $j:=3, J_{3} \in b_{3} \subseteq A u m(b)$; Para $j:=4, J_{4} \in b_{4} \subseteq \operatorname{Dim}(b)$; Para $j:=5, J_{5} \in b_{5} \subseteq A u m \operatorname{Dim}(b)$.

Localização do melhor intervalo de $b$ :

Para $t:=1$ :

$\left\{b_{k} \subseteq \operatorname{Aum}(b): C_{\text {primeiro }\left(b_{k}\right)} \leq i_{t}\right\}:=\varnothing ; \quad$ (Não há viabilidade nessa hipótese pois não há nenhuma ordem no bloco $b$ com término adiantado que está localizada antes de $i_{1}$ )

$\left\{b_{k} \subseteq \operatorname{Dim}(b): C_{\text {último }\left(b_{k}\right)} \geq i_{t}\right\}:=b_{4}, W\left(i_{1}, C_{4}\right)-o_{1}:=2-1-0,5:=0,5$;

$H^{*}=\max \left\{H\left(C_{\text {primeiro }\left(b_{k}\right)}, i_{t}\right)-o_{t}: C_{\text {primeiro }\left(b_{k}\right)} \leq i_{t}, i_{t} \in N_{b}\right\}:=\varnothing ;$

$W^{*}=\max \left\{W\left(i_{t}, C_{\text {último }\left(b_{k}\right)}\right)-o_{t}: C_{\text {ultimo }\left(b_{k}\right)} \geq i_{t}, i_{t} \in N_{b}\right\}:=\max \{0,5\}:=0,5$;

$\left(t^{*} ; b_{k}^{*} ; L^{*}\right):=\left(1 ; b_{4} ; 0,5\right)$

Inserção de capacidade:

$\lambda:=$ CalculaInterMáx $\left(i_{1}, C_{4}\right)=\left\{\min \left(C_{j}-C_{j}^{*}\right): 3,25<C_{J} \leq 5 ; j \in \operatorname{Dim}(1)\right\}$

$=\min (5-3)=2$;

$O_{1}:=\min \left\{\lambda, f_{1}-i_{1}\right\}=\min \{2 ; 0,5\}=0,5$;

$C_{3}:=C_{3}-O_{1}:=4-0,5:=3,5$;

$C_{4}:=C_{4}-O_{1}:=5-0,5:=4,5$;

Redefinição dos conjuntos de capacidade adicional e capacidade efetivamente utilizada:

$O:=O \cup\left\{O_{t^{*}} ; t^{*}\right\}:=\varnothing \cup\left\{O_{1} ; 1\right\}:=\{0,5 ; 1\} ;$

$N_{1}:=\{t=1\} \backslash\{t=1\}:=\varnothing ;$

Redefinição dos blocos do programa:

$C_{\text {último }\left(b_{k}^{*}\right)}:=C_{\text {último }\left(b_{4}^{*}\right)}=C_{4}=4,5 ; C_{\text {último }(b)}:=C_{5}=6$;

Como $C_{\text {último }\left(b_{k}^{*}\right)} \neq C_{\text {último }(b)}, B_{1}=\left\{J_{1}, J_{2}, J_{3}, J_{4}\right\}$ e $B_{2}=\left\{J_{5}\right\}$;

$\left(b=1, b+1=2, b_{k}^{*}=4\right.$ e $\left.b_{k+1}^{*}=5\right)$

$C_{\text {último(2) }}:=C_{\text {último }(1)}=C_{5}=6$;

$C_{\text {primeiro(2) }}:=C_{\text {primeiro(5) }}=C_{5}=6$;

$C_{\text {último(1) }}:=C_{\text {último(4) }}=C_{4}=4,5$; 
Avalia-se se os blocos mantêm a propriedade de posição de mínimo custo:

$$
\begin{aligned}
& \left(W(1)=w_{2}+w_{4}=4\right)<\left(H(1)=h_{1}+h_{3}=11\right) \\
& (W(2)=0)<\left(H(2)=h_{5}=10\right)
\end{aligned}
$$

Passo 2. Finalização. Fim.

Observe que a introdução de capacidade adicional fez com que um novo bloco fosse criado. Com os resultados gerados pelo AIC, podemos construir a Tabela 16 que se relaciona com as ordens e a Tabela 17 que se relaciona com o intervalo de capacidade adicional.

\begin{tabular}{ccccc}
\hline$j$ & $C_{j}$ & $E_{j}$ & $T_{j}$ & $h_{j} E_{j}+w_{j} T_{j}$ \\
\hline 1 & 2 & 0 & 0 & 0 \\
2 & 3 & 0 & 1 & 2 \\
3 & 3,5 & 2,5 & 0 & 2,5 \\
4 & 4,5 & 0 & 1,5 & 3 \\
5 & 6 & 0 & 0 & 0 \\
& & & total & 7,5 \\
\hline
\end{tabular}

Tabel 16 : C ustos de adíntam ento e atraso do terceiro exempb

\begin{tabular}{ccc}
\hline$t$ & $O_{t}$ & $O_{t} O_{t}$ \\
\hline 1 & 0,5 & 0,25 \\
& total & 0,25 \\
\hline
\end{tabular}

Tabeł $17:$ C usto de utilização de capacìlade adicinnaldo terceiro exempb

A função-objetivo para o programa gerado pelo AIC é equivalente a $\sum_{j \in J}\left(h_{j} E_{j}+w_{j} T_{j}\right)+\sum_{t \in N} o_{t} O_{t}=7,75$.

\subsection{Generalizações e casos particulares do AIC}

Esta seção apresenta dois casos particulares e duas generalizações do AIC. Os casos particulares são baseados em dois possiveis casos do valor dos 
custos de adição de capacidade. As generalizações acontecem, uma para o caso de haver possibilidade de diversos intervalos de capacidade adicional concatenados e a outra para a utilização do AIC como parte de uma heurística mais abrangente que serve para resolver problemas de múltiplas máquinas.

A finalidade desta seção é mostrar como pequenas alterações nos procedimentos propostos podem tornar as abordagens mais poderosas de modo que problemas mais sofisticados, tanto do ponto de vista teórico quanto prático, possam ser resolvidos.

\subsubsection{Casos particulares}

Muitos casos particulares poderiam ser gerados melhorando em muito o desempenho do AIC. GELDERS; KLEINDORFER (1974) por exemplo trabalharam com uma função-objetivo regular e com apenas um custo de utilização de capacidade adicional. Isso leva a uma simplificação significativa, pois os autores puderam assumir em todos os casos que a capacidade adicional seria utilizada necessariamente o mais cedo possivel. As duas proposições abaixo fornecem algumas idéias interessantes para casos particulares; após algumas modificações elas podem ser utilizadas como limitantes de utilização de capacidade.

Proposição 3.2. Se $o_{t} \geq H(b) \quad\left(o_{t} \geq W(b)\right)$ para $b \subseteq B$ e $t \in N_{b}$, não haverá inserção de capacidade adicional para diminuir o custo de adiantamento (atraso).

Demonstração: Se $o_{t} \geq H(b)\left(o_{t} \geq W(b)\right)$ para $b \subseteq B$ e $t \in N_{b}$, significa que não há estado ou configuração das ordens que faça com que $L^{*}>0$, e portanto o algoritmo não insere capacidade nas ordens de $b$ que estejam adiantadas (atrasadas). 
Proposição 3.3. Se $o_{t}<\min _{j \in b} h_{j}\left(o_{t}<\min _{j \in b} w_{j}\right)$ para $b \subseteq B$ e $t \in N_{b}$, então toda a capacidade adicional disponivel será utilizada para a realização de $b$, enquanto houver adiantamento (atraso).

Demonstração: Se $o_{t}<\min _{j \in b} h_{j}\left(o_{t}<\min _{j \in b} w_{j}\right)$ para $b \subseteq B$ e $t \in N_{b}$, significa que $L^{*}>0$ para qualquer configuração das ordens em $b$. Avaliando o passo 2.3 do AIC, percebemos que a capacidade vai ser inserida até que acabe ou o adiantamento (atraso) ou a capacidade adicional disponivel.

////

\subsubsection{Generalizações}

Diversas generalizações poderiam ser sugeridas ao AIC. Duas delas, que aparentemente são "naturais" e simples, são apresentadas a seguir.

3.9.2.1. Diversos custos de capacidade adicional entre dois intervalos de capacidade normal

O AIC básico foi elaborado tendo-se em mente que haveria apenas um intervalo de capacidade adicional, com seu custo associado, entre dois intervalos de capacidade normal. Em outras palavras, imediatamente antes, assim como imediatamente depois do intervalo de capacidade adicional, há um intervalo de capacidade normal, sendo que o mesmo pode ser utilizado no processamento das ordens, ou na inserção de espera. Esse caso é interessante pela maior simplicidade na construção do algoritmo e das provas.

Nos casos reais de produção, existem diversos custos de capacidade adicional concatenados. Por exemplo, supondo que não haja trabalho normal nos fins-de-semana, o sábado possui um valor de custo de hora-extra, enquanto que o domingo possui outro. Isso também acontece dependendo do número de horas-extras realizadas. Quanto maior o número de horas-extras, maior o custo unitário; normalmente a função que define o valor da hora-extra é contínua, crescente e composta por fragmentos lineares.

Para tratarmos desse problema, podemos utilizar o conceito de bloco mais uma vez. Vamos supor que exista um conjunto $R$ de índices de blocos de 
intervalos de capacidade adicional. Da mesma forma que nos blocos de ordens, um bloco de intervalos de capacidade adicional, $r \subseteq R$, é uma seqüência de intervalos de capacidade adicional concatenados. A seqüência de intervalos $r=\left\{t_{r_{1}}, t_{r_{2}}, \ldots, t_{r_{n}}\right\}$ é um bloco se $i_{k+1}=f_{k}$ (se $\left.r_{1} \leq k \leq r_{n-1}\right), i_{k}>f_{k-1}$ (para $\left.k=r_{1}\right)$ e $f_{k}<i_{k+1}$ (para $k=r_{n}$ ). Um bloco $r \subseteq R$ é considerado como um conjunto de intervalos, ou mesmo como um intervalo em si.

As modificações no AIC para tratar esse tipo de problema são as seguintes:

1. Os intervalos $t \in N_{b}$ passam a ser representados por $r \subseteq R_{b}$, ou seja, ao invés de se utilizar todos os intervalos de capacidade adicional do bloco $b$, utiliza-se todos os blocos de intervalos de capacidade adicional do bloco $b$;

2. Para cada bloco $r \subseteq R_{b}$ de intervalos, elege-se o de mínimo custo e este passa a ser o representativo do bloco, isto é, $o_{r}=\min _{\tau \in r} o_{\tau}$, $i_{r}=\left\{i_{k}: k=\arg \min _{\tau \in r} o_{\tau}\right\}$ e $f_{r}=\left\{f_{k}: k=\arg \min _{\tau \in r} o_{\tau}\right\}^{24}$.

Com essas modificações, o AIC funciona apropriadamente para o caso de múltiplos intervalos de capacidade adicional concatenados.

A abordagem sugerida pode trazer algum inconveniente num caso hipotético A, onde os custos de capacidade adicional não são não-decrescentes com o tempo. Por exemplo, supondo que a terceira hora após o término do horário normal de trabalho seja a mais barata, o operador teria que esperar duas horas antes de iniciar sua hora-extra. Apesar disso, segundo o conhecimento do autor, não há casos no mundo real onde isso venha a ocorrer.

Um caso hipotético $B$, onde o intervalo de capacidade adicional a ser utilizado deve ser o primeiro dos disponiveis também pode ser facilmente construído. Esse caso B é o que normalmente acontece no mundo real, entretanto ele também possui a propriedade de que os custos de capacidade

${ }^{24}$ Para o caso considerado até então, o procedimento proposto utilizava a tripla $\left(i_{t}, f_{t}, O_{t}\right)$ como sendo representativa do intervalo de capacidade adicional a ser utilizado. 
adicional são não-decrescentes com o tempo, fazendo assim com que a abordagem sugerida possa ser utilizada diretamente.

\subsubsection{Utilização do AIC em múltiplas máquinas}

Esta seção apresenta uma sugestão de utilização do AIC para um ambiente onde haja necessidade de se programar diversas máquinas ${ }^{25}$. Aqui o procedimento não será mais otimizante, mas sim uma heurística que utiliza como componente principal o AIC.

Estamos considerando que os custos serão definidos em cada máquina e não necessariamente na última operação. Então, para cada operação, haverá custos associados quando o término da mesma for discrepante da data da operação. Supondo que $C_{m j}$ represente o horário de término da operação $m j$, podemos dizer que o custo de adiantamento da operação $m j$ é definido como $h_{j} E_{m j}=h_{j} \max \left(0, d_{m j}-C_{m j}\right)$, ao passo que o custo de atraso da mesma operação será definido como $w_{j} T_{m j}=w_{j} \max \left(0, C_{m j}-d_{m j}\right)$.

Observe que no caso de uma implementação real, a definição dos custos pode acontecer de diversas maneiras. Por exemplo, a definição do custo de atraso do produto final pode ser mais fácil do que a definição do custo de atraso de cada operação. Aqui, diversas propostas de definição de custos poderiam ser feitas. No caso onde os custos de atraso e adiantamento sejam definidos para a ordem completa (constituída de produtos finais), a abordagem considerada aqui pode levar a uma distorção do valor de custo obtido pela função-objetivo. Apesar disso, acreditamos que nossa abordagem possa capturar a essência do problema pois cada operação em si contribui para o horário de término da última operação. Em outras palavras, os custos de atraso e de adiantamento de uma ordem podem ser considerados por sua importância relativa, mesmo antes que a ordem seja finalizada.

O caso de múltiplas máquinas pode ser conseqüência de diversos sistemas de programação. Poderíamos pensar no caso onde todas as

${ }^{25}$ Observe que o procedimento de uma máquina pode ser utilizado em ambientes com múltipla máquinas dependendo da abordagem utilizada para programação. Nas abordagens de tratamento de gargalo, onde também existem recursos de capacidade infinita, o caso tratado anteriormente na tese se aplica diretamente. Há um grupo de máquinas por onde um fluxo de produtos passa, sendo que nesse grupo de máquinas apenas uma delas é programada com capacidade finita, ou seja, a máquina-gargalo. Num outro caso, mais de uma máquina pode ser programada com capacidade finita. 
máquinas de uma empresas fossem programadas da forma proposta, ou num outro caso, poderíamos pensar na programação de máquinas-gargalo apenas. Sem entrarmos na discussão acerca das justificativas de onde uma ou outra abordagem é mais interessante, acreditamos que em ambos os casos a heurística apresentada aqui é aplicável.

Seja $M$ o conjunto de índices de máquinas a serem programadas, $M_{1}$ as máquinas já programadas e $M_{2}=M \backslash M_{1}$ as máquinas ainda não programadas. Vamos supor que para cada máquina, as seqüências e as esperas necessárias já tenham sido definidas de acordo com alguma outra heurística. Para esse problema, desenvolvemos uma heurística que se guia pelas máquinas que estão com os maiores custos. Esta heurística é apresentada a seguir:

HEURŚ TIA PARA NSERÇÃO DE CAPACDADE EM MÚLTPLAS MÁQUNAS

Passo 1. Inicialização. Comece com um programa já definido para cada máquina $m \in M ; M_{1} \leftarrow \varnothing ; M_{2} \leftarrow M \backslash M_{1}$.

Passo 2. Definição da importância da máquina. Calcule o custo total para cada máquina $m \in M_{2}$, ou seja, calcula-se o valor da soma das diferenças ponderadas de cada máquina ainda não programada definitivamente.

Passo 3. Localização da máquina mais importante, $m^{*} \in M_{2}$. Localize a máquina mais importante $m^{*} \in M_{2}$, dentre as que ainda não foram programadas definitivamente.

Passo 4. Inserção de capacidade, se vantajoso. Utilize o AIC para a máquina $m^{*}$.

Passo 5. Reprogramação das outras máquinas. Redefina o programa das outras $m \in M_{1}$ máquinas considerando o programa gerado para a máquina $m^{*} ; M_{1} \leftarrow M_{1} \cup m^{*} ; M_{2} \leftarrow M_{2} \backslash m^{*}$.

Passo 6. Condição de parada. Verifique a condição de parada da heurística.

Passo 7. Instrução de loop. Volte para o passo 2.

Passo 8. Término. Fim.

A heuristica é auto-explicativa. Ela programa as máquinas uma a uma, por ordem de importância, onde a importância é definida pelo custo total 
ocorrido na própria máquina. Os custos são gerados pelas datas das operações e não pelas datas finais. Após a programação de uma máquina, as outras máquinas devem ser reprogramadas para se analisar sua criticidade mais uma vez. Como a heurística seguramente consumiria muito tempo computacional, ela utiliza o passo 4.3 que é uma condição de parada qualquer que viabilize sua aplicação. Poderíamos pensar em alguma coisa como o próprio tempo de solução computacional ou como o valor da economia gerada pela iteração mais recente.

Para a elaboração dessa heurística, utilizamos como inspiração a heurística bastante conhecida por sua eficiência e genialidade de ADAMS et al. (1988) denominada gargalo móvel.

Diversas modificações poderiam ser feitas na heurística. Por exemplo, ao invés de localizarmos a máquina mais crítica, poderiamos localizar a ordem que está promovendo o maior custo, ou seja, poderíamos procurar por $k=\arg \max _{j \in J}\left\{h_{j} \sum_{m \in M} E_{m j}+w_{j} \sum_{m \in M} T_{m j}\right\}$.

Heurísticas aparentemente promissoras são as que utilizam procedimentos onde a seqüência das ordens pode ser alterada. Pela facilidade promovida devido a possibilidade de alteração de capacidade, procedimentos poderosos podem ser elaborados. Na realidade, como comentado anteriormente, a consideração da possibilidade de alteração da capacidade muda profundamente a maneira de se enxergar o problema de programação e sua solução.

\subsection{Procedimentos de variação de capacidade utilizados para definição de horas-extras e turnos de trabalho}

Os procedimentos tratados nesta tese podem ser utilizados de forma complementar se considerarmos que ambos possuem relacionamento com carga e capacidade. Nesta seção, considerar-se-á um problema mais aplicado, mostrando como os procedimentos propostos são relacionados.

No mundo real, assim como convencionalmente tratado nos modelos de planejamento agregado, existe uma ponderação para a distribuição de carga, utilizando, dentre outros instrumentos, a variação de capacidade. Existe a 
possibilidade de se criar ou fechar turnos de trabalho e de se utilizar horasextras, onde os custos de horas-extras são tratados como variáveis ao passo que os custos dos turnos como fixos. Normalmente o custo fixo possui um valor menor por unidade de tempo utilizado do que o custo variável. Além das utilizadas aqui, outras considerações menos tangiveis como a maior flexibilidade relacionada à abertura de turnos devem ser levadas em consideração pelo tomador de decisão.

Vamos supor que a capacidade normal utilizada seja constituída por $\theta$ turnos de trabalho. $\bar{\theta}$ e $\underline{\theta}$ representam respectivamente o número máximo e mínimo possível de turnos de trabalho ${ }^{26}$. O instante de início de início e término para $\theta$ turnos serão definidos como $\left(i_{\theta}, f_{\theta}\right)$. O intervalo em que a empresa trabalha com $\theta$ turnos é representado por $\left[i_{\theta}, f_{\theta}\right]$. Quando houver alteração no número de turnos, a empresa deve permanecer com o mesmo número de turnos por um intervalo mínimo de tempo $T \leq f_{\theta}-i_{\theta}$. Em outras palavras, é o intervalo de tempo que especifica, para uma alteração no número de turnos, quanto tempo deverá ser decorrido até que uma outra alteração possa ser feita. Essa característica é importante pois pode considerar fatores motivacionais e neurofisiológicos dos trabalhadores, assim como relacionamentos com os sindicatos. Para simplificar a natureza combinatória do problema, podemos considerar que haja instantes especificos onde possa ocorrer a abertura e fechamento de turnos. Essa questão não será abordada aqui; aqui a abertura e fechamento poderá acontecer em qualquer instante desde que a restrição seja respeitada.

Seja $C(\theta)$ o custo proveniente da utilização da capacidade normal quando a máquina trabalha $\theta$ turnos. Pode-se dizer que as quantidades $C(\theta)-C(\theta-1)$ $(\theta \geq \underline{\theta}+1)$ e $C(\theta+1)-C(\theta)(\theta \leq \bar{\theta}-1)$ representam respectivamente a economia em se diminuir e o custo em se adicionar um turno de trabalho respectivamente.

A idéia básica aqui é que deve haver uma ponderação entre os custos de acréscimo ou diminuição de um turno e os custos de horas-extras, de atraso e de adiantamento. Dois casos são possiveis:

\footnotetext{
${ }^{26} \mathrm{Na}$ maioria dos casos relacionados às empresas, o número mínimo de turnos será 1 enquanto que o número máximo será 4. Outros casos permitem outros tipos de revezamento do trabalhador, como por exemplo nos serviços militares e hospitalares.
} 
- Acréscimo de um turno de trabalho. Acontece se o custo total de um programa com um turno adicional for menor do que o custo de um programa sem o turno adicional. Os custos totais são compostos por custos de capacidade normal, de adiantamento, de atraso e de horas-extras no intervalo de alteração dos turnos $\left[i_{\theta}, f_{\theta}\right]$;

- Diminuição de um turno de trabalho. Idem ao caso anterior com a diferença que ao invés de se adicionar um turno, retira-se um turno.

Ao conjunto de índices de intervalos de capacidade normal $N$, acrescentaremos o argumento que define o número de turnos para essa capacidade $N(\theta)$.

Para um conjunto de ordens $A \subseteq J$ a ser processado no intervalo $\left[i_{\theta}, f_{\theta}\right]$, a criação de um turno acontecerá se a desigualdade

$$
\left\{C(\theta+1)+\sum_{t \in N(\theta+1)} o_{t} O_{t}+\sum_{j \in A}\left(h_{j} E_{j}+w_{j} T_{j}\right)\right\}<\left\{C(\theta)+\sum_{t \in N(\theta)} o_{t} O_{t}+\sum_{j \in A}\left(h_{j} E_{j}+w_{j} T_{j}\right)\right\}
$$

$\operatorname{com}(\theta \leq \bar{\theta}-1)$, for verdadeira. Para a eliminação de um turno, se a desigualdade

$$
\left\{C(\theta-1)+\sum_{t \in N(\theta-1)} o_{t} O_{t}+\sum_{j \in A}\left(h_{j} E_{j}+w_{j} T_{j}\right)\right\}<\left\{C(\theta)+\sum_{t \in N(\theta)} o_{t} O_{t}+\sum_{j \in A}\left(h_{j} E_{j}+w_{j} T_{j}\right)\right\}
$$

$\operatorname{com}(\theta \geq \underline{\theta}+1)$, for verdadeira, então um dos turnos deve ser eliminado. Repare que $\sum_{j \in A}\left(h_{j} E_{j}+w_{j} T_{j}\right)$ não é equivalente em ambos os lado das equações (3.5) e (3.6).

Um inconveniente evidente nessa abordagem é a necessidade de haver reprogramação para a verificação da adição ou eliminação de turnos ${ }^{27}$. Pela dificuldade em se elaborar programas completos e com a finalidade de diminuir esse esforço adicional, sugere-se abaixo um limitante que avalia $a$ priori (sem a necessidade de reprogramação) a introdução de um novo turno.

${ }^{27}$ Esse mesmo problema acontece no planejamento agregado. Os modelos convencionalmente propostos (HAX; CANDEA, 1984, cap. 3) consideram a capacidade regular (utilizada em turnos) como uma variável contínua, quando na realidade é discreta e possui poucos valores; valores representados pelo número possível de turnos. No caso genérico, para a verificação do número de turnos no planejamento agregado também faz-se necessário elaborar o planejamento mais de uma vez, considerando os possíveis turnos de trabalho devido à característica combinatória do problema. Obviamente que o problema poderia ser resolvido como um de variáveis inteiras, entretanto, mesmo assim, o problema 
Proposição 3.4. (Limitante para criação de um turno). Se

$$
C(\theta+1) \geq\left\{C(\theta)+\sum_{t \in N(\theta)} o_{t} O_{t}+\sum_{j \in A}\left(h_{j} E_{j}+w_{j} T_{j}\right)\right\},
$$

não há possibilidade da adição de um turno ser vantajosa.

Demonstração: Quando um turno é criado, na melhor condição possivel, os custos de adiantamento, atraso e horas-extras são eliminados. Levando isso em consideração, a demonstração é direta ao observarmos a inequação (3.5).

A elaboração de um limitante para a retirada de um turno não é simples visto que não se consegue prever com facilidade o quanto irão aumentar os atrasos e os adiantamentos. Sabemos que o tempo de espera vai diminuir e que a utilização da capacidade adicional vai ser no mínimo a que já é utilizada com um turno a mais.

Deixa-se aqui uma questão em aberto para a construção de um limitante de eliminação de turnos. Uma proposta é que para a elaboração do limitante, faz-se necessário a elaboração de uma expressão que associa a quantidade de capacidade normal retirada relacionada ao aumento dos custos de adiantamento e atraso.

estaria sendo resolvido mais de uma vez. 


\section{Discussão adicional e conclusões}

Este capitulo faz um apanhado geral do tema abordado na tese. São feitas algumas considerações acerca de assuntos relacionados ao tema aqui tratado que não tiveram uma boa oportunidade para serem comentados anteriormente. Numa segunda seção, as contribuições contidas na tese são separadas de modo que fique claro quais são. Posteriormente discute-se possiveis temas para pesquisas futuras que estariam relacionados à tese.

\subsection{Considerações adicionais}

Procedimentos e algoritmos como os gerados aqui geralmente são utilizados como parte de outros procedimentos e sistemas de maior abrangência. Pela complexidade computacional, o seqüenciamento do problema tratado aqui com a utilização de procedimentos otimizantes é inviável para instâncias de tamanhos "razoáveis". Apesar disso, diversos procedimentos com tempo de solução polinomial e com bons resultados são conhecidos. Regras de despacho são especialmente interessantes pela facilidade de implementação bem como pela rapidez com que uma boa solução viável é gerada.

Para outros procedimentos mais sofisticados e intensivos computacionalmente, pode-se citar: ADAMS et al. (1988) onde um algoritmo de uma máquina é utilizado intensivamente para a solução de um problema de múltiplas máquinas e COLIN (1997) onde um AIE é utilizado como parte de um procedimento de busca. Sempre deveríamos ter isso em mente para se justificar um estudo tão detalhado de um problema que não é a primeira preocupação dos tomadores de decisão dentro de uma empresa.

No mundo real, a variação da capacidade sempre trouxe inconvenientes especialmente do ponto de vista dos sindicatos. Mais recentemente, devido ao grande nivel de desemprego, os sindicatos têm se enfraquecido, fazendo assim com que uma variação de capacidade mais agressiva seja mais viável.

Numa implementação efetiva, a utilização dos custos de adiantamento e de atraso seguramente seria dificil. Embora a pesquisa científica que utilize os 
custos (chamados de penalidades muitas vezes) sejam abundantes, são pouquíssimos relatos de sua utilização efetiva.

Para o caso dos custos de atraso, a utilização "mais natural" provavelmente seria a transformação das multas de atraso em valores para utilização na programação. Outros parâmetros de dificil medição que deveriam ser utilizados seriam a perda de reputação no mercado e a perda de oportunidade de capital devido ao não-faturamento em uma data mais cedo.

Para o caso dos custos de adiantamento, custos como o de estoque em processamento e estoque final poderiam ser levados em consideração para sua definição. Produtos perecíveis e de rápida perda de valor, como subconjuntos utilizados na montagem de computadores, são exemplos de onde os custos de adiantamento são tão relevantes quanto os de atraso.

Os custos de adição de capacidade, como os de horas-extras especialmente, talvez sejam os mais evidentes e fáceis de serem definidos de uma maneira bastante real. Na realidade, o que forçaria as penalidades de adiantamento e atraso utilizarem custos como parâmetros são os custos de adição de capacidade para manter a função-objetivo dimensionalmente correta.

Para o caso onde os custos de utilização de capacidade adicional não fossem levados em conta, ou onde os custos de utilização de capacidade adicional pudessem ser transformados em indices não-financeiros, a definição das penalidades poderia ser mais fácil. Uma idéia seria a criação de um índice adimensional, onde um especialista, ou um grupo deles, poderia definir as importâncias das ordens levando-se em consideração diversos fatores de difícil quantificação.

\subsection{Contribuições contidas na tese}

As contribuições contidas na tese já foram mencionadas ao longo do texto, mas mesmo assim, nesta seção destacamos de maneira mais clara as contribuições deste trabalho. Em linhas gerais, podemos separar as contribuições contidas na tese em duas partes.

A primeira contribuição se relaciona com a elaboração de um algoritmo de inserção de espera para um problema ainda não tratado diretamente na 
literatura, pelo menos no conhecimento do autor. Ela é baseada na generalização do algoritmo de inserção de espera de GAREY et al. (1988). Os casos mais genéricos encontrados na literatura são baseados em funções lineares dos horários de término. A proposta feita aqui contempla toda a classe que pode ser representada por funções convexas do horário de término.

A segunda contribuição, se refere à criação de um algoritmo para a inserção de capacidade adicional em um programa predefinido pelo algoritmo de inserção de espera citado anteriormente. O problema ainda não havia sido tratado dessa forma na literatura científica do assunto. O único tratamento proposto é inviável computacionalmente para problemas de tamanhos minimamente razoáveis. Isso talvez tenha acontecido pela razão de mudar profundamente a natureza do problema de programação, ou seja, os dificeis procedimentos otimizantes existentes na literatura criados para seqüenciamento poderiam ficar obsoletos com essa consideração. Uma outra possibilidade é que convencionalmente considera-se a variação da capacidade em um nível mais elevado do planejamento, geralmente no planejamento agregado. Como comentado anteriormente, a utilização do planejamento agregado no problema aqui especificado não seria suficiente para garantir uma solução tão boa quanto a gerada aqui.

\subsection{Utilização na prática e impacto potencial na gestão de operações}

Como comentado anteriormente no capítulo 1 , os procedimentos aqui propostos devem ser utilizados em softwares de programação da produção. Os procedimentos são melhorativos e de grande detalhamento pois geram informações que provavelmente não precisam de tratamento adicional para serem utilizadas.

A utilização efetiva portanto vai depender da implementação dos procedimentos em softwares comerciais pois a utilização dos procedimentos de forma independente provavelmente não seria possivel. Podemos pensar nos ganhos potenciais dos beneficios gerados pelo melhor entendimento do problema. Mas mesmo assim, para que o ambiente produtivo se beneficie desse "conhecimento", deve haver uma disseminação dos resultados por 
intermédio de meios acessiveis aos tomadores de decisão. Um exemplo de resultado que pode gerar beneficios mais diretos às empresas é que a utilização de horas-extras deve acontecer o mais cedo possivel, se o ambiente for caracterizado pela penalização dos atrasos e não houver grandes prejuízos caso o término das ordens seja anterior às suas datas de entrega. O mesmo raciocínio é válido para ambientes onde o adiantamento é bastante prejudicial. Um outro resultado oriundo do trabalho é que de forma diferente do bom senso, há casos onde não existe inconsistência na utilização de horas-extras e espera em periodos relativamente próximos.

Uma definição do impacto potencial das propostas contidas na tese não é muito simples de fazer visto que ele é dependente de uma série de fatores como a própria disseminação do conhecimento aqui contido. Entretanto, de alguma forma, podemos estimar alguns números tentando definir o tamanho do "mercado" associado aos procedimentos propostos aqui.

A partir de novembro de 1988 a jornada legal de trabalho aqui no Brasil passou de 48 para 44 horas semanais. Em pesquisa realizada pela Secretaria de Economia e Planejamento, e publicada no anuário estatístico de São Paulo de 1996, observou-se que o percentual dos assalariados que trabalham mais do que 44 horas é $41,4 \%$ na região metropolitana de São Paulo28. Como a pesquisa não leva em conta os setores produtivos nem se as horas-extras foram efetivamente pagas, ou apenas utilizadas como banco de horas, vamos assumir que a utilização de horas-extras em ambientes produtivos corresponda a $5 \%$ de todo o custo de mão-de-obra (como a hora-extra mais barata custa $150 \%$ da hora-normal, esse número representa menos de 3,3\% da capacidade produtiva). Um número pessimista para a diferença entre a tomada de decisão com um modelo analítico otimizante e sem o modelo é $2 \%$. Assim, podemos dizer que o impacto potencial nas empresas pagadoras de horas-extras seja de uma diminuição de $0,1 \%$ dos custos de mão-de-obra. Mesmo considerando que os procedimentos propostos se aplicam em apenas uma parcela das empresas, o valor é bastante significativo.

É óbvio que associado a essa diminuição do custo produtivo, há o aumento do custo de gestão dos procedimentos. A utilização de procedimentos

${ }^{28}$ Anuário Estatístico de São Paulo, 1996. Emprego: Mão-de-obra. Tabela 19-Horas semanais trabalhadas pelos ocupados e assalariados no trabalho principal. Região metropolitana de São Paulo, Município de São Paulo e demais municípios da região metropolitana. Disponível na internet em http://www.seade.gov.br. 
sofisticados não é gratuita. Deve haver profissionais aptos a entender os procedimentos para o funcionamento esperado dos mesmos. Podemos por outro lado pensar que pelas vias normais (isto é, os procedimentos serem utilizados em softwares de programação) esse custo é insignificante pois o usuário deve necessariamente possuir um conhecimento teórico razoável.

Como os procedimentos propostos para a inserção de espera foram aperfeiçoados (especialmente do ponto de vista teórico) para casos mais abrangentes do que os existentes na literatura, fica dificil estimar o potencial de melhoria sobre os procedimentos já existentes. A relevância do trabalho é proporcional à importância de dois fatores: 1) modelagem considerando custos não-lineares e 2) nível de variação de carga existente no sistema produtivo dentro de um periodo de planejamento, ou seja, quanto mais a carga variar dentro do periodo de planejamento, mais importante são os algoritmos de inserção de espera.

\subsection{Algumas sugestões de temas para pesquisa futura}

O tema estudado aqui pode ter diversas extensões. Em especial o capítulo 3 pode ser estendido visto a grande carência de trabalhos relativos ao tema.

Diversos temas na teoria da programação chamam a atenção em um certo momento. Provavelmente é o mesmo que ocorre em todas as áreas de conhecimento que têm pesquisa ativa. Provas disso podem ser encontradas nos próprios problemas estudados aqui. A utilização de uma função-objetivo que considerou adiantamento só aconteceu em 1977 com o trabalho de EILON; CHOWDHURY (1977). Desde então, o tema tem sido amplamente estudado como pode ser observado na literatura disponivel. Outros temas que eram relativamente esquecidos pelos pesquisadores eram os de definição de datas de entrega e o de programação em ambiente estocástico. CONWAY et al. (1967) já haviam estudado ambos os temas, entretanto os mesmos só vieram chamar a atenção da comunidade científica no começo da década de 80 .

Pela profunda alteração que a utilização de capacidade variável pode trazer no tratamento dos problemas de programação, temos fortes evidências 
que o tema tenha um futuro com bastante fecundidade na criação de temas e obtenção de resultados de pesquisa.

Um trabalho que poderia ser interessante é a comparação entre os resultados alcançados pelos modelos de planejamento agregado geralmente encontrados na literatura e os resultados alcançados com a alteração de capacidade num nível de planejamento mais baixo, como fizemos neste trabalho.

Uma abordagem que parece natural é também incorporar questões relacionadas ao estoque na programação. A programação dessa forma estaria incorporando as principais questões da administração de operações (WILD, 1977). Assim, a programação poderia ser completa chegando até mesmo a eliminar o planejamento agregado em algum ponto. Nesse ponto, um estudo comparativo entre ambas as abordagens seria interessante. Devemos sempre ter em mente que o planejamento agregado será mais rápido, entretanto se o tempo adicional necessário para a realização do programa começar a se tornar aceitável, não há razões para não se utilizar uma abordagem que seja mais detalhada. ${ }^{29}$

O tema tratado no capítulo 2 parece ter mais desdobramentos na criação de procedimentos que o utilizem. Como ele já tem uma função-objetivo bastante genérica e o AIE associado possui um tempo de solução bastante baixo, parece improvável a obtenção de resultados muito interessantes. Talvez a expansão da abordagem para funções multimodais pudesse ser interessante do ponto de vista teórico. No mundo real, é pouco provável que uma abordagem desse tipo possua muitas aplicações.

${ }^{29}$ É evidente que informações agregadas são mais tratáveis do ponto de vista da tomada de decisão; o tomador de decisão se beneficia pela agregação da informação. Isso não impede que a informação gerada por um eventual procedimento de nível detalhado como a programação da produção possa ser agregada para simplificar a tomada de decisão. 


\section{Referências bibliográficas 30}

ADAMS, Joseph; BALAS, Egon; ZAWACK, Daniel. The shifting bottleneck procedure for job shop scheduling. Management Science, v. 34, n. 3, pp. 391-401, 1988. [3.9.2.2, 4.1]

ANTHONY, Robert Newton. Planning and Control Systems: A framework for Analysis. Boston, Harvard University, Graduate School of Business Administration, 1965. [1.2.1]

BAKER, Kenneth R. Introduction to sequencing and scheduling. New York, Wiley, 1974. [1.2.2]

BAKER, Kenneth R.; SCUDDER, Gary D. Sequencing with earliness and tardiness penalties: a review. Operations Research, v. 38, n. 1, pp. 22-36, 1990. [2]

BALAKRISHNAN, Nagraj; KANET, John J.; SRIDHARAN, 'Sri' V. Early/tardy scheduling with sequence dependent setups on uniform parallel machines. Computers \& Operations Research, v. 26, pp. 127-41, 1999. [2]

BAZARAA, Mokhtar S.; SHERALI, Hanif D.; SHETTY, C. M. Nonlinear programming: Theory and algorithms. 2. ed. New York, Wiley, 1993. [2.8.1] BITRAN, Gabriel R.; TIRUPATI, Devanath. Hierarchical Production Planning. In: GRAVES, S. C.; RINNOOY KAN, A. H. G.; ZIPKIN, P. H. (eds.) Logistics of Production and Inventory. Amsterdam, North-Holland, 1993. pp. 52370. [1.2.1]

BOWER, Joseph L.; HOUT, Thomas M. Fast-cycle capability for competitive power. Harvard Business Review, November-December 1988. [1.1]

COLIN, Emerson C. Beam search e inserção de ociosidade no problema de programação de uma máquina em ambiente do tipo JIT. Dissertação (Mestrado), Escola Politécnica, Universidade de São Paulo, São Paulo, 1997. 106 pp. [4.1]

COLIN, Emerson C. Beam search filtrado com inserção de ociosidade na programação de uma máquina em ambiente do tipo JIT. Gestão \& Produção, v. 5, n. 2, pp. 117-32, 1998. [2.3]

\footnotetext{
${ }^{30}$ Os números entre colchetes referem-se às seções cujos títulos estão imediatamente anteriores à referência citada.
} 
COLIN, Emerson C.; CIPPARRONE, Flávio A. M.; SHIMIZU, Tamio. Otimização do custo de transporte na distribuição-armazenagem de açúcar. Produção, v. 9, n. 1, pp. 23-30, 1999. [3.4]

COLIN, Emerson C.; SHIMIZU, Tamio. Algoritmo de programação de máquinas individuais com penalidades distintas de adiantamento e atraso. 10 pp. Aceito para publicação em Pesquisa Operacional, 2000. [2.3, 3.5] CONWAY, Richard W.; MAXWELL, William L.; MILLER, Louis W. Theory of scheduling. Reading, Massachusetts, Addison-Wesley, 1967. [3, 3.3, 4.4]

DAVIS, J. Steve; KANET, John J. Single-machine scheduling with early and tardy completions costs. Naval Research Logistics, v. 40, pp. 85-101, 1993. [2.3]

EILON, Samuel; CHOWDHURY, I. G. Minimising waiting time variance in the single machine problem. Management Science, v. 23, n. 6, 1977. [4.4]

FEDERGRUEN, Awi; MOSHEIOV, Gur. Single machine scheduling problems with general breakdowns, earliness and tardiness costs. Operations Research, v. 45, n. 1, pp. 66-71, 1997. [2]

FRENCH, Simon. Sequencing and scheduling: an introduction to the mathematics of the job-shop. New York, Wiley, 1982. [1.2.2, 2.3]

FRY, Timothy D.; ARMSTRONG, Ronald D.; BLACKSTONE, John H. Minimizing weighted absolute deviation in single machine scheduling. IIE Transactions, v. 19, n. 4, pp. 445-50, 1987. [2.3, 2.7]

GAREY; Michael; JOHNSON, David S. Computers and intractability: a guide to the theory of NP-Completeness. San Francisco, Freeman \& Company, 1979. [2.3]

GAREY, Michael R.; TARJAN, Robert E.; WILFONG, Gordon T. One-processor scheduling with symmetric earliness and tardiness penalties. Mathematics of Operations Research, v. 13, n. 2, pp. 330-48, 1988. [1.3, 1.5, 2.3, 2.4, 2.4.3, $3.5,4.2]$

GELDERS, L.; KLEINDORFER, P. R. Coordinating aggregate and detailed scheduling decisions in the one-machine job shop: part I. Theory. Operations Research, v. 22, n. 1, pp. 46-60, 1974. [3.3, 3.9.1]

GELDERS, L.; KLEINDORFER, P. R. Coordinating aggregate and detailed scheduling in the one-machine job shop: II-computation and structure. Operations Research, v. 23, n. 2, pp. 312-24, 1975. [3.3] 
GOLDRATT, Eliyahu M.; COX, J. A meta: um processo de aprimoramento contínuo. 4a. ed. Tradução de Claudiney Fullmann. São Paulo, Educator, 1992. [1.4]

GRAVES, Stephen C. A review of production scheduling. Operations Research, v. 29, pp. 646-75, 1981. [1.2.2]

HAX, Arnoldo C.; CANDEA, Dan. Production and inventory management. Englewood Cliffs, Prentice-Hall, 1984. [1.2.1, 3.10]

HOLLOWAY, Charles A.; NELSON, Rosser T. Alternative formulation of the job shop problem with due dates. Management Science, v. 20, n. 1, pp. 65-75, 1973. [1.2.2]

HOLLOWAY, C. A.; NELSON, R. T. Job shop scheduling with due dates and overtime capability. Management Science, v. 21, n. 1, pp. 68-78, 1974. [3.3]

LASSERRE, J. B. An integrated model for job-shop planning and scheduling. Management Science, v. 38, n. 8, pp. 1201-11, 1992. [1.2.1]

LAWLER, E. L. A "pseudopolynomial" algorithm for sequencing jobs to minimize total tardiness. Annals of Discrete Mathematics, v.1, pp. 33142, 1977. [2.3, 2.8.3]

LAWLER, Eugene L.; LENSTRA, Jan Karel; RINNOOY KAN, Alexander H. G.; SHMOYS, David B. Sequencing and scheduling: algorithms and complexity. In: GRAVES, S. C.; RINNOOY KAN, A. H. G.; ZIPKIN, P. H. (eds.) Logistics of production and inventory. Amsterdam, North-Holland, 1993. pp. 445522. [1.2.2, 2.1, 2.3]

LUENBERGER, David G. Linear and nonlinear programming. 2 ed. Reading, Addison-Wesley, 1984. [2.8.1, 2.8.2, 3.7]

MITTEN, L. G. Composition principles for synthesis of optimal multistage processes. Operations Research, v. 12, pp. 610-9, 1964. [3.6]

MORTON, Thomas E.; PENTICO, David W. Heuristic scheduling systems: with applications to production systems and project management. New York, Wiley, 1993. [1.2.2, 2.3]

NEMHAUSER, George L. Introduction to dynamic programming. New York, Wiley, 1966. [3.6]

NEMHAUSER, George L.; WOLSEY, Laurence A. Integer and combinatorial optimization. New York, Wiley, 1988. [3.4]

PINEDO, Michael. Scheduling: theory, algorithms, and systems. Englewood Cliffs, Prentice Hall, 1995. [1.2.2] 
PRESS, William H.; TEUKOLSKY, Saul A.; VETTERLING, William T.; FLANNERY, Brian P. Numerical recipes in FORTRAN: the art of science computing. 2. ed. Cambridge, MA, Cambridge University Press, 1992. [2.8.3] RINNOOY KAN, A. H. G.; TIMMER, G. T. Global optimization. In: NEMHAUSER, G. L.; RINNOOY KAN, A. H. G.; TODD, M. (eds.) Optimization. Amsterdam, North-Holland, 1989. pp. 631-62 [2.8] SERSON, Sandra Mindlin. Fábrica veloz: um modelo para competir com base no tempo. Dissertação (Mestrado), Escola Politécnica, Universidade de São Paulo, São Paulo, 1996. 159 pp. [1.1]

SMITH, Wayne E. Various optimizers for single-stage production. Naval Research Logistics Quarterly, v. 3, pp. 59-66, 1956. [1.1]

SPENCER, M. S.; COX, J. F. Optimum production technology (OPT) and the theory of constraints (TOC): analysis and genealogy. International Journal of Production Research, v. 33, n. 6, pp. 1495-504, 1995. [1.4]

STALK Jr., George. Time-The next source of competitive advantage. Harvard

Business Review, July-August 1988. [1.1]

STALK Jr., George; HOUT, Thomas M. Competing against time: How timebased competition is reshaping global markets. New York, The Free Press / London, Collier Macmillan Publishers, 1990. [1.1]

TARJAN, R. E. Data structures and network algorithms. Philadelphia, Society for Industrial and Applied Mathematics, 1983. [2.5]

VOLLMANN, Thomas E.; BERRY, William L.; WHYBARK, D. Clay. Manufacturing planning and control systems. 4. ed. New York, McGraw-Hill, 1997. [1.2.1]

WILD, Ray. Concepts for Operations Management. Chichester, Wiley, 1977. $[1.3,4.4]$

WINSTON, Wayne L. Introduction to mathematical programming: Applications and algorithms. 2. ed. Belmont, California, Wadsworth Publishing Company, 1995. [3.3]

YANO, Candace Arai; KIM, Yeong-Dae. Algorithms for a class of singlemachine weighted tardiness and earliness problems. European Journal of Operational Research, v. 52, pp. 167-78, 1991. [2.3]

ZIVIANI, Nivio. Projeto de algoritmos: com implementações em Pascal e C. 4. ed. São Paulo, Pioneira, 1999. [2.5] 
Errata da tese de doutoramento: Distribuição de carga e variação de capacidade na programação da produção: resultados na inserção de espera e na utilização de capacidade adicional

Autor: Emerson Carlos Colin; Data: 31/03/2000.

\begin{tabular}{|c|c|c|}
\hline página & onde se lê & leia-se \\
\hline iii & O tese & A tese \\
\hline xiii & $\begin{array}{l}\text { s soma de funções convexas do horá- } \\
\text { rio de término independentes para }\end{array}$ & a soma de funções independentes convexas do horário de término de \\
\hline xiii & $\begin{array}{l}\text { intervalos de tempo com diferentes } \\
\text { custos concatenados }\end{array}$ & intervalos de tempo concatenados com diversos custos \\
\hline 4 & atendimento pedidos & atendimento de pedidos \\
\hline 4 & SERSON (1993, p. 23) & SERSON (1996, p. 23) \\
\hline 6 & Nesse ambiente & Nesses ambientes \\
\hline 9 & desagregação produtos & desagregação de produtos \\
\hline 11 & mostra que & mostram que \\
\hline 17 & $\begin{array}{l}\text { funções convexas do horário de } \\
\text { término independentes para cada }\end{array}$ & funções independentes convexas do horário de término de cada \\
\hline 19 & $\begin{array}{l}\left(p_{1}, d_{1}, w_{1}, h_{1}\right)=(3,4,6,8) \\
\left(p_{2}, d_{2}, w_{2}, h_{2}\right)=(4,10,6,8)\end{array}$ & $\left(h_{1}, w_{1}, v_{1}, p_{1}, d_{1}\right)=(8,6,0,3,4),\left(h_{2}, w_{2}, v_{2}, p_{2}, d_{2}\right)=(8,6,0,4,10)$ \\
\hline 20 & $\mathrm{~J} 2$ & $J_{2}$ \\
\hline 20 & nota de rodapé 7 & desconsiderar \\
\hline 21 & de modo que a tempo & de modo que o tempo \\
\hline 24 & $t_{0}, d_{j}$ & {$\left[t_{0}, d_{j}\right]$} \\
\hline 32 & o mais tarde possível & o mais cedo possível \\
\hline 41 & tipo (3) Se & tipo (3). Se \\
\hline 42 & apenas um ponto de mínimo & apenas um ponto (ou uma região) de mínimo \\
\hline 43 & $b \in B$ & $b \subseteq B$ \\
\hline 47 & o programa resultante é $\pi_{j+1}$. & o programa resultante é $\pi_{j+1}^{A I E}$. \\
\hline 49 & acontecerão $k$ iterações & acontecerá um certo número $k$ de iterações \\
\hline 51 & na pilha & na fila de prioridade \\
\hline 53 & $\begin{array}{l}\text { Ao invés de adiantarmos uma } \\
\text { ordem, podemos postergar seu } \\
\text { processamento. Depois utilizamos } \\
\text { horas-extras de modo que o término } \\
\text { da ordem seja mais tarde. }\end{array}$ & $\begin{array}{l}\text { Se uma ordem } j \text { vai ser finalizada com adiantamento, é porque } \\
\text { alguma outra ordem que é realizada depois }(j+1, j+2, \ldots) \text {, fez com } \\
\text { que isso acontecesse. Podemos fazer com que o término de } j \text { seja } \\
\text { mais tarde e depois utilizamos horas-extras no processamento das } \\
\text { ordens posteriores. Dessa forma, temos a hora-extra sendo utilizada } \\
\text { para diminuir o adiantamento de } j \text {. Isso obviamente vai acontecer } \\
\text { caso os custos envolvidos justifiquem essa ação. }\end{array}$ \\
\hline 60,61 & branch-and-cut & branch-and-bound \\
\hline 61 & $\begin{array}{l}\text { 3.4. Formulação do problema de } \\
\text { programação da produção com } \\
\text { capacidade variável via programação } \\
\text { matemática }\end{array}$ & desconsiderar a seção toda \\
\hline 64 & $\begin{array}{l}\text { Para ordens que estejam adiantadas } \\
\text { deseja-se ... fazendo com que seus } \\
\text { términos possam ser antecipados. }\end{array}$ & $\begin{array}{l}\text { Basicamente o algoritmo faz a distribuição de carga: em períodos } \\
\text { onde a carga está baixa, o algoritmo insere espera e em períodos } \\
\text { onde a carga está alta, insere capacidade adicional. Todas as } \\
\text { decisões de se inserir capacidade e espera são basedas nos custos } \\
\text { associados à capacidade adicional, atraso e adiantamento. }\end{array}$ \\
\hline 65 Tab. & $b_{I}$ & $b_{I}$ \\
\hline 68 & adicional é feita & adicional são feitas \\
\hline $69(2.2)$ & $H\left(C_{\text {primeiro }\left(b_{k}\right)}, i_{t}\right)-o_{t}$ & $H\left(C_{\text {primeiro }\left(b_{k}\right)}, i_{t}\right)+o_{\tau}-o_{t}\left(\right.$ onde $\left.o_{\tau}=\left\{o_{t} \in O: e_{\text {primeiro }\left(b_{k}\right)} \in\left[i_{t}, f_{t}\right]\right\}\right)$ \\
\hline $69(2.2)$ & $W\left(i_{t}, C_{\text {último }\left(b_{k}\right)}\right)-o_{t}$ & $W\left(i_{t}, C_{\text {último }\left(b_{k}\right)}\right)+o_{\tau}-o_{t}\left(\right.$ onde $\left.o_{\tau}=\left\{o_{t} \in O: C_{\text {último }\left(b_{k}\right)} \in\left[i_{t}, f_{t}\right]\right\}\right)$ \\
\hline $69(2.3)$ & se $L^{*}=H^{*}$, calcule $\lambda$, ou se & $\begin{array}{l}\text { se } L^{*}=H^{*}, \text { calcule } \lambda \text { e } \phi\left(\text { mínima antecipação do bloco para que } C_{j} \equiv i_{\tau}\right. \\
\left.\text { ou } C_{j} \equiv f_{\tau}\left(C_{\text {primeiro }\left(b_{k}^{*}\right)} \leq C_{j} \leq i_{t^{*}} ; \tau \in N_{b}\right)\right) \text {, ou se }\end{array}$ \\
\hline $69(2.3)$ & se $L^{*}=W^{*}$, calcule $\lambda$, ou se & $\begin{array}{l}\text { se } L^{*}=W^{*} \text {, calcule } \lambda \text { e } \phi \text { (mínimo postergamento do bloco para que } \\
\left.C_{j} \equiv i_{\tau} \text { ou } C_{j} \equiv f_{\tau}\left(i_{t^{*}}<C_{j} \leq C_{u \text { ultimo }\left(b_{k}^{*}\right)} ; \tau \in N_{b}\right)\right) \text {, ou se }\end{array}$ \\
\hline $69(2.3)$ & $O_{t^{*}}=\min \left\{\lambda, f_{t^{*}}-i_{t^{*}}\right\}$ & $O_{t^{*}}=\min \left\{\lambda, \phi, f_{t^{*}}-i_{t^{*}}\right\}$ \\
\hline $69(2.4)$ & $N_{b} \leftarrow N_{b} \backslash t^{*}$ & $N_{b} \leftarrow N_{b} \backslash t^{*}$. Se $C_{\text {último(b) }} \in\left[i_{\tau} f_{\tau}\right](\tau \in O)$, então $O \leftarrow O \cup\left(-O_{t^{*}}, \tau\right)$; se \\
\hline
\end{tabular}




\begin{tabular}{|c|c|c|}
\hline & & $\tau \notin N_{b}$ então $N_{b} \leftarrow \tau \cup N_{b}$. \\
\hline 70 & passo corrente. & passo corrente ou que a capacidade alocada seja desalocada. \\
\hline 70 & seu horário de início. & $\begin{array}{l}\text { seu horário de início. Se uma capacidade adicional que fora alocada } \\
\text { não é mais necessária, ela é retirada do conjunto de capacidades } \\
\text { adicionais efetivamente utilizadas. }\end{array}$ \\
\hline 73 Def. & para $g_{1}$ e $g_{2}$ funções de valores reais, & para $g_{1}, g_{2}$ e $h_{i}(i=1, \ldots, k)$ funções de valores reais, \\
\hline 74 Teo. & bloco se divide. & $\begin{array}{l}\text { bloco se divide (para as duas partes de um bloco dividido, as } \\
\text { propriedades de separabilidade e monotonicidade se mantém). }\end{array}$ \\
\hline 75 Lema & $O_{t^{*}}=\min \left\{\lambda, f_{t^{*}}-i_{t^{*}}\right\}$ & $O_{t^{*}}=\min \left\{\lambda, \phi, f_{t^{*}}-i_{t^{*}}\right\}$ \\
\hline 75 Dem. & $\begin{array}{l}\text { O AIC pode inserir capacidade ou } \\
\text { não. }\end{array}$ & $\begin{array}{l}\text { Para cada } t \in N_{b} \text {, utiliza-se os lemas (3.1) e (3.2), conforme o caso, } \\
\text { para se definir o intervalo de movimentação que fornece a maior } \\
\text { redução da função-objetivo. } L^{*} \text { define a melhor de todas as } \\
\text { movimentações em unidades de diminuição da função-objetivo para } \\
\text { uma unidade de movimentação do intervalo. O AIC pode inserir } \\
\text { capacidade ou não. }\end{array}$ \\
\hline 75 Dem. & Caso 2a e Caso 2b, inteiros. & $\begin{array}{l}\text { Se o valor de } L^{*} \text { for alterado, perde-se a garantia que a movimenta- } \\
\text { ção que está sendo feita é a melhor de todas. O que pode alterar o } \\
\text { valor de } L^{*} \text { é: 1) } \lambda \text { : maior movimentação de um grupo de ordens } \\
\text { atrasadas (ou adiantadas, dependendo do caso), sem que as mesmas } \\
\text { deixem de estar atrasadas (adiantadas); } 2) \phi \text { : maior movimentação de } \\
\text { um grupo de ordens para que todos } C_{j} \in(t \in S \text { ) e dessa forma não haja } \\
\text { uma alteração na taxa de diminuição da função-objetivo para uma } \\
\text { unidade de movimentação do bloco; se } C_{j} \in(t \in N) \text { pode haver uma } \\
\text { alteração nessa taxa. Quando } O_{t^{*}}=f_{t^{*}}-i_{t^{*}} \text {, significa que toda } \\
\text { capacidade adicional disponível em } t^{*} \text { foi utilizada.//// }\end{array}$ \\
\hline 77 & que são pertencente & que são pertencentes \\
\hline $\begin{array}{c}77 \\
\text { Proc. } 4\end{array}$ & $\begin{array}{l}\text { de modo que as ordens não mudem } \\
\text { de conjuntos. }\end{array}$ & $\begin{array}{l}\text { de modo que as ordens não mudem de conjuntos ou que tenha pelo } \\
\text { menos um término coincidindo com um dos limites de intervalos de } \\
\text { capacidade adicional. }\end{array}$ \\
\hline 78 & $\lambda:=$ & $(\lambda, \phi):=$ \\
\hline 78 & $\begin{array}{l}\text { até que uma ordem mude de } \\
\text { conjunto. }\end{array}$ & $\begin{array}{l}\text { até que uma ordem mude de conjunto ou tenha o término } \\
\text { coincidindo com um limite de um intervalo de capacidade adicional. }\end{array}$ \\
\hline 78 & $O_{t^{*}}=\min \left\{\lambda, f_{t^{*}}-i_{t^{*}}\right\}$ & $O_{t^{*}}=\min \left\{\lambda, \phi, f_{t^{*}}-i_{t^{*}}\right\}$ \\
\hline 81 & com a utilização a utilização & com a utilização \\
\hline 84 & $\begin{array}{l}O_{3}:=\min \left\{\lambda, f_{3}-i_{3}\right\}=\min \{48,95-74\} \\
=21\end{array}$ & $\begin{array}{l}\phi:=118-95=23 \\
O_{3}:=\min \left\{\lambda, \phi_{2} f_{3}-i_{3}\right\}=\min \{48,23,95-74\}=21\end{array}$ \\
\hline 84 & $\begin{array}{l}O_{1}:=\min \left\{\lambda, f_{1}-i_{1}\right\}=\min \{27,29-25\} \\
=4 ; \\
C_{1}:=C_{1}-O_{1}:=47-4:=43 \\
C_{2}:=C_{2}-O_{1}:=97-4:=93\end{array}$ & $\begin{array}{l}\phi:=97-95=2 ; \\
O_{1}:=\min \left\{\lambda, \phi f_{1}-i_{1}\right\}=\min \{27,2,29-25\}=2 \\
C_{1}:=C_{1}-O_{1}-\left(f_{2}-i_{2}\right)=47-2-(45-42)=42 \\
C_{2}:=C_{2}-O_{1}=97-2=95\end{array}$ \\
\hline 84 & $\begin{array}{l}O:=O \cup\left\{O_{t^{*}}, t^{*}\right\}:=\{21,3\} \cup\left\{O_{1}, 1\right\} \\
:=\{4,1 ; 21,3\} ; \\
N_{1}:=\{t=1, t=2\} \backslash\{t=1\}:=\{t=2\} ; \\
\text { Passo 1. Iteração } 3 . b:=1 . N_{1}:=\{t=2\} .\end{array}$ & $\begin{array}{l}O:=O \cup\left\{O_{t^{*}}, t^{*}\right\}=\{21,3\} \cup\left\{O_{1}, 1\right\}=\{2,1 ; 21,3\} \\
i_{1}:=i_{1}+O_{1}=25+2=27 \\
\text { Passo 1. Iteração } 3 . b:=1 . N_{1}=\{t=1, t=2\} .\end{array}$ \\
\hline 85 & $\begin{array}{l}\text { Para } t:=2: \\
\left\{b_{k} \subseteq \operatorname{Aum}(b): C_{\text {primeiro }\left(b_{k}\right)} \leq i_{t}\right\}:=\varnothing ; \\
\left\{b_{k} \subseteq \operatorname{Dim}(b): C_{\text {último }\left(b_{k}\right)} \geq i_{t}\right\}:=b_{2}, \\
W\left(i_{2}, C_{2}\right)-o_{2}:=6-4-2:=0 ; \\
W^{*}=\max \left\{W\left(i_{t}, C_{\text {último }\left(b_{k}\right)}\right)-o_{t}:\right. \\
\left.\quad C_{\text {último }\left(b_{k}\right)} \geq i_{t}, i_{t} \in N_{b}\right\}:=\max \{0\}:=0 ; \\
\left(t^{*}, b_{k}^{*}, L^{*}\right):=\left(2, b_{2}, 0\right) ;\end{array}$ & $\begin{array}{l}\text { Para } t:=1: \\
\left\{b_{k} \subseteq \operatorname{Aum}(b): C_{\text {primeiro }\left(b_{k}\right)} \leq i_{t}\right\}:=\varnothing ; \\
\left\{b_{k} \subseteq \operatorname{Dim}(b): C_{\text {último }\left(b_{k}\right)} \geq i_{t}\right\}:=b_{2} ; W\left(i_{2}, C_{2}\right)+o_{3}-o_{1}:=6-4+2-1=3 ; \\
\text { Para } t:=2: \\
\left\{b_{k} \subseteq \operatorname{Aum}(b): C_{\text {primeiro }\left(b_{k}\right)} \leq i_{t}\right\}:=\varnothing ; \\
\left\{b_{k} \subseteq \operatorname{Dim}(b): C_{\text {último }\left(b_{k}\right)} \geq i_{t}\right\}:=b_{2} ; W\left(i_{2}, C_{2}\right)+o_{3}-o_{2}:=6-4+2-2=2 ; \\
W^{*}=\max \left\{W\left(i_{t}, C_{\text {último }\left(b_{k}\right)}\right)+o_{3}-o_{t}: C_{\text {ultimo }\left(b_{k}\right)} \geq i_{t}, i_{t} \in N_{b}\right\}:=\max \{3,2\}=3 ; \\
\left(t^{*}, b_{k}^{*}, L^{*}\right):=\left(2, b_{2}, 3\right) ; \\
\text { Inserção de capacidade: } \\
\lambda:=\text { CalculaInterMáx }\left(i_{2}, C_{2}\right)=\left\{\min \left(C_{j}-C_{j}^{*}\right): 42<C_{j} \leq 95 ; j \in \operatorname{Dim}(1)\right\}\end{array}$ \\
\hline
\end{tabular}




\begin{tabular}{|c|c|c|}
\hline & & 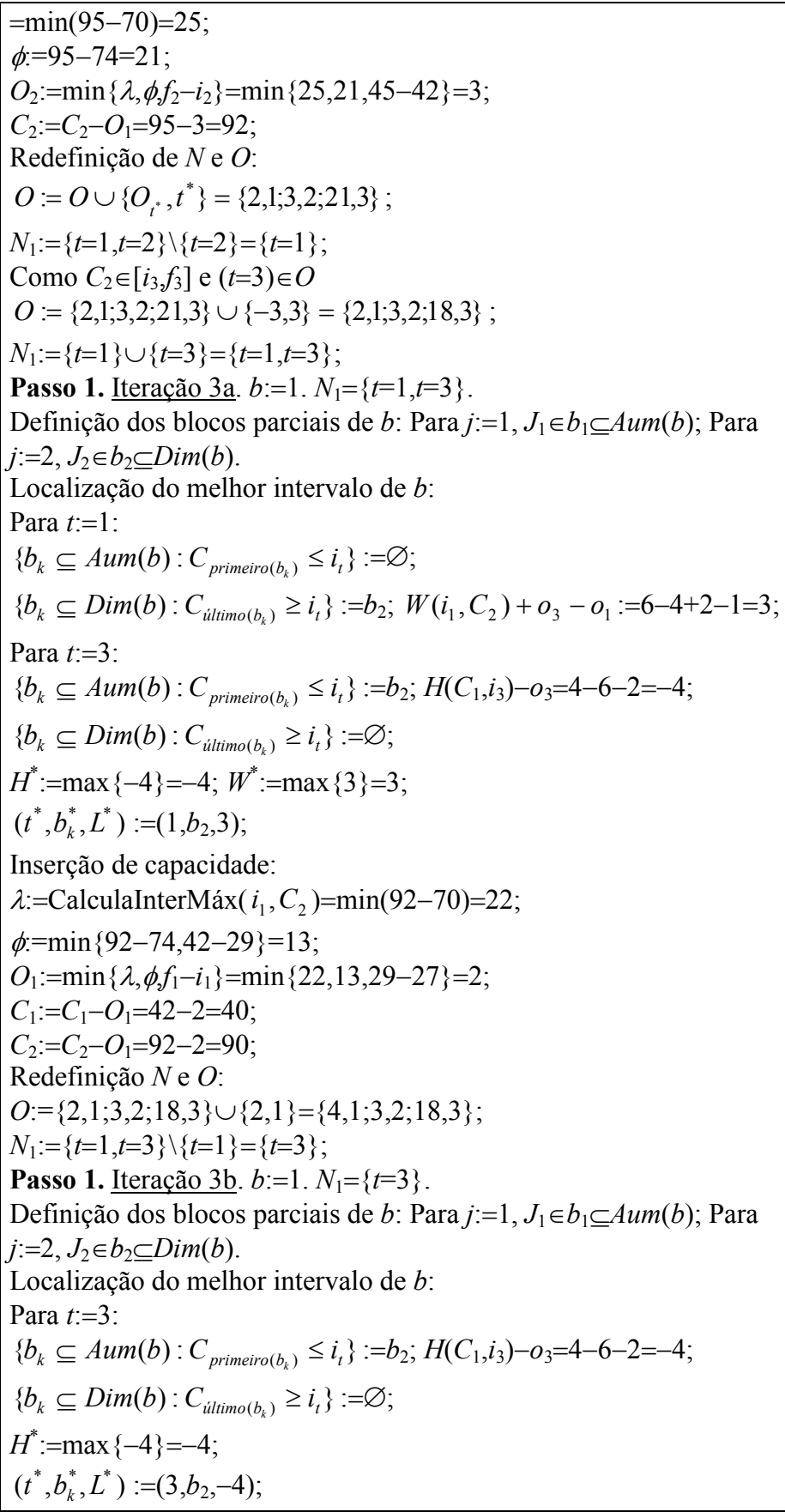 \\
\hline 85 & $\begin{array}{l}O_{5}:=\min \left\{\lambda, f_{5}-i_{5}\right\}=\min \{10,248-228\} \\
=10\end{array}$ & $\begin{array}{l}\phi:=\min \{30,12\}=12 \\
O_{5}:=\min \left\{\lambda, \phi f_{5}-i_{5}\right\}=\min \{10,12,260-248\}=10\end{array}$ \\
\hline 85 & $\begin{array}{l}O:=\{4,1 ; 21,3\} \cup\left\{O_{5}, 10\right\} \\
=\{4,1 ; 21,3 ; 10,5\}\end{array}$ & $O:=\{4,1 ; 3,2 ; 18,3\} \cup\left\{O_{5}, 5\right\}=\{4,1 ; 3,2 ; 18,3 ; 10,5\}$ \\
\hline $\begin{array}{c}86 \\
\text { Tab. } 11\end{array}$ & $\begin{array}{l}\left(C_{j}, E_{j}, T_{j}, h_{j} E_{j}+w_{j} T_{j}\right)=(43,7,0,28)(\text { para } \\
j=1) ;(93,0,23,138)(j=2) ; \text { total } 166\end{array}$ & $\begin{array}{l}\left(C_{j}, E_{j}, T_{j}, h_{j} E_{j}+w_{j} T_{j}\right)=(40,10,0,40)(\text { para } j=1) ;(90,0,20,120)(j=2) ; \text { total } \\
160\end{array}$ \\
\hline $\begin{array}{c}86 \\
\text { Tab. } 12\end{array}$ & $\begin{array}{l}\left(O_{t}, o_{t} O_{t}\right)=(0,0)(\text { para } t=2) ;(21,42) \\
(t=3) ; \text { total } 56\end{array}$ & $\left(O_{t}, o_{t} O_{t}\right)=(3,6)($ para $t=2) ;(16,32)(t=3) ;$ total 52 \\
\hline 86 & $=222$ & $=212$ \\
\hline 88 & $O_{1}:=\min \left\{\lambda, f_{1}-i_{1}\right\}=\min \{2 ; 0,5\}=0,5$ & $\begin{array}{l}\phi:=\min \{(6-3,75)\}=2,25 \\
O_{1}:=\min \left\{\lambda, \phi f_{1}-i_{1}\right\}=\min \{2 ; 2,25 ; 0,5\}=0,5\end{array}$ \\
\hline 94 & de uma empresas fossem & de uma empresa fossem \\
\hline
\end{tabular}

